\title{
Predicting Evaporation from Mountain Streams
}

\author{
by \\ Andras J. Szeitz \\ B.Sc., The University of British Columbia, 2017 \\ A THESIS SUBMITTED IN PARTIAL FULFILLMENT OF THE REQUIREMENTS FOR \\ THE DEGREE OF \\ Master of Science \\ in \\ THE FACULTY OF GRADUATE AND POSTDOCTORAL STUDIES \\ (Geography)
}

The University of British Columbia

(Vancouver)

September 2019

(C) Andras J. Szeitz, 2019 
The following individuals certify that they have read, and recommend to the Faculty of Graduate and Postdoctoral Studies for acceptance, the thesis entitled:

Predicting Evaporation from Mountain Streams

submitted by Andras J. Szeitz in partial fulfillment of the requirements for the degree

of $\quad$ Master of Science

in Geography

\section{Examining Committee:}

R. Dan Moore, Geography

Supervisor

Brett Eaton, Geography

Supervisory Committee Member

Ian McKendry, Geography

Supervisory Committee Member 


\section{Abstract}

Evaporation can be an important control on stream temperature, particularly in the summer when it acts to limit daily maximum stream temperature. Evaporation from streams is usually modelled with the use of a wind function that includes empirically derived coefficients. A small number of studies derived wind functions for individual streams; the fitted parameters varied substantially among sites. In this study, stream evaporation and above-stream meteorological conditions (at 0.5 and $1.5 \mathrm{~m}$ above the water surface) were measured at nine mountain streams in southwestern British Columbia, Canada, covering a range of stream widths, temperatures, and riparian vegetation. Evaporation was measured on several days at each stream, at approximately hourly intervals, using nine floating evaporation pans distributed across the channels. The wind function was fit using mixed-effects models to account explicitly for among-stream variability in the parameters. The fixed-effects parameters were tested using leave-one-out cross-validation. The model based on 0.5-m measurements provided improved model performance compared to that based on 1.5-m values, with RMSE of 0.0162 and $0.0187 \mathrm{~mm} \mathrm{~h}^{-1}$, respectively, relative to a mean evaporation rate of $0.06 \mathrm{~mm} \mathrm{~h}^{-1}$. Inclusion of atmospheric stability and canopy openness as predictors improved model performance when using the 1.5-m meteorological measurements, with minimal improvement when based on 0.5-m measurements. A laboratory experiment was conducted to test the influences of aeration and flow velocity on evaporation; no significant relationship was observed, but this may be attributable to several methodological issues. 


\section{Lay Summary}

Evaporation is one of the processes through which streams lose heat. As a result, evaporation can be an important control on stream temperature in the summer months. The models currently used to predict stream evaporation vary substantially, as they have been developed to predict evaporation from specific stream types. In this study, stream evaporation and weather conditions were measured at a range of forested streams in southwestern British Columbia, and a model was developed to be able to predict stream evaporation from streams similar to those surveyed through this study. Additional characteristics describing the streams were added as variables to the model, which improved model performance. The results of this research will enable more accurate prediction of evaporation from mountain streams, which is particularly relevant when we are trying to understand how stream temperatures will respond to climate change, land-use activites, or water management. 


\section{Preface}

This thesis is original work completed by the author. Guidance was given by the supervisory committee (Dan Moore, Brett Eaton, and Ian McKendry). Field assistance was provided by Anna Kaveney, Virgile Laurent, Emily West, Annie Dufficy, Stefan Gronsdahl, Emily Ballon, and Ed Yu. Laboratory assistance was provided by Rick Ketler and David Waine.

A version of this work has been published as a poster presentation (Szeitz AJ, and Moore

RD. Predicting Evaporation from Mountain Streams) on which the author acted as lead investigator and presented at the 27th IUGG General Assembly in Montréal, Canada. 


\section{Table of Contents}

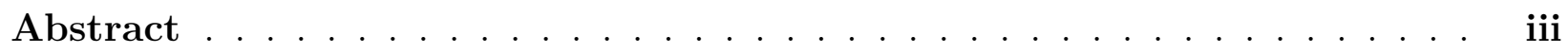

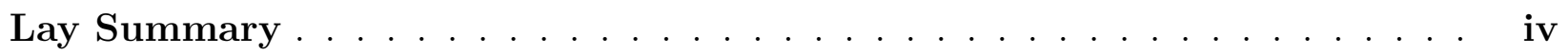

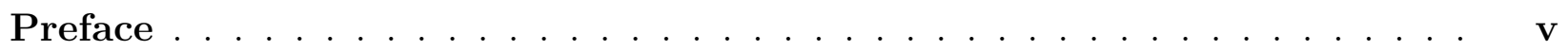

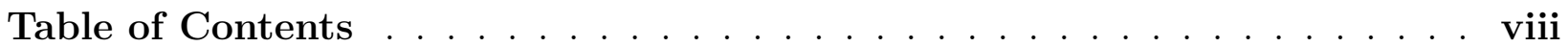

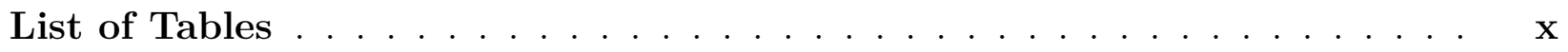

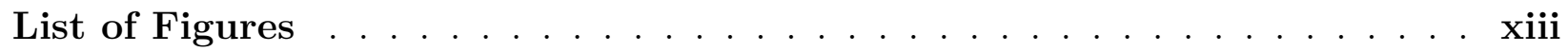

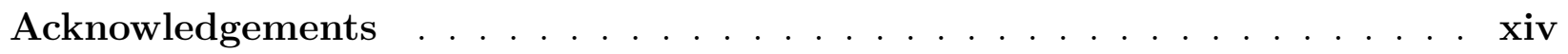

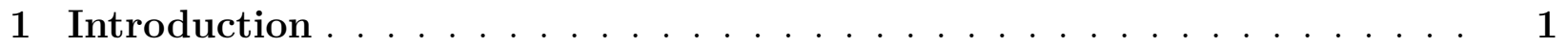

1.1 Motivation . . . . . . . . . . . . . . . . . . . 1

1.2 Measuring Stream Evaporation _. . . . . . . . . . . . . . . 3

1.3 Modelling Stream Evaporation . . . . . . . . . . . . . . . . . 5

1.4 Research Objectives and Thesis Structure . . . . . . . . . . . 7

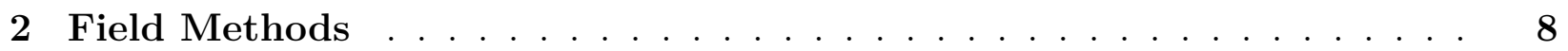

2.1 Study Area and Streams . . . . . . . . . . . . . . . . . . . . . 8

2.2 Site Characteristics . . . . . . . . . . . . . . . . . . . . . . . 11

2.3 Meteorological and Stream Temperature Data . . . . . . . . . . . . . 12

2.3 .1 Field Measurements _. . . . . . . . . . . . . . . . . . . 12

2.3 .2 Data Processing . . . . . . . . . . . . . . . . . . . . . . . 12

2.4 Stream Evaporation . . . . . . . . . . . . . . . . . . . . . . . 13

2.4 .1 Field Measurements . . . . . . . . . . . . . . . . . . . . 13

2.4 .2 Data Processing and Analysis . . . . . . . . . . . . . . 15

2.5 Evaporation Model Variables . . . . . . . . . . . . . . . . . . . . . 17

2.6 Statistical Analysis . . . . . . . . . . . . . . . . . . . . . 18 
3 Laboratory Methods . . . . . . . . . . . . . . . . . . . . . 21

3.1 Design and Construction . . . . . . . . . . . . . . . . . . . 21

3.2 Flume Flow Properties . . . . . . . . . . . . . . . . . . . . . 22

3.3 Evaporation Trials . . . . . . . . . . . . . . . . . . . . 22

3.4 Flume Data Collection . . . . . . . . . . . . . . . . . 25

3.5 Data Processing and Analysis . . . . . . . . . . . . . . 25

3.6 Statistical Analysis . . . . . . . . . . . . . . . . . . . 28

4 Field Results . . . . . . . . . . . . . . . . . . . . . . . . . . 29

4.1 Overview of the Study Period . . . . . . . . . . . . . . . 29

4.2 Evaporation Pan Water Temperature . . . . . . . . . . . . . . 30

4.3 Meteorological Conditions and Evaporation Rates . . . . . . . . . . . . 30

4.4 Statistical Analysis . . . . . . . . . . . . . . . . . . . 34

4.4 .1 Model Filtering and Performance . . . . . . . . . . . . . . . 34

4.4 .2 Wind Function Comparison _. . . . . . . . . . . . . . . . . 43

5 Laboratory Results . . . . . . . . . . . . . . . . . . . . 46

5.1 Relation Between Solution Molarity and Electrical Conductivity . . . . . . . 46

5.2 Meteorological Conditions and Evaporation Rates . . . . . . . . . . . . 46

5.3 Statistical Analysis . . . . . . . . . . . . . . . . . . . 47

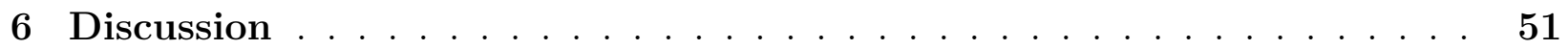

6.1 Field Results . . . . . . . . . . . . . . . . . . . . . . 51

6.1.1 Evaporation as a Component of a Stream Heat Budget . . . . . . . 51

6.1.2 Assessment of Evaporation Pan Methodology . . . . . . . . . . . 51

6.1.3 Effect of Measurement Height on Performance of the Base Model . . 54

6.1.4 Effects of Additional Predictor Variables . . . . . . . . . . . . 55

6.1.5 Comparison of Wind Function Coefficients . . . . . . . . . . . 56

6.1.6 Application in Stream Temperature Modelling . . . . . . . . . . . 58

6.2 Laboratory Results . . . . . . . . . . . . . . . . . . . . . 58

6.2 .1 Flume Experiment Design _ . . . . . . . . . . . . . . 58

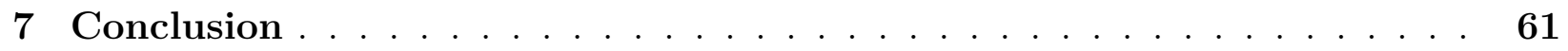

7.1 Key Findings . . . . . . . . . . . . . . . . . . . . . . . . . 61

7.2 Recommendations for Future Work . . . . . . . . . . . . . . . 62

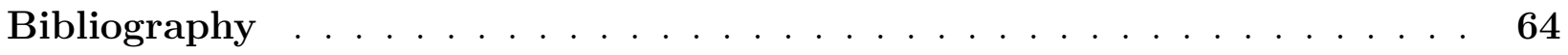


A Anemometer Calibration . . . . . . . . . . . . . . . 70

B Evaporation Pan Water Temperature and Surface Area . . . . . . . . 73

C Meteorological Conditions and Evaporation Rates . . . . . . . . . 76

D Evaporation Rate Error Analysis . . . . . . . . . . . . . . . . . . 87

E Relation Between Solution Molarity and Electrical Conductivity . . . . . 88 


\section{List of Tables}

2.1 The selected study sites and their stream and riparian properties. . . . . . . 11

4.1 Historical mean monthly air temperatures and total precipitation for the Pemberton region from 1969 to 2018, and for the Malcolm Knapp Research Forest (MKRF), from 1969 to 2018. . . . . . . . . . . . . . . . . . .

4.2 Stream physiography, average wind speeds, and differences in wind speed. The sheltering ratio is computed as tree height $\div$ stream width, and $u_{h}$ refers to wind speed in $\mathrm{m} \mathrm{s}^{-1}$ measured $h$ metres above the stream surface. The streams are arranged by decreasing values of wind speed difference. . . . . . . . . .

4.3 All unique model random effect distributions, depending on the number of model parameters. ID is a code to identify the significant random effects for each model form as presented in Table 4.4. . . . . . . . . . . . . . . . . .

4.4 Model significance after the initial round of model testing. The significant model forms refers to the random effect distributions identified in Table 4.3. The models were fit to measurements made 0.5 and $1.5 \mathrm{~m}$ above the stream surface. . . . . . . . . . . . . . . . . .

4.5 Goodness-of-fit statistics computed from leave-one-out cross-validated model predictions for a selection of models. The random effect distribution (R.E. dist.) used for each model is provided, and the corresponding model parameters are indicated in bold. The root-mean-square error (RMSE, $\mathrm{mm} \mathrm{h}^{-1}$ ), mean bias error (MBE $\mathrm{mm} \mathrm{h}^{-1}$ ), mean absolute error $\left(\mathrm{MAE}, \mathrm{mm} \mathrm{h}^{-1}\right.$ ), and the Nash-Sutcliffe efficiency (NSE) are the model goodness-of-fit statistics provided. 38

4.6 The population-level estimated coefficients and coefficient standard errors for the selected models. . . . . . . . . . . . . . . . .

4.7 A comparison of wind function coefficients, $a$ and $b$, derived from stream evaporation measurements, and one commonly cited in stream temperature modelling studies. In the seventh column, $T_{p}$ indicates the evaporation pan water temperature. . . . . . . . . . . . . . . . 
5.1 Analysis of variance for the difference between the reduced and full evaporation models (Equations 3.6 and 3.5). RSS is the residual sum of squares and DF is the degrees of freedom for the model. . . . . . . . . . . . . .

6.1 Reported latent heat fluxes from a range of streams. In the table, $T_{w}$ is the stream temperature, $\phi$ is the canopy closure, $\bar{u}$ is the mean wind speed, and $\bar{Q}_{e}$ is the mean latent heat flux. . . . . . . . . . . . . . . .

A.1 The statistics of anemometer measurement difference prior to and post calibration. The differences were computed as Field Anemometer - Calibration Anemometer. . . . . . . . . . . . . . . . . . . 70 


\section{List of Figures}

2.1 The locations of the study streams, indicated by red dots, in southwest British Columbia. The climate stations providing data of the regional hydroclimate are indicated by white dots. The base map source is the Stamen Terrain tile set (C) OpenStreetMap contributors. . . . . . . . . . . . . . . . . . . . . 9 9

2.2 Photographs of the nine study sites. . . . . . . . . . . . . . . . . . 10

2.3 The evaporation pans and meteorological station set up at Spring Creek. The TidbiT water temperature logger is submersed near the meteorological station. This demonstrates the ideal distribution of evaporation pans in a stream and the location of the meteorological station with respect to the pans; individual stream characteristics resulted in deviations from this ideal. . . . . . . . . .

2.4 The method of photographing an evaporation pan with blue dyed water for the determination of the pan water surface area. . . . . . . . . . .

3.1 Photograph of the laboratory flume. The constant-head tank is visible at the top of the frame, with the valved plumbing supplying water to the flume. A return-flow pipe returns excess water to the catch-basin, seen at the bottom of the frame. The yellow Kestrel weather meter is seen mounted in the flume, and the fan is angled to blow air down into the flume channel. In this image, the pump supplies water to the head tank through a garden hose, but this was later replaced by plumbing. . . . . . . . . . . . . . . . . . .

3.2 Photograph illustrating the use of LEGO blocks to produce steps and roughness. The blue LEGO baseplates are glued to the top paving brick on each step and the white LEGO bricks are attached to the baseplates. . . . . . . . . . .

3.3 Photograph showing the Kestrel weather meter measuring the wind speed over the surface of the flow in the flume. The impeller is approximately $20 \mathrm{~cm}$ above the surface of the flow. . . . . . . . . . . . . . . . . . .

4.1 The stream-averaged distributions of water temperature difference between the evaporation pans and the stream. 
4.2 Stream and evaporation pan water temperatures at Spring Creek during field work on July 12 th, 2018. . . . . . . . . . . . . . . . . .

4.3 The stream and air temperatures at glacier-fed study sites. The panel titles give the day of year and location. . . . . . . . . . . . . . . .

4.4 The distributions of meteorological conditions at each stream during stream evaporation measurements, arranged by increasing mean stream temperature.

4.5 The distributions of meteorological conditions measured 0.5 and $1.5 \mathrm{~m}$ above the stream surface, arranged by increasing mean stream temperature. . . . . 36

4.6 The observed evaporation rates at each stream, arranged by increasing mean evaporation rate. The $95 \%$ confidence intervals associated with each observation due to sampling variability are indicated by the bars extending above and below each point. . . . . . . . . . . . . . . . . . .

4.7 Cross-validated model predictions for the base mass transfer model and the two best expanded models, Models 15 and 19, for meteorological measurements made $0.5 \mathrm{~m}$ and $1.5 \mathrm{~m}$ above the stream surface, respectively. . . . . . . .

4.8 The site-specific residual error distribution for the base and expanded 0.5-m and 1.5-m models. The residuals were computed from cross-validated model predictions. . . . . . . . . . . . . . . . . .

4.9 The site-specific adjustments for each model. The 0.5-m base model had adjustments to the $b$ coefficient, while the other models had adjustments to the $a$ coefficient.

4.10 The evaporation rates estimated by applying six literature wind functions to this study's dataset. The wind function coefficients and the study references are provided in Table 4.7. The two panels for Maheu correspond to the wind functions for Catamaran Brook (CB) and the Little Southwest Miramichi River (LSWM). The panels are ordered from 1 to 6 by decreasing model root-mean-square error. The predicted evaporation rates for this study are cross-validated predictions from the $1.5-\mathrm{m}$ model. . . . . . . . . . . . . .

5.1 The meteorological conditions, flume water electrical conductivity, and calculated evaporation rates for each of the flume trials. Each subfigure title provides the state of the flume parameters of slope and LEGO. . . . . . . . .

5.2 The model-predicted evaporation rates with $95 \%$ confidence intervals, for each trial. 
A.1 The uncorrected and corrected field-deployed anemometer wind speed measurements over the calibration period compared to the calibration anemometers. The black lines represent the $1: 1$ line. . . . . . . . . . . . . . . .

A.2 Comparing the agreement in wind speed measurements between field anemometer and calibration anemometer pairs during the calibration period. The black lines are the $1: 1$ lines. . . . . . . . . . . . . . . . . .

B.1 Stream and evaporation pan water temperatures over the course of evaporation measurements. The stream water temperatures are at 10 minute temporal resolution, while the pan water temperature measurements are at approximately 20 minute intervals. The grid panels are titled with the day of year and location. Days with insufficient pan water temperature measurements were omitted from this figure. . . . . . . . . . . . . . . . . . . .

B.2 The calibration of evaporation pan water surface area. The line is the fit regression. . . . . . . . . . . . . . . . . . .

C.1 Meteorological and stream conditions, and measured evaporation rates for each day of data collection. . . . . . . . . . . . . . . . . . . . . .

E.1 The calibration results relating electrical conductivity to a salt solution molarity. The line is the fit regression. . . . . . . . . . . . . . . 


\section{Acknowledgements}

This research project was realized through the contributions of many people. First and foremost, I would like to thank my supervisor, Dan Moore, for his ongoing enthusiasm for field-based research, insistence on holding oneself to a high standard, keen attention to detail, and patient guidance. I would also like to express my deep gratitude to my lab group, Johannes Exler, Annie Dufficy, and Stefan Gronsdahl, for sharing technical expertise in coordinating a field data collection campaign and for always being available and willing to discuss my questions and quandaries. Anna Kaveney and Virgile Laurent were invaluable for their assistance in conducting field work, as well as Emily West and Edward Yu. The staff of the Department of Geography played a key role in enabling this research project to occur. I would also like to acknowledge the contributions of William Sparling, who provided insightful suggestions and recommendations on several aspects of my research.

This work was funded by a Natural Sciences and Engineering Research Council Discovery grant to Dr. Dan Moore, and a CGS-M scholarship to Andras J. Szeitz.

Finally, I would like to thank my family and friends, who have always supported me through my studies. 


\section{Chapter 1}

\section{Introduction}

\subsection{Motivation}

Stream temperature is a persistent and important topic in hydrology, and is an important control on water quality through its influence on aquatic organisms' growth rates (Jensen, 1990; Elliott and Hurley, 1997), species distributions (Wichert and Lin, 1996; Ebersole et al., 2001; Parkinson et al.), and concentrations of dissolved oxygen and other nutrients (LeBosquet and Tsivoglou, 1950). Mountain stream temperatures are sensitive to climatic change and increasing air temperatures (Isaak et al., 2016). Through climate change, it is 'likely' that global air temperatures will increase by up to $0.7{ }^{\circ} \mathrm{C}$ by 2035 (Intergovernmental Panel on Climate Change, 2014), which will contribute to stream temperature increases through greater sensible heat fluxes or decreased seasonal snowmelt contributions to streamflow (Wu et al., 2012; Ficklin et al., 2014; Luce et al., 2014). Climatic change can also induce landscape disturbances (e.g., wildfires, changing forest composition, insect outbreaks) that may impact stream temperature regimes (Fried et al., 2004; Isaak et al., 2010; Luce et al., 2014). Forestry practices and natural disturbances that reduce shading by riparian vegetation increase solar radiation at the stream surface and generate increases in summer stream temperature (Brown and Krygier, 1970; Leach and Moore, 2010; Guenther et al., 2014). Additionally, flow reduction or alteration through irrigation withdrawals or impoundment can influence stream thermal regimes (Morse, 1972; Morin et al., 1994; Sinokrot and Gulliver, 2000). There is growing concern that increasing air temperatures, land-use changes, and water management activities could perturb stream temperature regimes to the point where streams may no longer be suitable habitats for some of their present species (Eaton et al., 1995).

A stream's temperature is controlled by its energy balance (Brown, 1969; Webb et al., 2008). The most robust approach to quantifying stream temperature response to land cover changes (e.g., forest harvesting), water management, and climate change is the application of 
process-based models that simulate energy and water exchanges between the stream and its environment. Process-based models have been extensively applied (e.g., Brown, 1969; Vugts, 1974; Sinokrot and Stefan, 1993; Kim and Chapra, 1997; Leach and Moore, 2010, 2019) and benefit from being able to model stream temperature response to changes in heat fluxes resulting from environmental changes (Bartholow, 2000; Caissie, 2006; Leach and Moore, 2010). Stream energy budgets are typically dominated by solar radiation and net longwave radiation, followed by the latent heat fluxes associated with evaporation and condensation (Morin et al., 1994; Leach and Moore, 2010; Maheu et al., 2014). While robust models exist to simulate stream surface radiation, including the effects of riparian vegetation and topography (e.g., Leach and Moore, 2010), less attention has focused on modelling the latent heat fluxes, especially evaporation, which can be the dominant mechanism of heat loss at higher stream temperatures (Webb and Zhang, 1997, 1999).

Evaporation acts as a heat loss process and is incorporated into process-based models as the latent heat flux. The latent heat flux, $Q_{e}\left(\mathrm{~W} \mathrm{~m}^{-2}\right)$, is difficult to measure, but can be related to evaporation as follows:

$$
Q_{e}=E \cdot L_{v} \cdot \rho_{w}
$$

where $E$ is the evaporation rate $\left(\mathrm{m} \mathrm{s}^{-1}\right), L_{v}$ is the latent heat of vaporization $\left(\mathrm{J} \mathrm{kg}^{-1}\right)$, and $\rho_{w}$ is the density of water $\left(\mathrm{kg} \mathrm{m}^{-3}\right)$. The evaporation rate is often predicted through the use of empirically derived mass transfer equations. A Dalton-type mass transfer equation has the following form:

$$
E=(a+b \cdot u) \cdot\left(e_{w}-e_{a}\right)
$$

where $u$ is the wind speed $\left(\mathrm{m} \mathrm{s}^{-1}\right), e_{w}$ and $e_{a}$ are the vapour pressures at the water surface and the overlying air $(\mathrm{kPa})$, respectively, and $a$ and $b$ are model parameters. The term $(a+b \cdot u)$ is commonly referred to as the wind function, and is given the symbol $\psi$. In the wind function, $a$ represents evaporation occurring due to free convection, and $b$ represents forced convection. Some empirically based and modelling studies of stream temperature have quantified the evaporative heat fluxes for small and/or forested streams. For example, Webb and Zhang (1997) found average daily losses of heat from evaporation, in the summer, to range from $15.1 \%$ to $47.7 \%$ of the total heat loss, from nine small, sheltered streams in the southwestern United Kingdom. They also reported average daily evaporative heat loss in the winter, from two streams, to range from $20.7 \%$ to $31.2 \%$ of the daily total heat loss. For a forested, interior plateau stream in British Columbia, Leach and Moore (2010) found the summer latent heat flux to be minor compared to the net radiation, but from the months of 
October to March, the latent heat flux and net radiation were of the same magnitude. More recently, Maheu et al. (2014) and Caissie (2016) observed heat loss through evaporation as $42 \%$ and $10 \%$ of total summer heat loss in a stream and its tributary, respectively, in New Brunswick. As stream evaporation increases with increasing stream temperature, evaporation could act to impose an upper limit on stream temperature in the summer months.

\subsection{Measuring Stream Evaporation}

Of the studies investigating evaporation from natural or artificial water bodies, most focused on lake evaporation and derived mass transfer coefficients to represent those conditions. The processes controlling evaporation from streams are subject to different influences than lakes. For example, riparian vegetation and stream sinuosity can inhibit wind profile development above the stream, due in part to a lack of fetch. As a result, many of the mass transfer models derived from lake studies may perform poorly when estimating stream evaporation (e.g, Benyahya et al., 2010), in particular from small, sheltered streams (Guenther et al., 2012). To address these concerns, two studies derived wind function coefficients from streams using energy-balance approaches (Jobson, 1980; Gulliver and Stefan, 1986), and four studies have directly measured stream evaporation and derived empirical coefficients for the wind function (Benner, 2000; Guenther et al., 2012; Maheu et al., 2014; and Caissie, 2016).

Jobson (1980) derived wind function coefficients from meteorological and water temperature measurements made along a $26 \mathrm{~km}$ concrete canal near San Diego, California. He measured wind speed at several locations along the canal, some of which were positioned over the canal while others were on weather stations adjacent to it. Side banks provided an additional bank height of 1 to $20 \mathrm{~m}$ above the top of the canal over its length. Jobson reported wind function coefficients that were similar to existing lake-derived wind functions, but notably had higher predictions of evaporation at low wind speeds, which indicated a greater role of free convection than evaporation from lake surfaces. Jobson did not discuss the potential influence of atmospheric stability on evaporation or the wind function coefficients, nor the possibility of an internal boundary layer developing over the canal during periods when the wind blew across rather than along the canal.

Gulliver and Stefan (1986) also derived wind function coefficients from meteorological and water temperature measurements, but their study investigated a thermally loaded power plant cooling stream in Minnesota. They measured wind speed at $9 \mathrm{~m}$ above the stream, and downscaled the measurements to a height of $2 \mathrm{~m}$. Meteorological and stream temperature measurements were made at night, under the assumption that the stream was at steady-state conditions; atmospheric conditions were always unstable. They reported wind 
function coefficients similar to those reported by Jobson (1980), but preferred an alternative formulation that incorporated the cube root of a stability index as a variable. The model was developed based on measurements with unstable conditions and thus may not be applicable to stable conditions. Gulliver et al. also noted that there could be instances where an internal boundary layer developed over the stream, due to crosswinds over the stream, but did not discuss how that may have influenced their estimated coefficients.

Benner (2000) measured evaporation on nine reaches of the Upper Middle Fork of the John Day River in Oregon, an aridland environment, by measuring the change in water depth in pans (similar to Class A evaporation pans) submerged in the stream. They also measured meteorological conditions in-stream above the evaporation pans. Benner reported wind function coefficients similar to those of Jobson (1980), who derived coefficients for predicting evaporation from a concrete aqueduct in an arid environment. Benner also reported variability in wind function coefficients when fit to each study reach. The wind function coefficient, $a$, ranged from 0.011 to $0.204\left(\mathrm{~mm} \mathrm{~h}^{-1} \mathrm{kPa}^{-1}\right)$, while $b$ ranged from 0.026 to $0.309(\mathrm{~mm}$ $\left.\mathrm{h}^{-1} \mathrm{~s} \mathrm{~m}^{-1} \mathrm{kPa}^{-1}\right)$. A laboratory experiment was conducted to investigate the influence of water flow velocity on evaporation. In these experiments, evaporation was measured using a pressure transducer in an evaporation pan which had a 'mixing wheel' to simulate water flow, and air flow from a fan. Benner reported a significant but decreasing influence of flow velocity on evaporation as the vapour pressure difference or wind speed increased.

Guenther et al. (2012) measured evaporation from a headwater stream prior to and after partial-retention harvesting in an attempt to quantify the influence of riparian vegetation density on stream evaporation. They measured evaporation using evaporation pans connected to a Mariotte cylinder, and related the change in water level in the cylinder to pan evaporation. They found the $a$ coefficient was not significant. This differed from all previous literature deriving wind function coefficients for streams (Jobson, 1980; Gulliver and Stefan, 1986; Benner, 2000), raising the notion that the existing mass transfer model, having been originally developed for sites with no vegetation canopy, does not work well in closed canopy, sheltered stream environments. The lack of an intercept for their wind function was suggested to represent the suppressing influence of stable conditions on evaporation.

Maheu et al. (2014) measured evaporation rates from two temperate, forested streams of different widths $(8$ and $80 \mathrm{~m}$ ). They introduced a method of evaporation measurement using floating evaporation pans, where they related the change in the mass of water in the pans to evaporation. Similarly to the aforementioned studies, they used above-stream meteorological data with the evaporation measurements to derive wind function coefficients. They reported unique wind function coefficients for each stream, in line with Benner (2000). However, they also reported wind function coefficients fit to evaporation and meteorological measurements 
made during the night. Night-time conditions were unstable, and previous work suggested that instability should enhance evaporation (Ryan and Harleman, 1973; Gulliver and Stefan, 1986). However, Maheu et al. found the free convection coefficient, a, fit to night-time measurements decreased relative to its value fit to daytime measurements, which was contrary to the role of stability reported by Gulliver and Stefan (1986), and suggested by Guenther et al. (2012).

Caissie (2016) expanded upon the work of Maheu et al. (2014) by measuring evaporation from a small, sheltered tributary to the streams studied by Maheu et al. Evaporation was measured using floating evaporation pans, and meteorological measurements were made above-stream as well as in a forest clearing nearby. He derived wind function coefficients, and compared the observed evaporation against predicted evaporation estimated using the meteorological observations from the forest clearing as input data. Using these data as inputs to the wind function accounted for $86 \%$ of the variability in evaporation, which indicates that nearby meteorological data may be useful inputs to the wind function when above-stream measurements are unavailable. Additionally, the findings of Caissie were congruous with the previously identified trends of lower evaporation rates with increased sheltering and

the associated differences in wind speed. Caissie also suggested that there is a positive relationship between the proportion of evaporative heat loss with respect to the stream heat budget and the stream width.

\subsection{Modelling Stream Evaporation}

The general principles underlying the mass transfer equation (Equation 1.2) were first described by Dalton (1802), and a model of this form was proposed by Stelling (1882) to estimate evaporation from a land surface (Brutsaert, 1982). Many variants of Stelling's model have been derived, stemming from the different environments and measurement heights used to make meteorological observations, as well as the incorporation of modified or additional variables including squared wind speeds (Brady et al., 1969) or atmospheric stability (Ryan and Harleman, 1973). The mass transfer equations most commonly applied to modern stream evaporation studies were developed by Brady et al. (1969) and Webb and Zhang (1997), although equations derived by Brutsaert and Yu (1968) and Gulliver and Stefan (1986), among others, have also been utilized to predict stream evaporation.

Brutsaert and $\mathrm{Yu}$ (1968) sought to quantify the performance of the wind function and gain insight into the variability of the wind function parameter values. To address this question, they measured evaporation from eight square evaporation pans of $0.09,1.48$, and $5.96 \mathrm{~m}^{2}$ surface area. Wind speed was measured $0.5,1,2$, and $3 \mathrm{~m}$ above the surface. Brutsaert and $\mathrm{Yu}$ 
also investigated the applicability of micrometeorology theory in predicting evaporation; they considered the relative performance of the wind speed or the friction velocity as input data to the wind function. The concept of the friction velocity describes the vertical momentum, heat, or by extension, vapour flux above a surface of a given roughness (Brutsaert, 1982; Arya, 1988). Brutsaert and Yu found that wind speed was better correlated to the observed evaporation rates and suggested that at the measurement heights of 2 and $3 \mathrm{~m}$, the wind speed represented the turbulent mixing just as well as the friction velocity. They also observed that the correlation between wind speed and evaporation decreased with lower measurement heights, and concluded that wind speed measurements higher above the surface provide more accurate measures of turbulent mixing.

Brady et al. (1969) derived a wind function from meteorological observations made at three thermally loaded power plant cooling lakes. They measured wind speed at $7 \mathrm{~m}$ above the lake surface, and were primarily interested in developing a model for predicting evaporative heat loss from cooling ponds. The wind function developed by Brady et al. has been incorporated into process-based studies to predict evaporation in distinctly different study environments and systems including natural streams (Kim and Chapra, 1997) and high Arctic streams (King and Neilson, 2019). Similarly to Brady et al., Gulliver and Stefan (1986) derived wind functions from meteorological conditions measured $9 \mathrm{~m}$ above heated, unsheltered, artifical channels. The channels were warmed by waste heat from a nearby power plant, so conditions above the streams were always unstable. The wind function of Gulliver and Stefan (1986) commented on the role of stability in evaporation, and compared their wind function favourably with that of Ryan and Harleman (1973), which also included a stability variable. The wind function derived by Gulliver et al. has also been used in other modelling studies (e.g., Sinokrot and Stefan, 1993), but is limited in its application to natural, sheltered streams which may frequently have stable conditions.

Webb and Zhang (1997) did not specify how they derived the coefficients in their wind function, but did compare predictions to evaporation in a streamside evaporation pan. Their meteorological measurements were made at $2 \mathrm{~m}$ height. This model has been applied, with apparent success, to predict evaporation and stream temperature for a range of streams (Leach and Moore, 2011; Magnusson et al., 2012; Garner et al., 2014).

The studies that measured evaporation from streams directly have primarily been focused on deriving wind functions representative of the evaporation processes at one or two streams (Benner, 2000; Guenther et al., 2012; Maheu et al., 2014; Caissie, 2016). There is substantial variability in the wind function coefficients from these four studies, which likely reflects the effects of site-specific characteristics influencing evaporation. For example, the atmospheric boundary layer conditions above streams vary between sites due, in part, to differences in 
stream sheltering and the associated differences in wind speeds. Guenther et al. commented on the evaporation-suppressing role of stable conditions and how turbulent mixing theory may not be applicable to small streams under dense canopy cover. Maheu et al. observed variable stability conditions, which was unique among these four studies, but found a trend that was different to that reported by Guenther et al. The differences in the atmospheric boundary layer between streams, and its role in wind function coefficient variability, suggests that the ratio of instrument height to fetch is an important consideration when applying site-specific wind functions. Also, the site-specific nature of these wind functions, or their representativeness of arid environments (e.g., Benner), has perhaps been a limiting factor against their widespread adoption in process-based modelling studies.

\subsection{Research Objectives and Thesis Structure}

The review of the stream evaporation studies in section 1.2 indicates the need for a generalized wind function that can be applied to a broad range of stream widths and physiographies. Micrometeorology theory supports the limited observations of the role of stability in promoting or suppressing evaporation from sheltered streams, and the influence of riparian vegetation in disrupting turbulent mixing. Furthermore, the role of flow velocity and aeration on stream evaporation has received little attention.

The goals of this study were: (1) to measure evaporation from a range of streams representative of the low-gradient, forested streams in southwest British Columbia; (2) to develop a generalized wind function to be applicable to similar streams; (3) to improve the model predictions through the addition of stability and riparian vegetation model variables; and (4) to test the influence of flow velocity and aeration on evaporation through a controlled, laboratory experiment.

The remainder of this thesis is organized by the following chapters: Methods, Results, Discussion, and Conclusion. The Methods and Results chapters present the field study and laboratory experiment separately. 


\section{Chapter 2}

\section{Field Methods}

\subsection{Study Area and Streams}

Evaporation measurements were made at nine streams in southwest British Columbia, which were selected to sample a range of stream widths, thermal regimes, and riparian vegetation conditions that are common in the southern British Columbia Coast Mountains (Table 2.1; Figure 2.1; Figure 2.2). The streams were distributed between a coastal region (the Malcolm Knapp Research Forest) and a region approximately $100 \mathrm{~km}$ inland (Pemberton). The two regions have distinct climates. The Malcolm Knapp Research Forest (MKRF) has a typical maritime climate with cool and wet winters, and mild summers. The Pemberton region has relatively colder and drier winters, with warmer and drier summers.

Regional hydroclimate data were sourced from the Pemberton BCFS climate station from 1969 to 1984 and from the Pemberton Airport climate station from 1985 to 2018, and for the Malcolm Knapp Research Forest UBC Haney RF Admin climate station for 1969 to 2018. The climate stations' respective Environment Canada Climate identifiers are 1086083, 1086082, and 1103332, and the locations of the stations are shown in Figure 2.1.

The streams were primarily located in coniferous forests, although Blaney Creek (Lower), Miller Creek, and Rutherford Creek had deciduous trees dominant in their riparian vegetation. Stream bankfull widths ranged from $3.1 \mathrm{~m}$ to $27.6 \mathrm{~m}$, average tree heights ranged from $5.3 \mathrm{~m}$ to $46.7 \mathrm{~m}$, and canopy openness ranged from $9 \%$ to $70 \%$. Because the evaporation pans were unstable in high-velocity flow, streams with pools or reaches with low flow velocities were chosen. A preference was also given to locations where evaporation pans could be distributed across the width of the channel, or if that was not feasible, then across the width of a pool. Stream evaporation, stream water temperature, and above-stream meteorological conditions were measured on 20 days between the 6th June 2018 and the 17th August 2018, and field measurements were restricted to days without precipitation. 


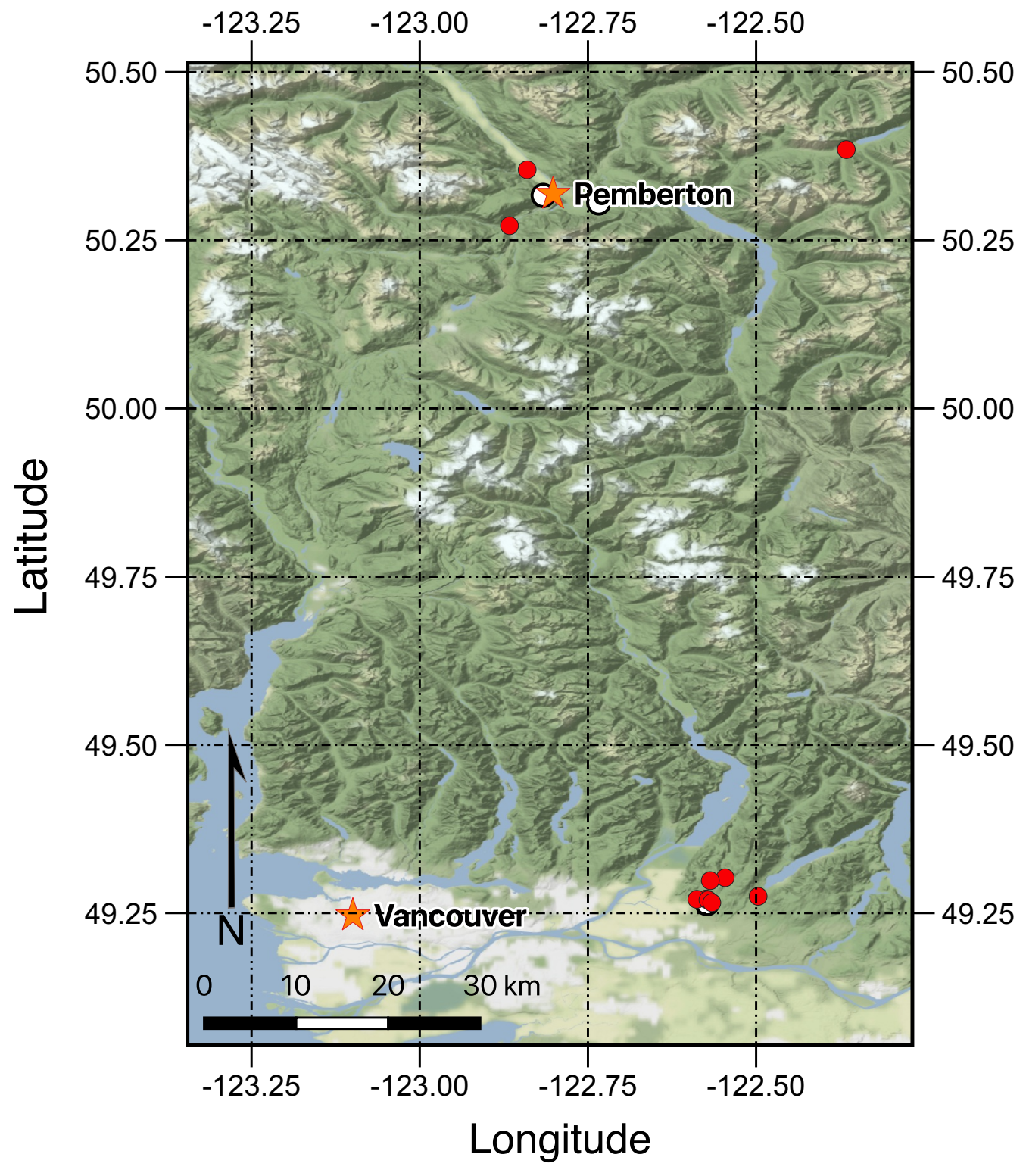

Figure 2.1: The locations of the study streams, indicated by red dots, in southwest British Columbia. The climate stations providing data of the regional hydroclimate are indicated by white dots. The base map source is the Stamen Terrain tile set @ O OpenStreetMap contributors. 


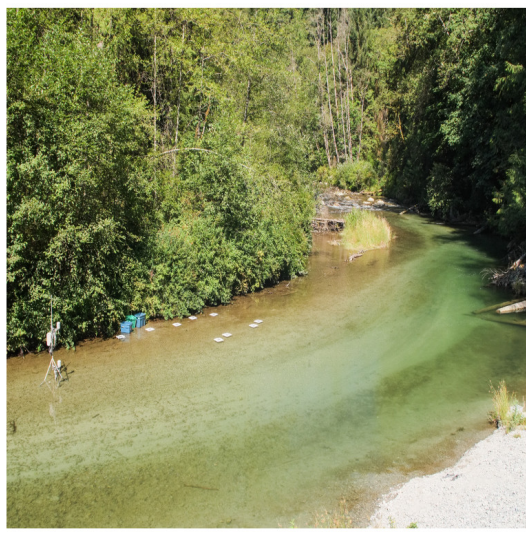

(a) Alouette River

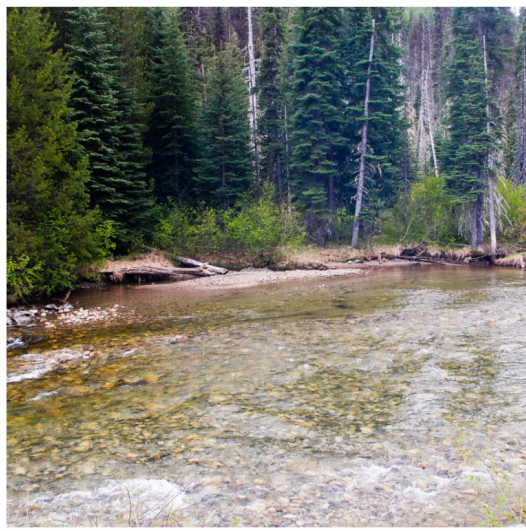

(d) Cayoosh Creek

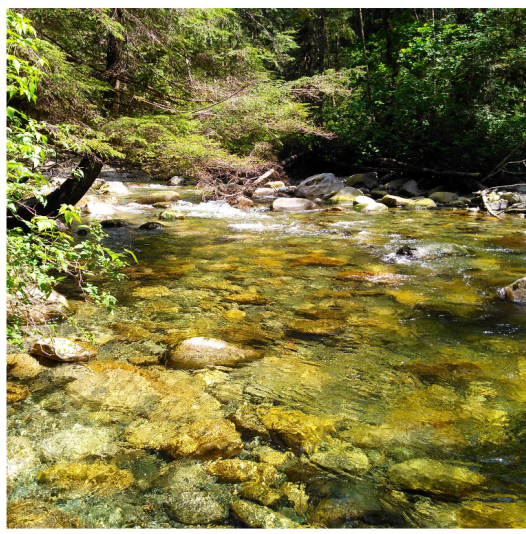

(g) North Alouette River

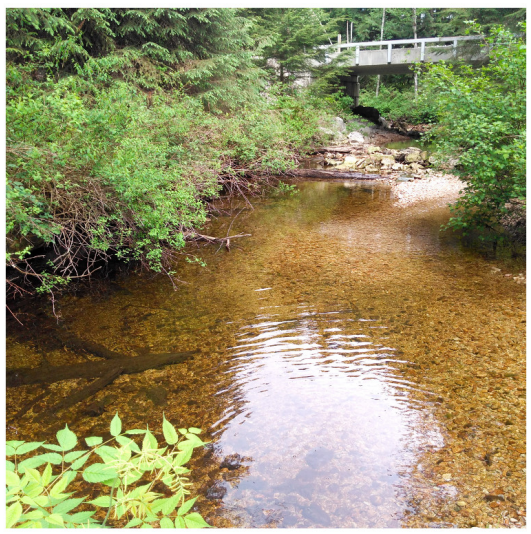

(b) Blaney Creek (Upper)

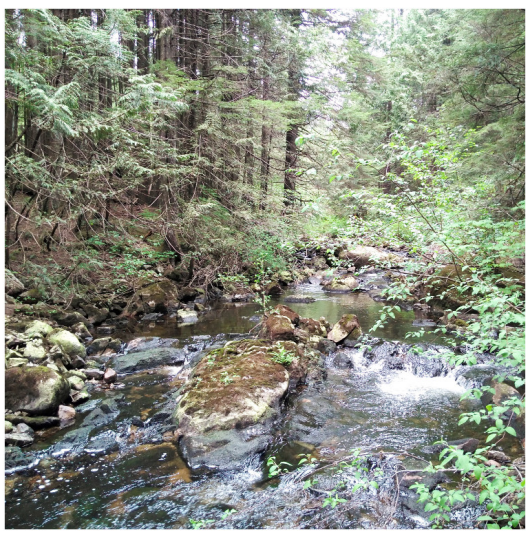

(e) Marion Creek

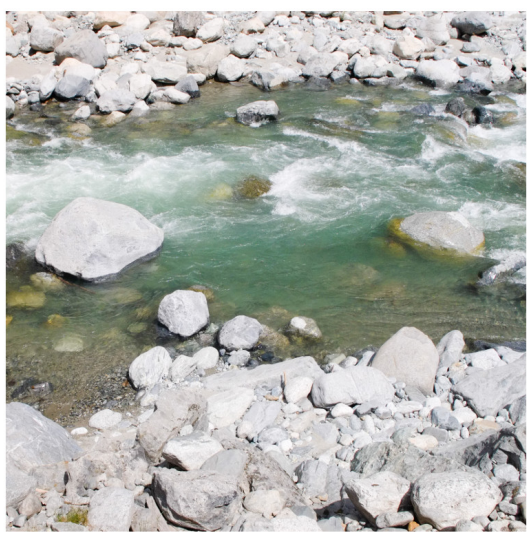

(h) Rutherford Creek

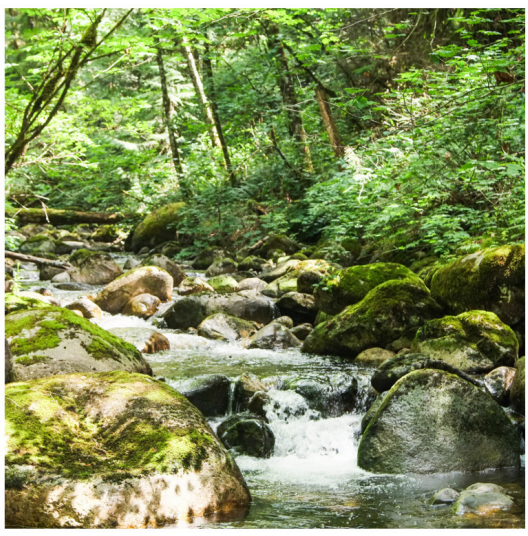

(c) Blaney Creek (Lower)

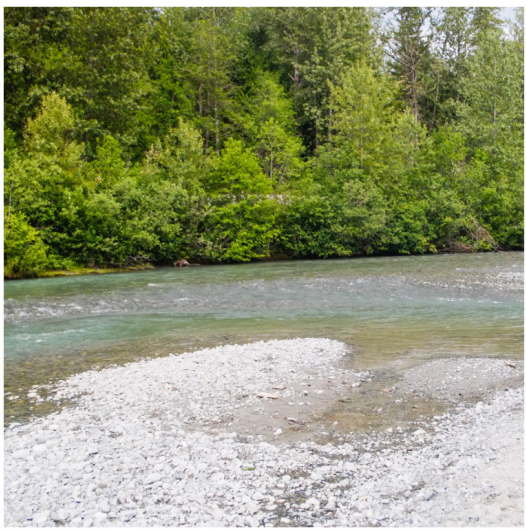

(f) Miller Creek

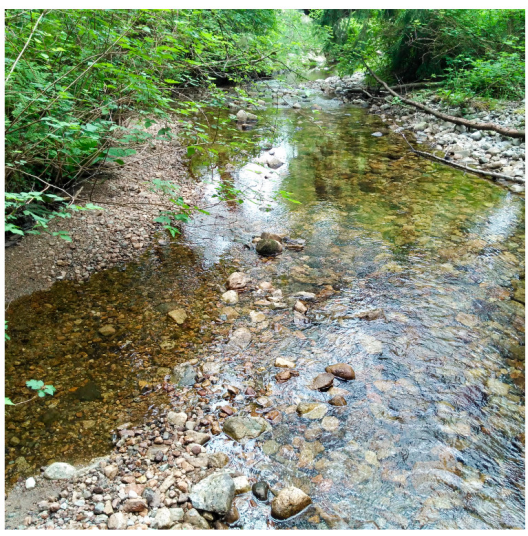

(i) Spring Creek

Figure 2.2: Photographs of the nine study sites. 
Table 2.1: The selected study sites and their stream and riparian properties.

\begin{tabular}{|c|c|c|c|c|c|c|}
\hline Stream & $\begin{array}{l}\text { Stream } \\
\text { Width } \\
(\mathrm{m})\end{array}$ & $\begin{array}{l}\text { Tree } \\
\text { Height } \\
(\mathrm{m})\end{array}$ & $\begin{array}{l}\text { Canopy } \\
\text { Open- } \\
\text { ness } \\
(\%)\end{array}$ & $\begin{array}{l}\text { Elevat } \\
(\mathrm{m})\end{array}$ & Longitude & Latitude \\
\hline Alouette River & 18.1 & 33.1 & 45 & 96 & -122.497 & 49.275 \\
\hline Blaney Creek (Lower) & 5.5 & 46.7 & 9 & 52 & -122.588 & 49.271 \\
\hline Blaney Creek (Upper) & 6.8 & 28.5 & 24 & 358 & -122.568 & 49.299 \\
\hline Cayoosh Creek & 23.0 & 19.7 & 50 & 1139 & -122.366 & 50.385 \\
\hline Marion Creek & 4.0 & 31.6 & 11 & 320 & -122.546 & 49.303 \\
\hline Miller Creek & 27.6 & 26.8 & 57 & 210 & -122.841 & 50.355 \\
\hline North Alouette River & 8.5 & 35.8 & 15 & 172 & -122.566 & 49.266 \\
\hline Rutherford Creek & 18.0 & 5.3 & 70 & 353 & -122.867 & 50.272 \\
\hline Spring Creek & 3.1 & 32.4 & 16 & 162 & -122.574 & 49.271 \\
\hline
\end{tabular}

\subsection{Site Characteristics}

At each location, measurements were made to determine bankfull stream width, tree height, and canopy openness. Bankfull stream width was measured using a Sokkia/Eslon 30m fibreglass tape measure, except at Rutherford Creek, where an LTI Impulse 200 laser rangefinder was used. At each stream, bankfull width was measured across three transects along the reach in which the evaporation pans and meteorological station were deployed.

At each site, five to six mature trees representative of the local species distribution were selected for tree height measurements. Tree height, $h_{t}(\mathrm{~m})$, was calculated as follows:

$$
h_{t}=H D \times\left(\tan \left(\theta_{t}\right)-\tan \left(\theta_{b}\right)\right)
$$

where $H D$ is the horizontal distance from the measurement location to the tree $(\mathrm{m})$, and $\theta_{t}$ and $\theta_{b}$ are the angles of inclination, in degrees, from the measurement location to the top and the bottom of the tree, respectively. The horizontal distance was measured using the fibreglass tape measure, and the angles of inclination from the measurement location were measured using a Suunto PM-5 inclinometer.

Canopy openness, as a proportion, was estimated from a hemispherical photograph taken at each site using the image processing software, Gap Light Analyzer (GLA) following the methods detailed by Frazer et al. (1999). Hemispherical photographs were taken using a Nikon Coolpix 4500 digital camera with a Fisheye Converter FC-E8 lens attached. The camera was mounted on a Manfrotto 190Pro tripod, placed in the centre of the stream reach where evaporation and meteorological measurements were made, and levelled prior to taking a photograph. The hemispherical photographs were taken on days when the sky was uniformly 
overcast, or in the early morning on days with clear skies.

\subsection{Meteorological and Stream Temperature Data}

\subsubsection{Field Measurements}

Air temperature, relative humidity, and wind speed were measured approximately $1.5 \mathrm{~m}$ and $0.5 \mathrm{~m}$ above the stream surface in the vicinity of the evaporation pans deployed in the stream. Rotronic HygroClip-S3 sensors were used to measure air temperature and relative humidity, and were installed in R. M. Young Model 41003 radiation shields to reduce the influence of direct solar radiation on their measurements. Wind speed was measured with MetOne 014A 3-cup anemometers, which have nominal starting threshold speeds of $0.45 \mathrm{~m} \mathrm{~s}^{-1}$. All sensors were mounted on tripod cross-arms that extended the sensors over the centre of the stream (Figure 2.3), or in cases where the evaporation pans did not span the full stream width, the sensors were positioned over the centre of the evaporation pans' distribution. All meteorological sensors were scanned every 10 seconds, and 10-minute averages were logged on a Campbell Scientific CR10X datalogger.

Stream temperature was measured with an Onset TidbiT v2 water temperature logger, which recorded stream temperature every 10 minutes. The temperature logger was housed in a white PVC radiation shield to reduce direct solar radiation effects, and was tethered to a concrete anchor to keep the logger submerged and in the vicinity of the meteorological station.

\subsubsection{Data Processing}

The two MetOne 014A anemometers used to measure above-stream wind speed were crosscalibrated with two recently manufacturer-serviced and calibrated 014A anemometers. Each field-deployed anemometer was paired with a serviced and calibrated anemometer, and they simultaneously measured wind speed over the course of two days, with wind speed measured every 10 seconds and 10-minute averages logged on a Campbell Scientific CR10X datalogger. The uncalibrated anemometers consistently under-reported low wind speeds in comparison to the serviced and calibrated anemometers' measurements, so a segmented linear regression was fit to each pair of uncalibrated-calibrated anemometers' measurements. The anemometerspecific regressions were applied to adjust the above-stream wind speed measurements made by the uncalibrated anemometers. Information regarding the calibration of the anemometers and the correction of their measurements can be found in Appendix A.

The meteorological and stream temperature measurements did not typically align with 
the times of evaporation measurements, so the data were processed and synchronized with the evaporation measurement intervals. To this end, the wind speed, relative humidity, air and stream temperature measurements, and the computed vapour pressures at the two measurement heights were linearly interpolated from 10-minute intervals to 1-minute intervals. The evaporation pan water temperature measurements and computed saturation vapour pressures were interpolated to 1-minute intervals using cubic spline interpolation (Forsythe et al., 1977), except during the first four days of field data when insufficient pan temperature measurements restricted the use of spline interpolation. For these data, a computed temperature difference between stream and pan water was applied instead. Finally, average values of wind speed, relative humidity, air, stream, and pan water temperature, and vapour pressures were calculated for each evaporation pan measurement interval using the 1-minute interpolations.

\subsection{Stream Evaporation}

\subsubsection{Field Measurements}

Stream evaporation was measured using the gravimetric approach developed by Maheu et al. (2014). Each evaporation pan consisted of a plastic container with dimensions of $21.3 \times 21.3 \times 5.1 \mathrm{~cm}$ that was supported by a square wooden frame $34 \mathrm{~cm}$ wide, $1.9 \mathrm{~cm}$ thick, with an inner opening of $21.4 \times 21.4 \mathrm{~cm}$. The frame was painted white to minimize absorption of solar radiation and warming. The frame was tethered to a concrete anchor to keep it in place when deployed in a stream. On each sampling day, nine evaporation pans were distributed across the channel, with three placed along the left and right banks, and three in the centre of the channel (Figure 2.3).

Each evaporation pan was initially filled with stream water to within about $2 \mathrm{~cm}$ of its rim, and then weighed using an Ohaus Scout SPX2201 portable balance (resolution \pm $0.1 \mathrm{~g})$. Approximately every 1 to 1.5 hours throughout the day, each evaporation pan was removed from its frame, the outside of the pan was carefully wiped dry, and its mass was reweighed. The change in mass between weighings provided the measurement of evaporation or condensation that occurred over that time interval. The temperature of the water in each evaporation pan was measured approximately every 20 minutes using an Omega Engineering HH-25TC thermocouple thermometer, to allow for later adjustment of the difference in water temperature between the evaporation pans and the stream. 


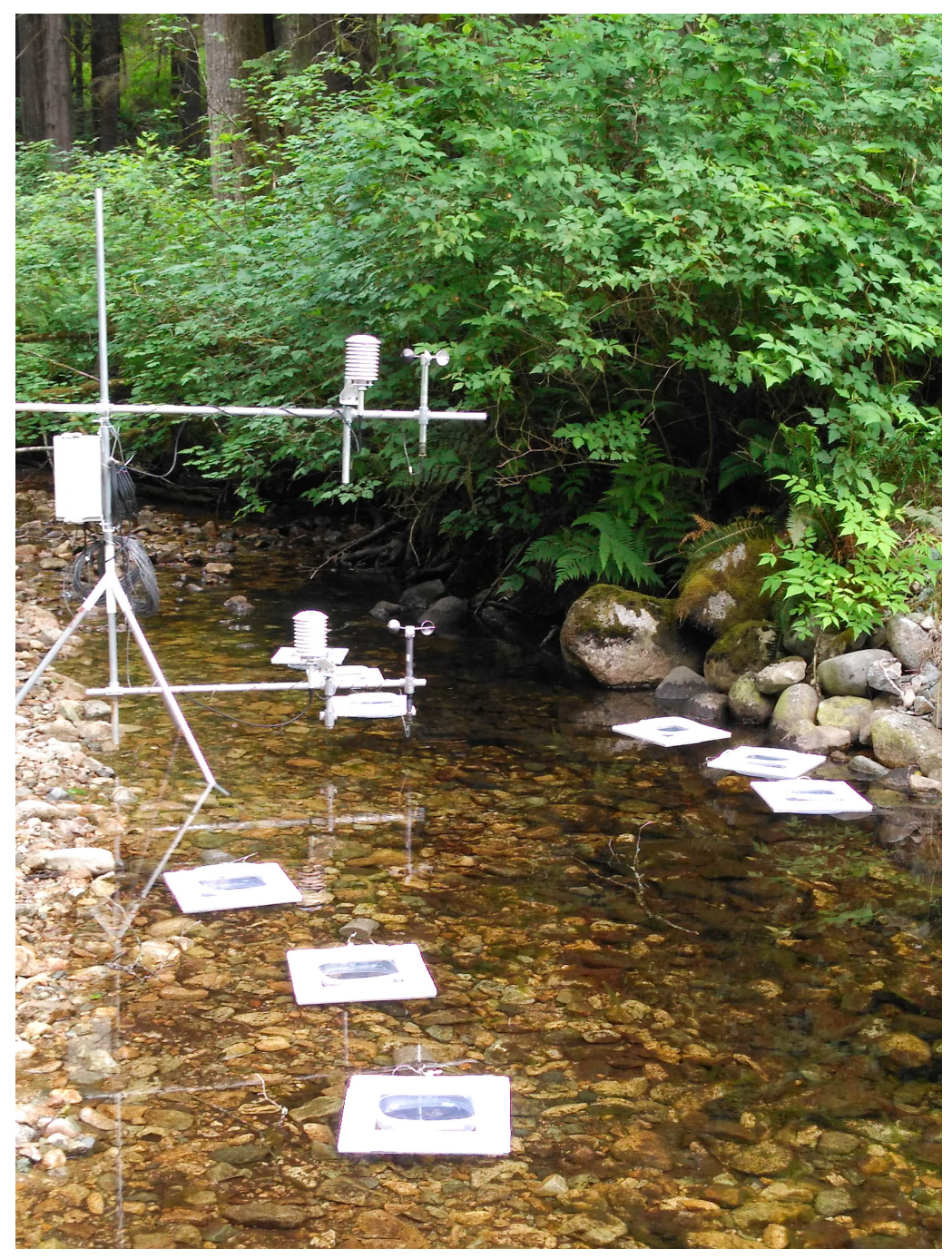

Figure 2.3: The evaporation pans and meteorological station set up at Spring Creek. The TidbiT water temperature logger is submersed near the meteorological station. This demonstrates the ideal distribution of evaporation pans in a stream and the location of the meteorological station with respect to the pans; individual stream characteristics resulted in deviations from this ideal. 


\subsubsection{Data Processing and Analysis}

The evaporation pans had slightly curved sides, so the surface area of the water in a pan varied as a function of the mass of water in the pan. Using photographic image analysis, a simple model was developed to estimate the surface area associated with a given mass of water in an evaporation pan.

An evaporation pan was filled with water dyed with blue food colouring. The initial mass of water, $m_{w}(\mathrm{~g})$, was measured using the same portable balance used in the field. A Fuji $\mathrm{X}$-E1 digital camera was mounted on a tripod and positioned directly above the evaporation pan to take photographs of it, and a tape measure was placed beside the evaporation pan at the water level to provide a scale reference (Figure 2.4). Water was added to the evaporation pan in approximately $25 \mathrm{~g}$ increments, and a photograph of the evaporation pan was taken after each addition. ImageJ, the image analysis software developed by Schneider et al. (2012), was used to set a scale for each image, and determine the surface area of the blue-dyed water, $A_{p}\left(\mathrm{~m}^{2}\right)$, in the evaporation pan. A regression of the following form was used to predict water surface area from pan mass:

$$
\log \hat{\left(A_{p}\right)}=a_{1} \cdot m_{w}+a_{2} \cdot \log \left(m_{w}\right)+a_{0}
$$

where $a_{1}, a_{2}$, and $a_{0}$ are model fitting parameters with values of $-1.74 \times 10^{-4}, 2.42 \times 10^{-1}$, and 4.74, respectively. The regression had an adjusted $R^{2}$ of 0.88 and a root-mean-square error of $1.0 \times 10^{-4} \mathrm{~m}^{2}$ relative to the average observed water surface area of $3.92 \times 10^{-2} \mathrm{~m}^{2}$. Information regarding the evaporation pan water surface area calibration can be found in Appendix B.

Pan evaporation for each measurement period was computed as follows:

$$
E=\frac{\Delta m \cdot c_{f}}{\rho_{w} \cdot A_{p} \cdot \Delta t}
$$

where $E$ is the evaporation rate in $\mathrm{mm} \mathrm{h}^{-1}, \Delta m$ is the change in pan mass in $\mathrm{g}, \rho_{w}$ is the density of water, assumed to be $1000 \mathrm{~kg} \mathrm{~m}^{-3}$, and $\Delta t$ is the elapsed time (s), and $c_{f}$ is a conversion factor equal to 3600 for converting units to $\mathrm{mm} \mathrm{h}^{-1}$. Finally, the calculated evaporation rates from all nine pans were averaged per measurement interval, along with their associated meteorological conditions. 


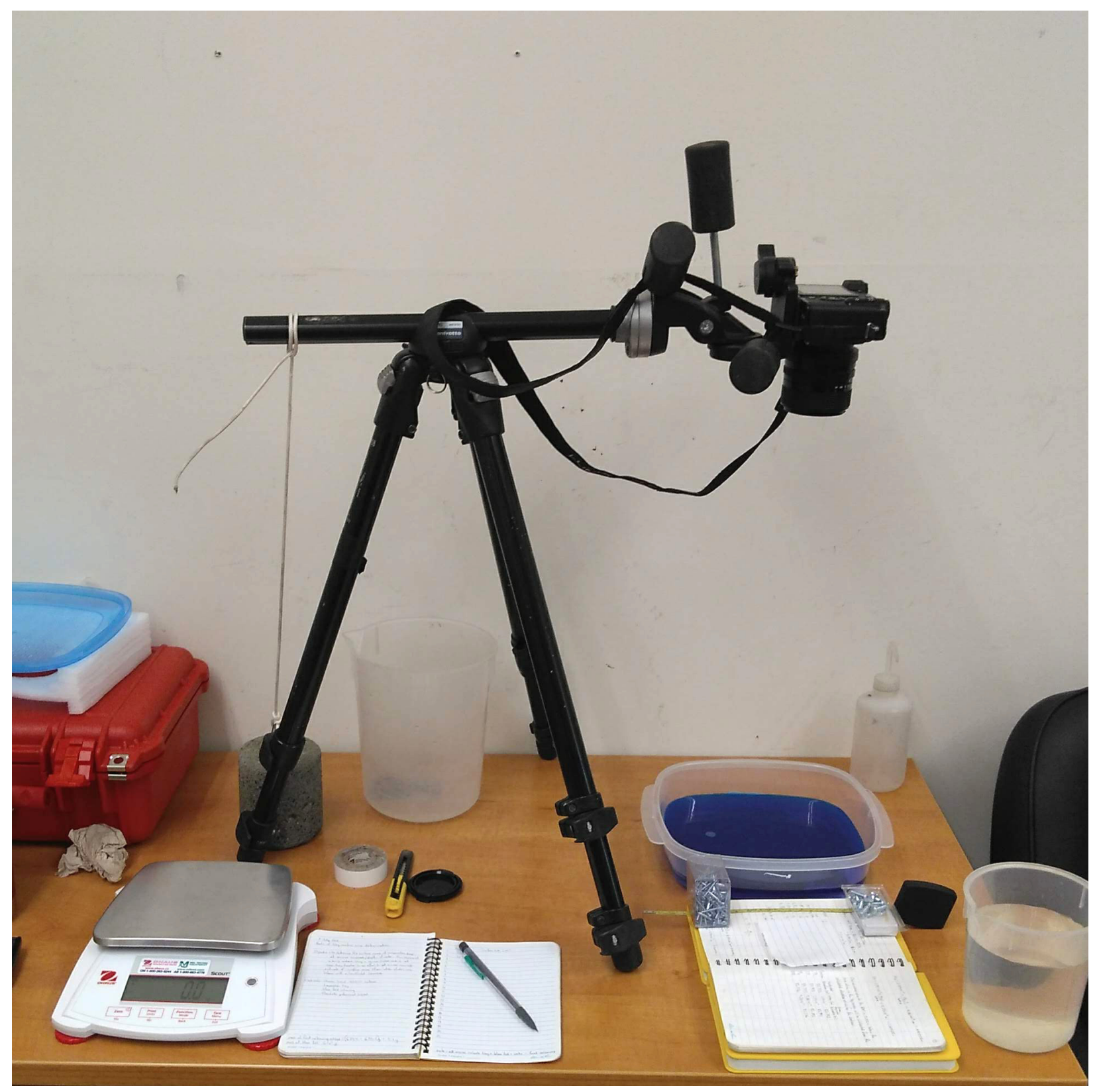

Figure 2.4: The method of photographing an evaporation pan with blue dyed water for the determination of the pan water surface area. 


\subsection{Evaporation Model Variables}

Several variables were calculated from the processed meteorological, stream, and evaporation pan temperature data. The saturation vapour pressure, $e_{s}(T)(\mathrm{kPa})$, at a temperature $T$ $\left({ }^{\circ} \mathrm{C}\right)$ was computed as:

$$
e_{s}(T)=0.611 \times \exp \left(\frac{17.27 \cdot T}{T+237.26}\right)
$$

The vapour pressure at the water surface, $e_{w}$, was then computed as:

$$
e_{w}=e_{s}\left(T_{w}\right)
$$

where $T_{w}$ is the pan water temperature. The vapour pressure of the air, $e_{a}$, was calculated as:

$$
e_{a}=e_{s}\left(T_{a}\right) \cdot \frac{R H}{100}
$$

where $T_{a}$ is the air temperature and $R H$ is the relative humidity (\%). The vapour pressure difference, $\Delta e$, driving evaporation was then calculated as:

$$
\Delta e=e_{w}-e_{a}
$$

Two atmospheric stability indices were calculated. Both indices represent neutral conditions at a value of zero, with unstable conditions at values $>0$. One is the virtual temperature difference between the stream surface and the air above it, $\Delta \theta\left({ }^{\circ} \mathrm{C}\right)$, which represents the vertical variation in air density above the stream (Gulliver and Stefan, 1986). The virtual temperature, $\theta(\mathrm{K})$, of an air parcel is calculated as:

$$
\theta=\frac{T+273.15}{1+0.378 \cdot e / p}
$$

where $p$ is the atmospheric pressure $(\mathrm{kPa}), e$ is the vapour pressure $(\mathrm{kPa})$, and $T$ is the temperature $\left({ }^{\circ} \mathrm{C}\right)$ of the fluid parcel. As $p$ was not measured, a standard pressure, $P$, for each field site's elevation was estimated using the U.S. Standard Atmosphere, 1976, atmosphere model (U.S. Standard Atmosphere, 1976, 1976) as follows:

$$
P=P_{b} \cdot\left(\frac{T_{b}}{T_{b}+L_{b} \cdot\left(h-h_{b}\right)}\right)^{\frac{g \cdot M_{a}}{R^{*} \cdot L_{b}}} \times c_{p}
$$

where $h$ is the elevation of the field site $(\mathrm{m})$, and $P_{b}, T_{b}, L_{b}$, and $h_{b}$ are the standard pressure $(101.325 \mathrm{kPa})$, temperature $(288.15 \mathrm{~K})$, temperature lapse rate $(0.0065 \mathrm{~K} / \mathrm{km})$, and reference elevation $(0 \mathrm{~m})$ where $0<h \leq 11,000 \mathrm{~m} ; g\left(\mathrm{~m} \mathrm{~s}^{-2}\right)$ is gravitational acceleration, $M_{a}(\mathrm{~kg}$ 
$\left.\mathrm{mol}^{-1}\right)$ is the molar mass of air, $R^{*}\left(\mathrm{~J} \mathrm{~mol}^{-1} \mathrm{~K}^{-1}\right)$ is the universal gas constant, and $c_{p}$ is a conversion factor equal to $1 \times 10^{-3}$ to convert from units of $\mathrm{Pa}$ to $\mathrm{kPa}$. The virtual temperature difference was then calculated as:

$$
\Delta \theta=\theta_{w}-\theta_{a}
$$

where $\theta_{w}$ is the virtual temperature at the water surface, and $\theta_{a}$ is the virtual temperature of the air above the water.

The second stability index used was the buoyant force, $F\left(\mathrm{~m} \mathrm{~s}^{-2}\right)$, which relates buoyant differences to temperature differences between two fluid parcels. It was calculated as:

$$
F=g\left(\frac{T_{w}+273.15}{T_{a}+273.15}-1\right)
$$

\subsection{Statistical Analysis}

Model fitting began by fitting a base model with the following form:

$$
E=(a+b \cdot u) \cdot \Delta e
$$

where $u$ is the wind speed in $\mathrm{m} \mathrm{s}^{-1}$, and $a$ and $b$ are model fitting parameters. The stream properties and stability indices were then incorporated as additional model variables to form the full complement of candidate models, as shown through Equations 2.13 to 2.23:

$$
\begin{gathered}
E=(a+b \cdot u+c \cdot \phi) \cdot \Delta e \\
E=(a+b \cdot u+c \cdot \gamma) \cdot \Delta e \\
E=(a+b \cdot u+c \cdot \phi \cdot u) \cdot \Delta e \\
E=(a+b \cdot u+c \cdot \gamma \cdot u) \cdot \Delta e \\
E=(a+b \cdot u+c \cdot \phi+d \cdot \gamma) \cdot \Delta e \\
E=(a+b \cdot u+c \cdot \phi \cdot u+d \cdot \gamma) \cdot \Delta e
\end{gathered}
$$




$$
\begin{gathered}
E=(a+b \cdot u+c \cdot \phi+d \cdot \gamma \cdot u) \cdot \Delta e \\
E=(a+b \cdot u+c \cdot \phi \cdot u+d \cdot \gamma \cdot u) \cdot \Delta e \\
E=(a+b \cdot \phi \cdot u) \cdot \Delta e \\
E=(a+b \cdot \phi \cdot u+c \cdot \gamma) \cdot \Delta e \\
E=(a+b \cdot \phi \cdot u+c \cdot \gamma \cdot u) \cdot \Delta e
\end{gathered}
$$

where $\phi$ is canopy openness, $\gamma$ represents one of the stability indices tested (the buoyant force and the virtual temperature difference), and $c$ and $d$ are model fitting parameters. Linear mixed-effects modelling was used to fit regressions to the models described above.

A linear mixed-effects model fits a linear regression to a dataset, but allows for temporal, spatial, or other subject correlations in the data to be accounted for through subject-specific adjustments to the fixed-effects coefficients. For example, a model has a fixed-effect parameter, $a$, and subject-specific adjustments, $\alpha_{i}$, are added such that each unique subject, $i$, has a subject-specific coefficient, $a+\alpha_{i}$. When there is little variability between subjects, the values of $\alpha_{i}$ will be small in absolute magnitude relative to the value of the fixed-effects coefficients. It is the fixed-effects coefficients that are used for model validation and application to external datasets.

The first round of model testing was done through fitting mixed-effects linear models to each candidate model using the maximum-likelihood approach for parameter estimation. The mixed-effects models allowed each model parameter, $(a, b$, and if present, $c$ and $d$ ), to vary by site, by estimating a site-specific random effect for each parameter. All possible distributions of random effects on a given model's variables were tested, and model/random-effect combinations which had any number of insignificant population-level estimated coefficients ( $\mathrm{p}$-value $>0.05)$ were dropped from further consideration.

The remaining models were refit to test their performance under leave-one-out crossvalidation. In each iteration of the cross validation, all data for one site were withheld; the model was fit using data for the remaining sites and then applied using data for the withheld site. Model performance was determined by computing the root-mean-square error ( $R M S E$, $\left.\mathrm{mm} \mathrm{h}^{-1}\right)$, the mean bias error $\left(M B E, \mathrm{~mm} \mathrm{~h}^{-1}\right)$, the mean absolute error, $\left(M A E, \mathrm{~mm} \mathrm{~h}^{-1}\right)$, and the Nash-Sutcliffe efficiency (NSE), as follows: 


$$
\begin{gathered}
R M S E=\sqrt{\frac{1}{n} \sum_{i=1}^{n}\left(\hat{E}_{i}-E_{i}\right)^{2}} \\
M B E=\frac{1}{n} \sum_{i=1}^{n}\left(\hat{E}_{i}-E_{i}\right)^{2} \\
M A E=\frac{1}{n} \sum_{i=1}^{n}\left|\hat{E}_{i}-E_{i}\right| \\
N S E=1-\frac{\sum_{i=1}^{n}\left(\hat{E}_{i}-E_{i}\right)^{2}}{\sum_{i=1}^{n}\left(E_{i}-\bar{E}\right)^{2}}
\end{gathered}
$$

where $\hat{E}_{i}$ is the modelled evaporation rate, and $\bar{E}$ is the mean observed evaporation rate. 


\section{Chapter 3}

\section{Laboratory Methods}

Considering the constraints imposed by the need for the evaporation pans to be located in areas with placid flow, a laboratory study was conducted to allow study of the effects of aeration and flow velocity on stream evaporation.

\subsection{Design and Construction}

A research flume was constructed in the Mountain Channel Hydraulic Experimental Laboratory in the Department of Geography at the University of British Columbia. The flume was designed based on the following principles: (1) to allow for the continuous measurement of evaporation from the recirculating water; (2) to aerate the water as it flowed; (3) to allow for variable flow velocity; and (4) to allow for wind to blow over the water in the flume in a quantifiable manner.

The continuous measurement of evaporation from the flume was achieved through the principles of conservation of mass and electrical conductivity. For a sodium chloride (salt) solution of a known volume of water and a known mass of salt, any change in the temperaturecorrected electrical conductivity can be attributed to a change in the volume of water or a change in the mass of salt. By keeping the mass of salt constant and closing the system to any throughput of water other than condensation or evaporation, changes in the solution's electrical conductivity can be related to the amount of water that is condensing or evaporating.

As shown in Figure 3.1, the flume was constructed of plywood, and the channel had $L \times W \times H$ dimensions of $1.5 \times 0.2 \times 0.45 \mathrm{~m}$. An elevated constant-head tank supplied approximately $1 \mathrm{~L} \mathrm{~s}^{-1}$ of water to the flume through a manifold mounted at the head of the flume. To meet the design principles, the following features were incorporated into the flume construction: two stacks of four and two concrete paving bricks (each brick measuring $0.39 \times 0.19 \times 0.05 \mathrm{~m}$ ) were placed at the beginning of the flume to produce two steps for the 
water to fall over as it flowed; a LEGO baseplate was glued to the top brick in each stack to allow for LEGO bricks to be attached for the function of aerating the flow (Figure 3.2); and a platform was added to the end of the flume, where a fan could be placed to blow air over the water in the flume.

At the end of the flume, the water was piped into a catch-basin that contained a Mastercraft 1/2 HP utility pump. From the catch-basin, the water was pumped back to the constant-head tank for recirculation. The plywood and the concrete paving bricks were painted with latex-based exterior paint to prevent water from leaching into the plywood, or solutes from the bricks leaching into the water. The head tank and the catch-basin were 94.6-L lidded plastic tubs and were directly connected to the flume with ABS piping; as a result, the system was only open to the ambient environment where the water flowed through the flume.

\subsection{Flume Flow Properties}

The discharge through the flume was measured by diverting flow from the catch-basin into a receptacle over a measured time interval. The minimum discharge was measured with the flume set at a $2^{\circ}$ gradient with LEGO bricks impeding flow, and the maximum discharge was measured with the flume set at a $6^{\circ}$ gradient without LEGO bricks. The intercepted water was weighed and its mass converted to a volume assuming a water density of $0.998 \mathrm{~kg} \mathrm{~L}^{-1}$ at

$21{ }^{\circ} \mathrm{C}$. Discharge through the flume averaged $1.04 \mathrm{~L} \mathrm{~s}^{-1}$ with a $2^{\circ}$ gradient, and $1.17 \mathrm{~L} \mathrm{~s}^{-1}$ with a $6^{\circ}$ gradient.

Flow velocity was measured by adding blue dye to the water as it exited the manifold, and timing its travel along the length of the flume to the drain. The travel of the blue dye was recorded as video by a Fuji X-E1 digital camera and a frame-by-frame analysis of the video was used to determine the flow velocity. This procedure was conducted with the flume set up with a $2^{\circ}$ gradient without LEGO bricks, and a $6^{\circ}$ gradient without LEGO bricks. The average flow velocity with $2^{\circ}$ gradient was $0.68 \mathrm{~m} \mathrm{~s}^{-1}$, and $0.92 \mathrm{~m} \mathrm{~s}^{-1}$ with a $6^{\circ}$ gradient.

\subsection{Evaporation Trials}

The flume parameters of flow aeration and flow velocity were varied to investigate what influence they have on evaporation rates. These parameters were difficult to finely control, or even quantify in the case of aeration, so a series of binary trials were designed to test their effects. The amount of aeration produced was controlled by the addition or removal of LEGO brick obstacles from the flume and the flow velocity was controlled by changing the gradient of the flume. A total of four combinations of the flume parameters were tested with flume 


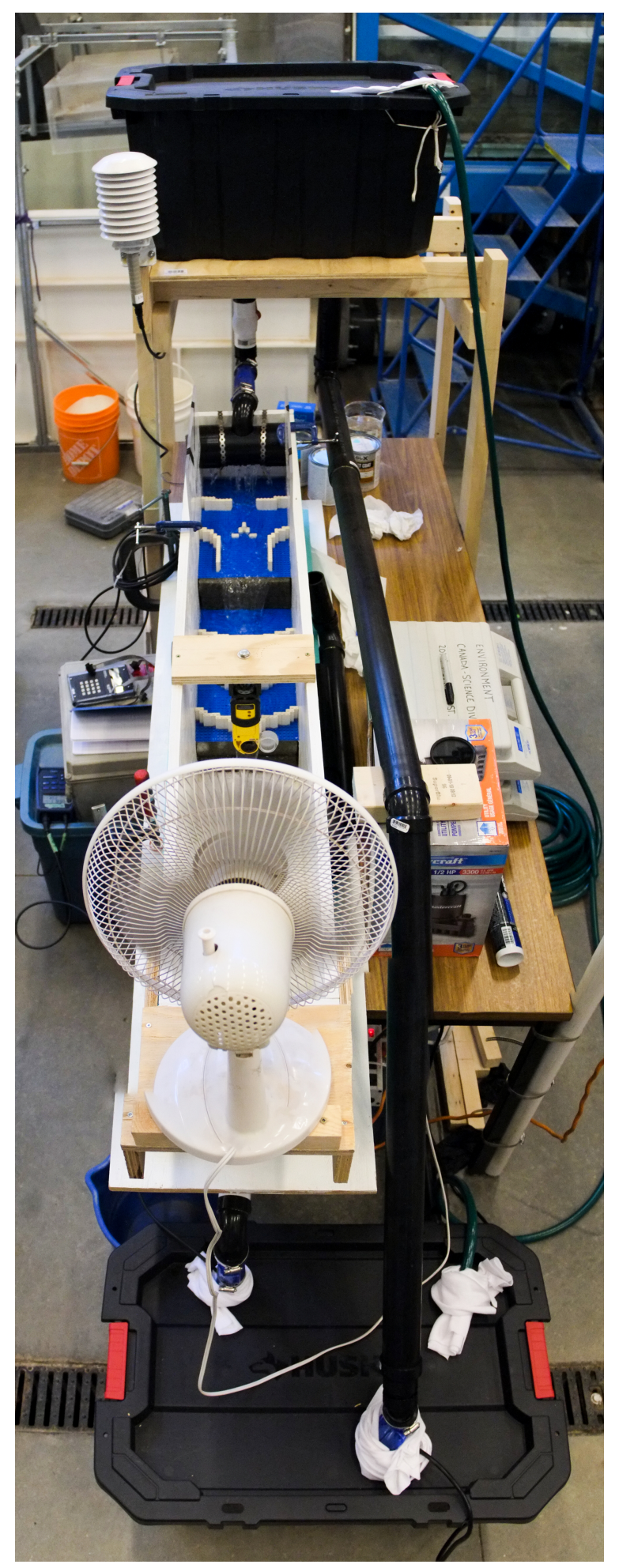

Figure 3.1: Photograph of the laboratory flume. The constant-head tank is visible at the top of the frame, with the valved plumbing supplying water to the flume. A return-flow pipe returns excess water to the catch-basin, seen at the bottom of the frame. The yellow Kestrel weather meter is seen mounted in the flume, and the fan is angled to blow air down into the flume channel. In this image, the pump supplies water to the head tank through a garden hose, but this was later replaced by plumbing. 


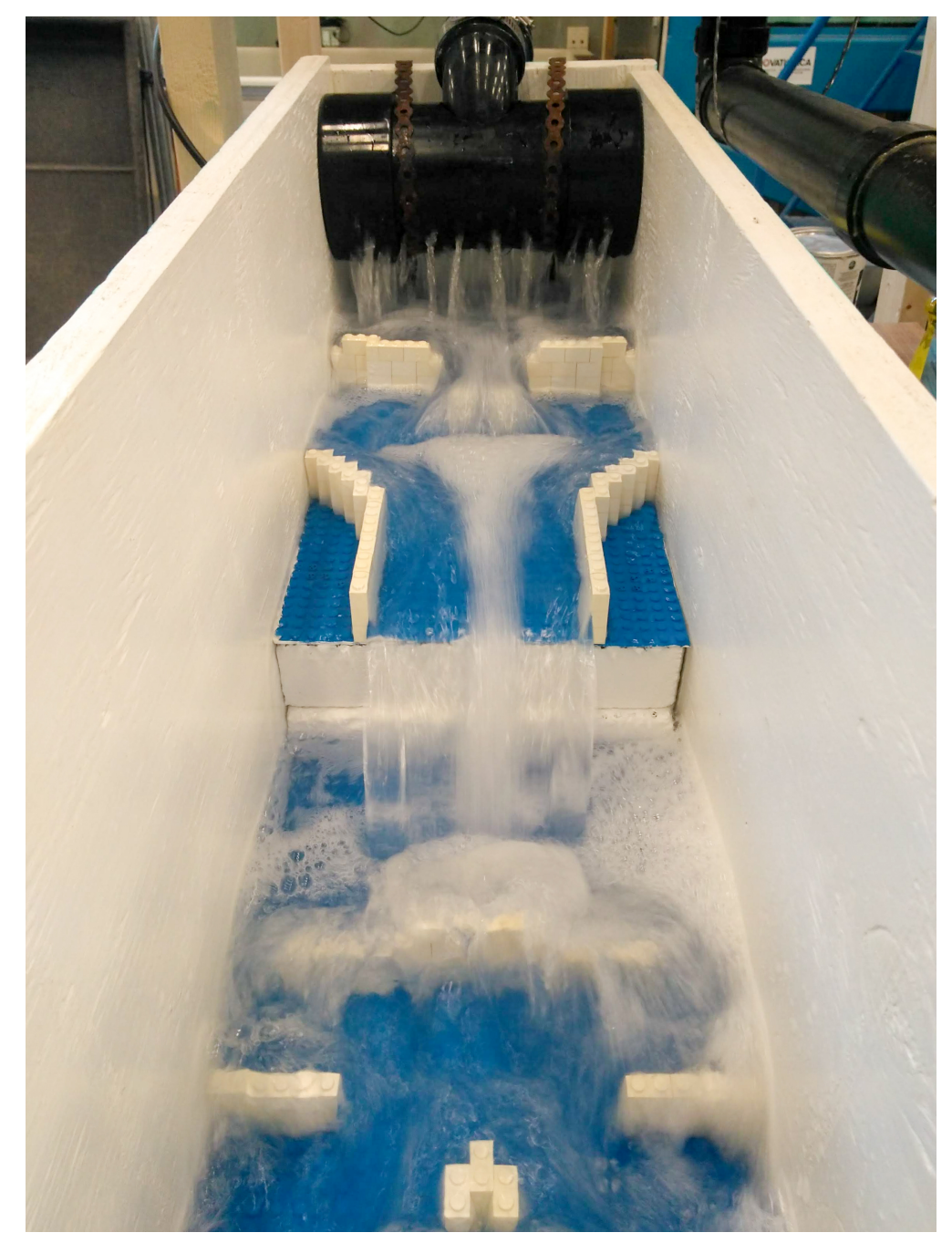

Figure 3.2: Photograph illustrating the use of LEGO blocks to produce steps and roughness. The blue LEGO baseplates are glued to the top paving brick on each step and the white LEGO bricks are attached to the baseplates. 
trials $\left(2^{\circ}\right.$, no LEGO; $2^{\circ}$, LEGO; $6^{\circ}$, no LEGO; $6^{\circ}$, LEGO).

For each trial, after ensuring the flume was dry, approximately $750 \mathrm{~g}$ of table salt was weighed using a Mettler Toledo PG5002-S DeltaRange analytical balance $( \pm 0.01 \mathrm{~g})$ and added to approximately $72 \mathrm{~kg}$ of tap water weighed on an Ohaus Ranger 3000 balance $( \pm 1$ g). Once the flume parameters were set and the sensors were operating, the pump in the catch-basin was powered on and the flume recirculated for approximately five hours to allow for a sufficient amount of data to be collected. At the conclusion of each trial, the flume was drained and flushed with fresh water, and dried in preparation for the next trial.

\subsection{Flume Data Collection}

Electrical conductivity was measured with a WTW Condi 340i conductivity meter connected to a Campbell Scientific CR10X datalogger. The conductivity probe was first immersed in a beaker filled with a sample of the water used to fill the flume for any given trial; this background electrical conductivity was recorded to adjust the measured salt solution conductivity later. The conductivity meter was sensitive to aerated water, so the probe was immersed in the flume adjacent to the drain or in the catch-basin, dependent on which location provided the least aerated water given the current flume setup. The conductivity meter measured the voltage across the probe every 10 seconds, calculated a non-linearly temperature-corrected voltage $(\mathrm{mV})$ that is proportional to the electrical conductivity $(\mathrm{mS}$ $\mathrm{cm}^{-1}$ ), and recorded 10 minute averages.

Ambient atmospheric conditions were measured using a Rotronic HygroClip-S3 in a white radiation shield mounted approximately $0.5 \mathrm{~m}$ above the flume. It measured relative humidity and air temperature every 10 seconds and logged 10 minute averages on a Campbell Scientific CR10X datalogger. Wind speed, relative humidity, and air temperature were measured with a Nielsen-Kellerman Kestrel 5500 weather meter that logged measurements every 10 minutes. The Kestrel weather meter was affixed to a crossbeam spanning the flume walls, and measured wind speed approximately $0.2 \mathrm{~m}$ above the surface of flow (Figure 3.3). Water temperature was measured with an Onset TidbiT v2 water temperature logger suspended in the standing water in the catch-basin. It measured and logged water temperature every 10 minutes.

\subsection{Data Processing and Analysis}

The first procedure was to create a calibration curve to relate the measured electrical conductivity to an estimated molarity of the solution $\left(\mathrm{mol} \mathrm{L}^{-1}\right)$. To achieve this, a solution below the typical operating electrical conductivity of the flume experiments was prepared by 


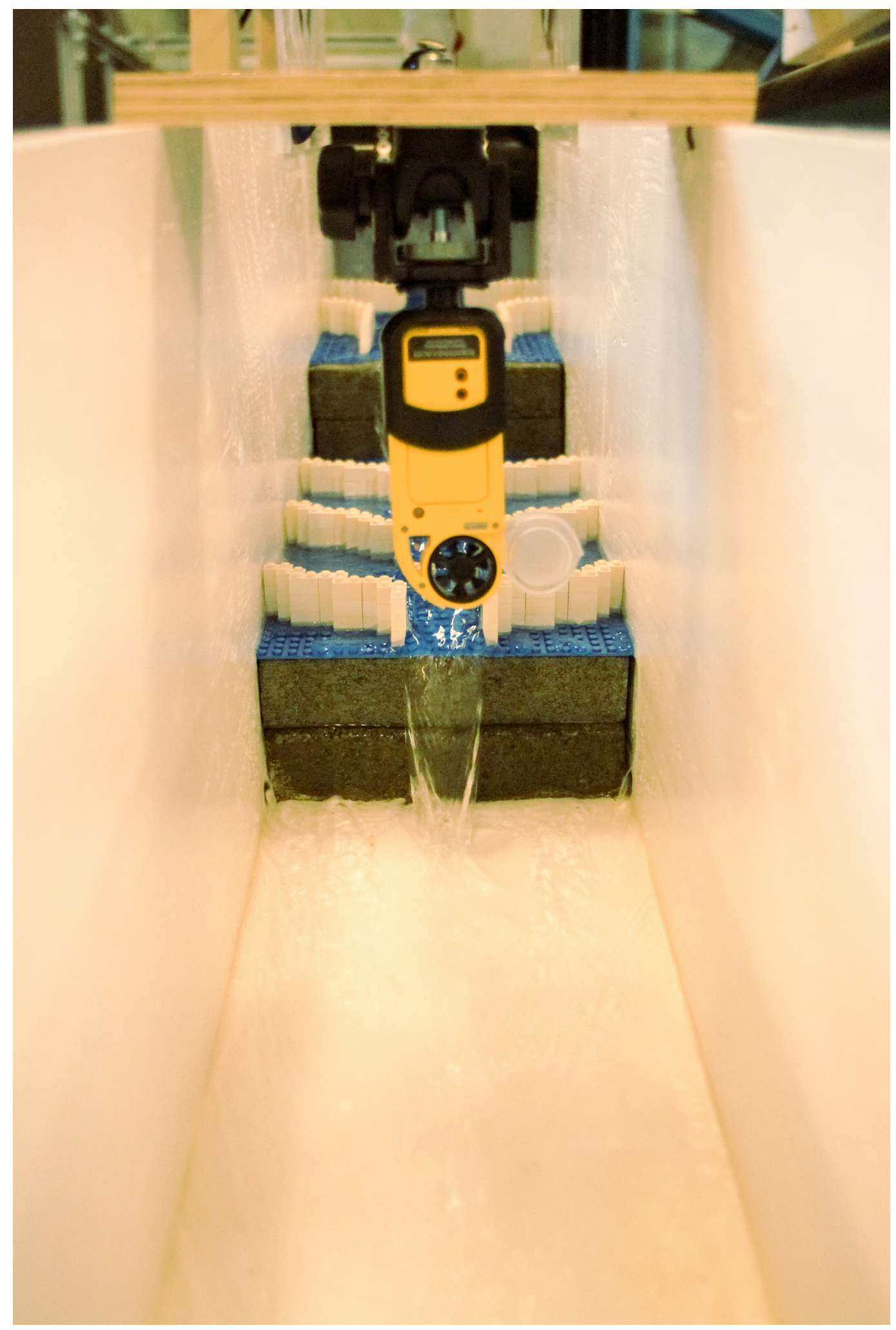

Figure 3.3: Photograph showing the Kestrel weather meter measuring the wind speed over the surface of the flow in the flume. The impeller is approximately $20 \mathrm{~cm}$ above the surface of the flow. 
weighing a mass of approximately $11 \mathrm{~g}$ of table salt on the analytical balance, and dissolving it in a $1000 \mathrm{~mL}$ Pyrex No. 5600 volumetric flask $( \pm 0.30 \mathrm{~mL})$ filled with water. This solution was decanted into a beaker, and the initial electrical conductivity was measured with the WTW 340i conductivity meter and recorded. Subsequently, additions of $5 \mathrm{~mL}$ ( \pm $0.1 \mathrm{~mL}$ ) of water were added to the solution using a Kimax No. 37000 pipette, and the electrical conductivity recorded, once stable, after each addition. This continued until the electrical conductivity of the solution was greater than the maximum electrical conductivity measured during the flume experiments. A linear regression was fit to the data to conclude the calibration.

The pump produced heat as it operated and caused the flume water to rapidly warm during the beginning of each evaporation trial. The first hour of observations from each trial were removed to allow for the sensors to adjust and for the rate of water warming to decrease. The wind speed, air temperature, and relative humidity data from the Kestrel weather meter along with the flume water temperature data were linearly interpolated from 10 minute intervals to 1 minute intervals. The interpolated data were then synchronized with the electrical conductivity data and subsequently averaged over 30 minute intervals. The electrical conductivity calibration regression (Equation 3.1) was used to estimate the molarity of the solution as follows:

$$
\hat{M}=m \times \Gamma+b
$$

where $\hat{M}$ is the estimated molarity of the solution in $\mathrm{mol} \mathrm{L}^{-1}, \Gamma$ is the electrical conductivity in $\mathrm{mS} \mathrm{cm}{ }^{-1}$, and $m$ and $b$ are the regression coefficients. The $\hat{M}$ values were then converted to the estimated volume of water in the flume:

$$
\hat{V}=\frac{n}{\hat{M}}
$$

where $\hat{V}$ is the estimated volume in $\mathrm{L}, n$ is the number of moles of salt in solution, calculated as the mass of salt divided by its molar mass $\left(58.443 \mathrm{~g} \mathrm{~mol}^{-1}\right)$. The difference in volume, $\Delta \hat{V}$, between datapoints in the time series was computed and converted to a difference in depth of water, $\Delta d_{w}$, in $\mathrm{m}$, assuming water density is $998 \mathrm{~kg} \mathrm{~m}^{-3}$ at $21^{\circ} \mathrm{C}$. The evaporation rate was calculated as follows:

$$
E_{f}=\frac{\Delta d_{w}}{A_{f}} \times C
$$

where $E_{f}$ is the estimated evaporation rate from the flume in $\mathrm{mm} \mathrm{h}^{-1}, A_{f}$ is the area of the flume in $\mathrm{m}^{2}$, and $C$ is a conversion factor equal to 2000 to convert units from $\mathrm{m}$ per 
30 minutes to $\mathrm{mm} \mathrm{h}^{-1}$. Following Equations 2.4 to 2.10, several meteorological variables were computed, and an adjustment to the saturation vapour pressure to account for vapour pressure suppression was applied using Raoult's Law as follows:

$$
e_{1}=\frac{n_{w}}{n_{w}+n_{i}} \cdot e_{0}
$$

where $e_{0}$ is the saturation vapour pressure of pure water in $\mathrm{kPa}, n_{w}$ is the number of moles of water, $n_{i}$ is the number of moles of dissociated salt ions in the flume solution, and $e_{1}$ is the adjusted saturation vapour pressure, in $\mathrm{kPa}$.

\subsection{Statistical Analysis}

Two linear models were used to test the influence of the flume parameters on the evaporation rate. A model incorporating the flume parameters as binary variables was compared to a reduced model with the flume parameters omitted. The full and nested model forms were as follows:

$$
\begin{gathered}
E_{f}=\left(q_{0}+q_{2 L} I_{2 L}+q_{6 n L} I_{6 n L}+q_{6 L} I_{6 L}\right) \cdot \Delta e+\left(r_{0}+r_{2 L} I_{2 L}+r_{6 n L} I_{6 n L}+r_{6 L} I_{6 L}\right) \cdot \Delta \theta+ \\
s_{0}+s_{2 L} I_{2 L}+s_{6 n L} I_{6 n L}+s_{6 L} I_{6 L} \\
E_{f}=q_{0} \cdot \Delta e+r_{0} \cdot \Delta \theta+s_{0}
\end{gathered}
$$

where $E_{f}$ is the evaporation rate in $\mathrm{mm} \mathrm{h}^{-1}, \Delta e$ is the vapour pressure difference between the flume water surface and the air above it $(\mathrm{kPa}), \Delta \theta$ is the virtual temperature difference in ${ }^{\circ} \mathrm{C}, I_{2 L}, I_{6 n L}$, and $I_{6 L}$ are binary indicator variables representing the state of the flume parameters for aeration and flow velocity, and $q_{i}, r_{i}$, and $s_{i}$ are estimated coefficients. The model coefficients, $q_{i}, r_{i}$, and $s_{i}$ are added to the respective slopes and intercept, $q_{0}, r_{0}$, and $s_{0}$, when the indicator variables have values of 1 , representing the state of the flume parameters.

The model described by Equation 3.5 produces a unique regression for each flume trial; to test whether any of the regressions were significantly different than the regression fit by Equation 3.6, an analysis of variance test was conducted. A p-value $<0.05$ was the threshold chosen for statistical significance. 


\section{Chapter 4}

\section{Field Results}

\subsection{Overview of the Study Period}

In general, the field work season was characterized by above-average air temperatures and below-average precipitation both in the Malcolm Knapp Research Forest (MKRF) and around Pemberton. For the months of the year when field work was conducted, the historical monthly air temperatures and mean monthly precipitation for the two field work regions are presented in Table 4.1. The mean air temperature of the months of June, July, and August 2018 was $1.7{ }^{\circ} \mathrm{C}$ above the historical mean for the MKRF, with $37 \%(31 \mathrm{~mm})$ less total precipitation than the historical mean. The mean air temperature for the same period in Pemberton was $2.3{ }^{\circ} \mathrm{C}$ above the historical mean and there was $19 \%(7 \mathrm{~mm})$ less precipitation than average. The Pemberton region has a drier climate than the MKRF, with historical mean summer relative humidities of $69 \%$ and $73 \%$, respectively.

Table 4.1: Historical mean monthly air temperatures and total precipitation for the Pemberton region from 1969 to 2018, and for the Malcolm Knapp Research Forest (MKRF), from 1969 to 2018 .

\begin{tabular}{rrrrrrrrrrr}
\hline & & \multicolumn{4}{c}{ Air Temperature $\left({ }^{\circ} \mathrm{C}\right)$} & \multicolumn{3}{c}{ Precipitation $(\mathrm{mm})$} \\
& & \multicolumn{3}{c}{ Means } & \multicolumn{3}{c}{ 2018 } & & Mean & 2018 \\
& & Min. & Mean & Max. & Min. & Mean & Max. & Total & Total \\
\hline \multirow{3}{*}{ Pemberton } & June & 9.1 & 16.3 & 23.5 & 11.3 & 19.6 & 27.8 & 44.1 & 65.3 \\
& July & 11.0 & 19.2 & 27.4 & 11.7 & 21.6 & 31.4 & 33.4 & 9.3 \\
& August & 10.7 & 18.9 & 27.0 & 11.6 & 20.1 & 28.6 & 34.0 & 15.6 \\
MKRF & June & 9.8 & 14.9 & 19.9 & 10.3 & 15.2 & 20.0 & 96.4 & 73.4 \\
& July & 11.7 & 17.6 & 23.4 & 13.6 & 20.5 & 27.4 & 68.6 & 55.4 \\
& August & 11.9 & 17.7 & 23.5 & 13.0 & 19.3 & 25.5 & 68.4 & 17.2 \\
\hline
\end{tabular}




\subsection{Evaporation Pan Water Temperature}

For eight of the nine streams, the evaporation pans averaged between 0.51 to $1.64{ }^{\circ} \mathrm{C}$ warmer than stream temperature. Marion Creek, however, had consistently lower pan water temperatures, however, with an average difference of $-0.66{ }^{\circ} \mathrm{C}$ (Figure 4.1 ). The trend in the water temperature difference typically followed the stream temperature trend, but there was further variability in the water temperature difference between the in-stream locations of the evaporation pans and the time of day. Individual openings in the canopy provided localized increases in direct sunlight to the stream. These pools of sunlight typically travelled along or across a stream over the course of a day, and would increase the water temperature of any evaporation pans they passed over. For example, in Figure 4.2, it can be seen that, early in the day, the temperatures were generally highest in the right-hand pans, intermediate in the centre pans, and lowest in the left-hand pans. By the end of the day, this pattern had reversed as the solar position and the pattern of shading varied. The full daily time series of stream and evaporation pan temperatures can be found in Appendix B.

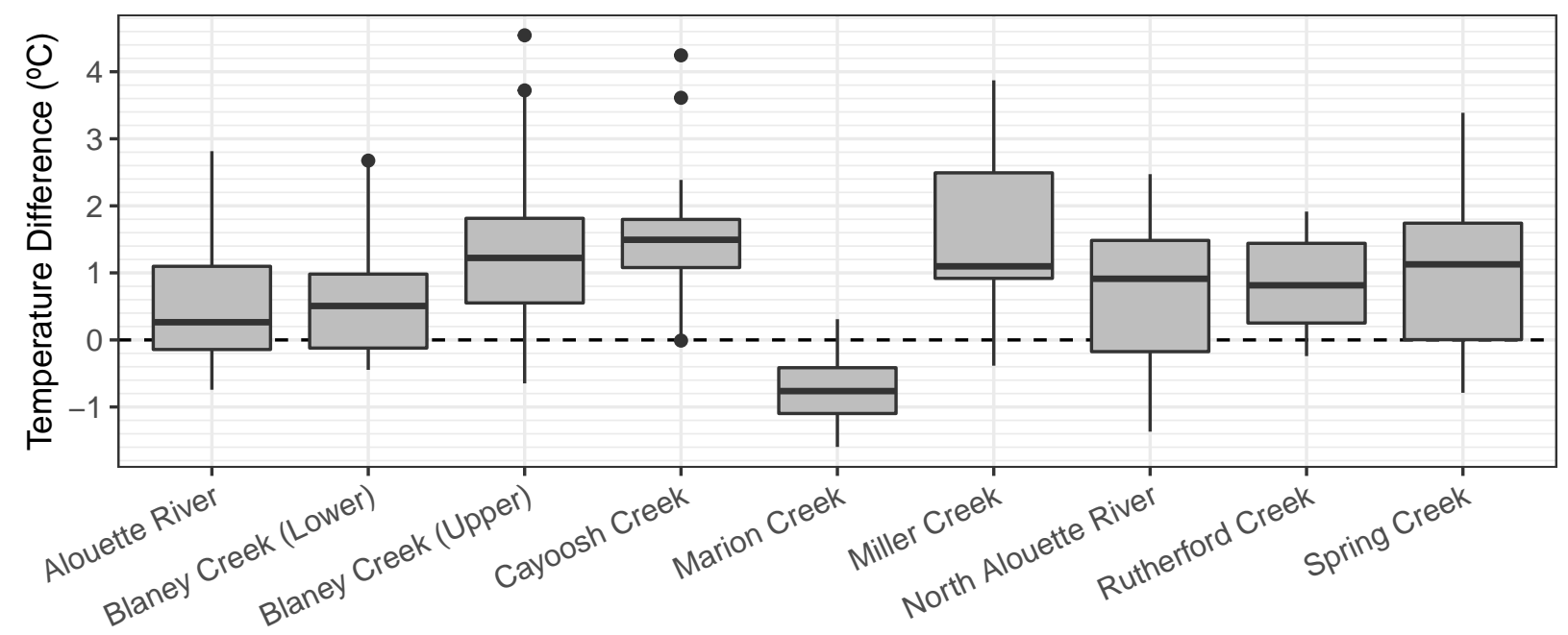

Figure 4.1: The stream-averaged distributions of water temperature difference between the evaporation pans and the stream.

\subsection{Meteorological Conditions and Evaporation Rates}

The distribution of measured and derived meteorological conditions, and the measured evaporation rates, are presented in Figure 4.4. The meteorological and stream temperature data are at 10-minute intervals, and the evaporation rate measurements are at approximately 


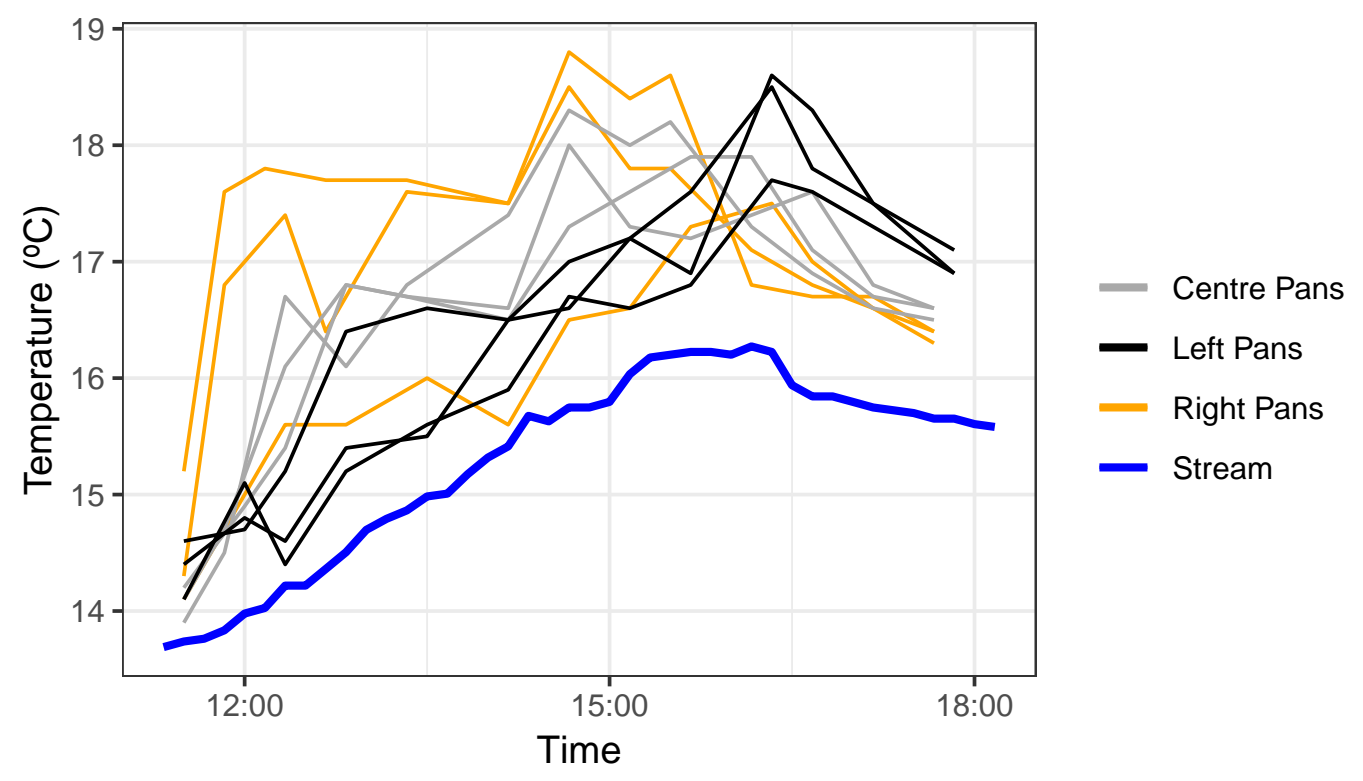

Figure 4.2: Stream and evaporation pan water temperatures at Spring Creek during field work on July 12th, 2018.

1- to 1.5-hour intervals. The full daily time series of the meteorological observations are available in Appendix C, in Figures C.1a to C.1t.

As seen in Figure 4.4 (top panel), air temperatures were typically greater than stream temperature, and increased with height above the stream surface (Figure 4.5, top panel). Some exceptions exist to this trend, however, as Marion Creek had higher stream temperatures than air temperatures at almost all times, and Blaney Creek (Lower) experienced several hours of nearly equal stream and air temperatures on July 5th. The study site on Marion Creek is downstream of a shallow lake that experiences substantial warming; the site at Blaney Creek (Lower) is comparatively further downstream from a lake, and one that is deeper and remains cooler than Marion Lake. Glacier-fed streams (Miller Creek, Rutherford Creek, and Cayoosh Creek) showed an increase in the air temperature difference 1.5 and 0.5 $\mathrm{m}$ above the stream in the afternoons, coinciding with the timing of the expected increase in streamflow contribution from glacial meltwater (Figure 4.3).

Measured wind speeds also typically increased with height above the stream surface, as expected (Figure 4.5, middle panel). A generally negative relationship exists between the average difference in wind speeds, the local canopy openness, and a 'sheltering ratio' computed as the ratio between tree height and stream width. As seen in Table 4.2, both of the Blaney Creek sites and Spring Creek have sheltering ratio values $>4$ and canopy openness values $<$ 0.25 , and they experienced the greatest average wind speed differences, ranging from 0.12 to $0.22 \mathrm{~m} \mathrm{~s}^{-1}$. Conversely, Alouette River and Miller Creek have low sheltering ratios $(<$ 


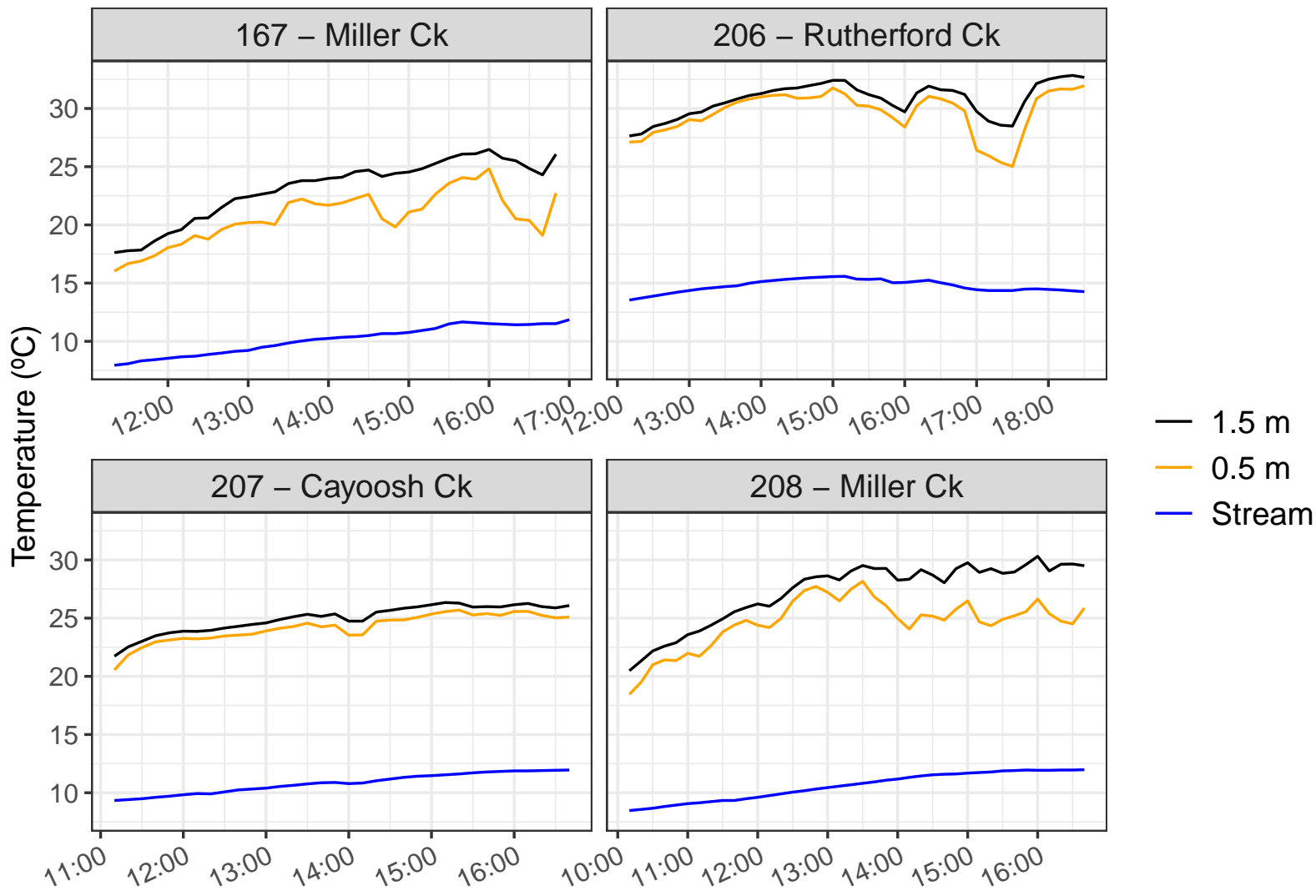

Figure 4.3: The stream and air temperatures at glacier-fed study sites. The panel titles give the day of year and location. 
Table 4.2: Stream physiography, average wind speeds, and differences in wind speed. The sheltering ratio is computed as tree height $\div$ stream width, and $u_{h}$ refers to wind speed in $\mathrm{m}$ $\mathrm{s}^{-1}$ measured $h$ metres above the stream surface. The streams are arranged by decreasing values of wind speed difference.

\begin{tabular}{lllllr}
\hline Stream & $\begin{array}{l}\text { Canopy } \\
\text { Open- } \\
\text { ness }\end{array}$ & $\begin{array}{l}\text { Sheltering } \\
\text { Ratio }\end{array}$ & $u_{1.5}$ & $u_{0.5}$ & $\Delta u$ \\
\hline Blaney Ck. (Lower) & 0.09 & 8.41 & 0.61 & 0.39 & 0.22 \\
Blaney Ck. (Upper) & 0.24 & 4.21 & 0.30 & 0.16 & 0.14 \\
Spring Ck. & 0.16 & 10.55 & 0.38 & 0.26 & 0.12 \\
Rutherford Ck. & 0.70 & 0.29 & 1.63 & 1.53 & 0.10 \\
Marion Ck. & 0.11 & 7.88 & 0.45 & 0.38 & 0.07 \\
Miller Ck. & 0.57 & 0.97 & 0.48 & 0.42 & 0.05 \\
Alouette R. & 0.45 & 1.83 & 1.27 & 1.25 & 0.02 \\
Cayoosh Ck. & 0.50 & 0.86 & 1.19 & 1.17 & 0.02 \\
North Alouette R. & 0.15 & 4.19 & 0.17 & 0.18 & -0.01 \\
\hline
\end{tabular}

1) and greater canopy openness values $(>0.50)$, and they experienced average wind speed differences of approximately $0.02 \mathrm{~m} \mathrm{~s}^{-1}$.

The vapour pressure at $0.5 \mathrm{~m}$ was greater than the vapour pressure at $1.5 \mathrm{~m}$ for $95 \%$ of the observations (Figure 4.5, bottom panel). The greatest vapour pressure differences were associated with the highest stream temperatures, as observed at Marion Creek and Alouette River (Figure 4.4). The vapour pressure difference favoured evaporation for most observations.

The two stability indices, the virtual temperature difference $(\Delta \theta)$ and the buoyant force $(F)$, were nearly identical in form across all days and conditions. Both stability indices had similar relative differences between the values at 1.5 and $0.5 \mathrm{~m}$, with 13 and $12 \%$ differences, respectively (Figure 4.5). The value of $F$ indicated unstable conditions more frequently than was indicated by $\Delta \theta$. Conditions were generally stable at all streams except Marion Creek, with unstable conditions indicated for only 12 to $14 \%$ of the time at heights of 1.5 and $0.5 \mathrm{~m}$, respectively, when considering $F$, and 10 to $11 \%$ of the time when considering $\Delta \theta$. Marion Creek was dominated by unstable conditions, which occurred $>97 \%$ of the time, at both heights, when considering $F$, and $86 \%$ to $89 \%$ of the time at heights of 1.5 and $0.5 \mathrm{~m}$, respectively, when considering $\Delta \theta$.

Evaporation rates ranged from -0.01 to $0.20 \mathrm{~mm} \mathrm{~h}^{-1}$ with a mean evaporation rate of $0.06 \mathrm{~mm} \mathrm{~h}^{-1}$ (Figure 4.4). An error analysis indicated that the mean uncertainty in the evaporation rate was $0.004 \mathrm{~mm} \mathrm{~h}^{-1}$, with maximum relative errors of $134 \%$ for the lowest evaporation rates and minimum relative errors of $3 \%$ for high evaporation rates. The 
sampling variability was greater than the measurement uncertainty. For three observations of low evaporation rates, the $95 \%$ confidence intervals of the sampling variability were greater than the magnitude of the observations (Figure 4.6). The median relative magnitude of the sampling variability, however, was $13 \%$ of the magnitude of the respective evaporation rates. Details of the evaporation rate error analysis and computation of the sampling variability can be found in Appendix D. As expected, evaporation rates generally increased with increasing vapour pressure differences and/or higher wind speed (e.g. comparing Alouette River to Marion Creek, Figure 4.4 panel 4).

\subsection{Statistical Analysis}

\subsubsection{Model Filtering and Performance}

The combinations of random effect distributions used in the model filtering process are provided in Table 4.3, and the models that were found to be significant through the filtering process are summarized in Table 4.4. Of all the 196 model forms fit to the measurements made at $0.5 \mathrm{~m}$ above the stream surface, only $6 \%$ were fully significant; of the same model forms fit to the measurements made at $1.5 \mathrm{~m}, 42 \%$ were fully significant. All of the models with fully significant parameters had physically realistic estimated coefficients.

No models that expanded upon the base model with a stability index alone were significant in any form. Both stability indices, $\Delta \theta$ and $F$, were similarly frequent among the significant model forms when present along with a canopy openness variable. Models that expanded upon the base model with a canopy openness variable alone were only significant when the canopy variable was an interaction term on the wind speed. Models that included both a stability and canopy variable often had multiple forms fully significant (e.g. Models 13, 14, 18, and 19, Table 4.4).

The results of the leave-one-out cross-validation model performance testing of the significant models are summarized in Table 4.5, and the best performing models' estimated coefficients are provided in Table 4.6. The base model performed well under cross-validation for both the 0.5-m and 1.5-m measurements; the 0.5-m model had a root-mean-square error (RMSE) of

$0.0162 \mathrm{~mm} \mathrm{~h}^{-1}$ and a Nash-Sutcliffe efficiency of 0.897 , while the 1.5 -m model had respective values of $0.0187 \mathrm{~mm} \mathrm{~h}^{-1}$ and 0.862 .

Of the models based on 1.5-m measurements that passed the initial filter, $72 \%$ improved upon the performance of the base model under cross-validation compared to $29 \%$ for the filtered 0.5-m models. For the 0.5-m measurements, the best performing expanded model, Model 15, provided a $2 \%$ reduction in the RMSE from the base model. The best performing 

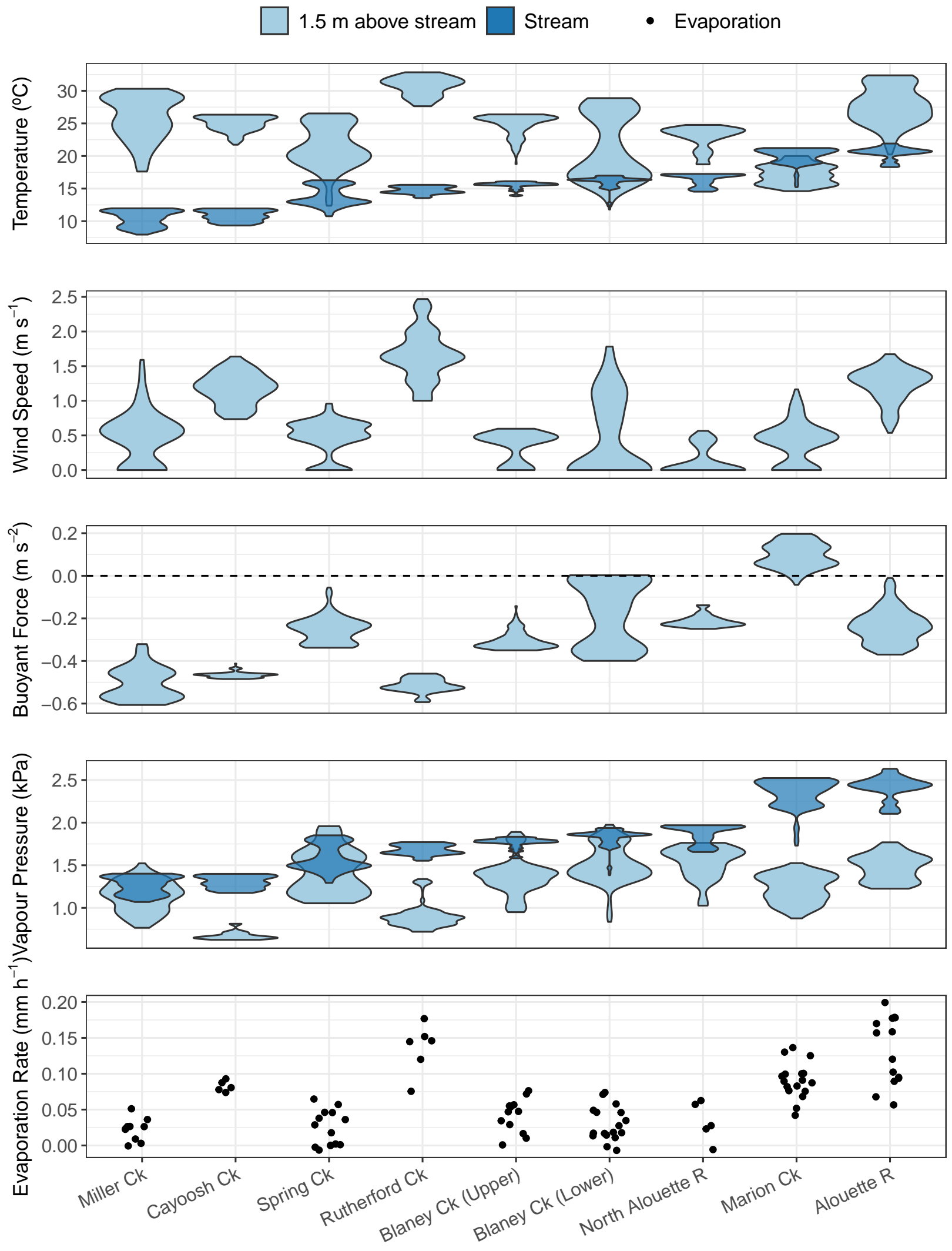

Figure 4.4: The distributions of meteorological conditions at each stream during stream evaporation measurements, arranged by increasing mean stream temperature. 
$\square 0.5$ m above stream $\square 1.5 \mathrm{~m}$ above stream
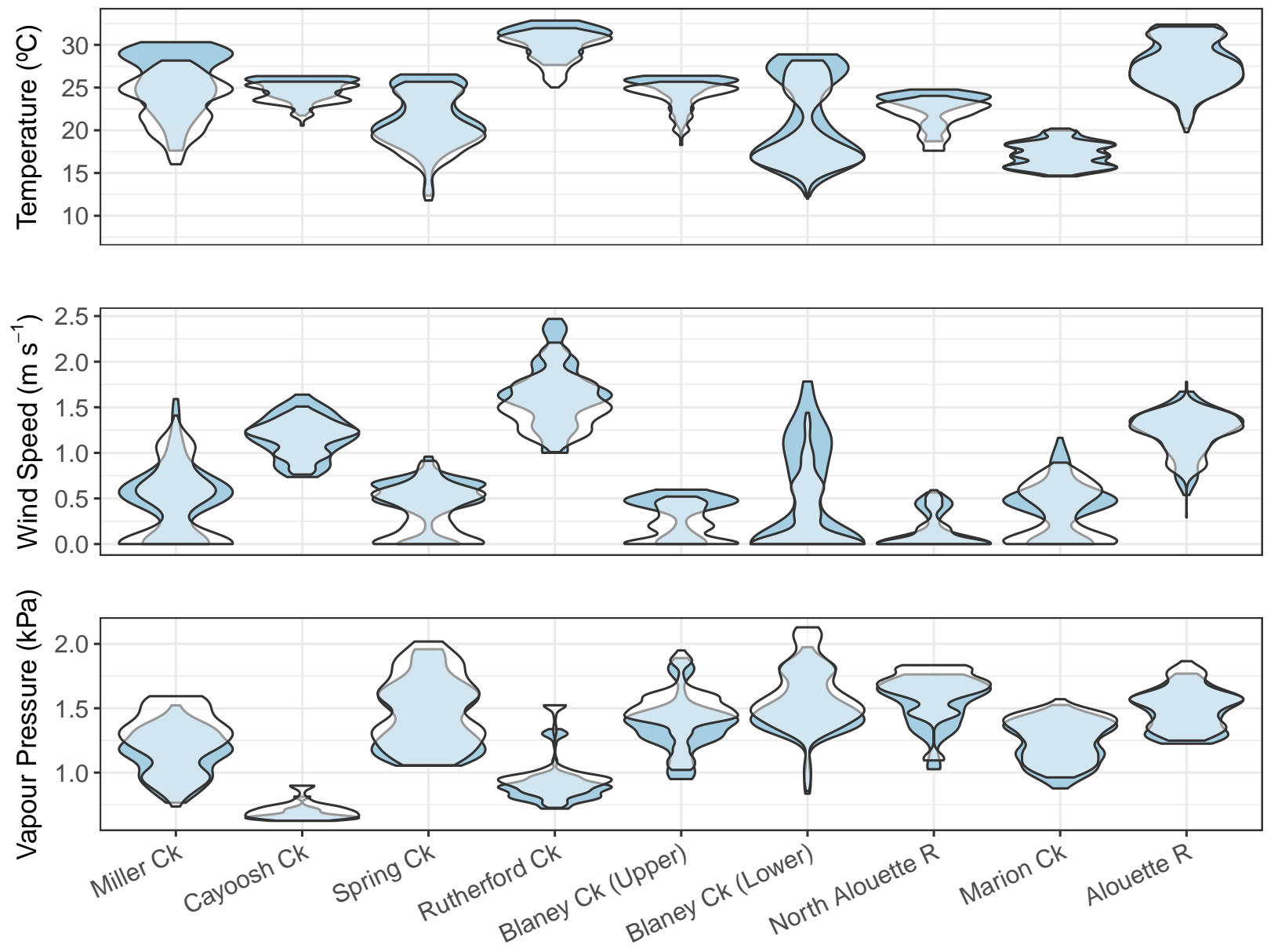

Figure 4.5: The distributions of meteorological conditions measured 0.5 and $1.5 \mathrm{~m}$ above the stream surface, arranged by increasing mean stream temperature. 


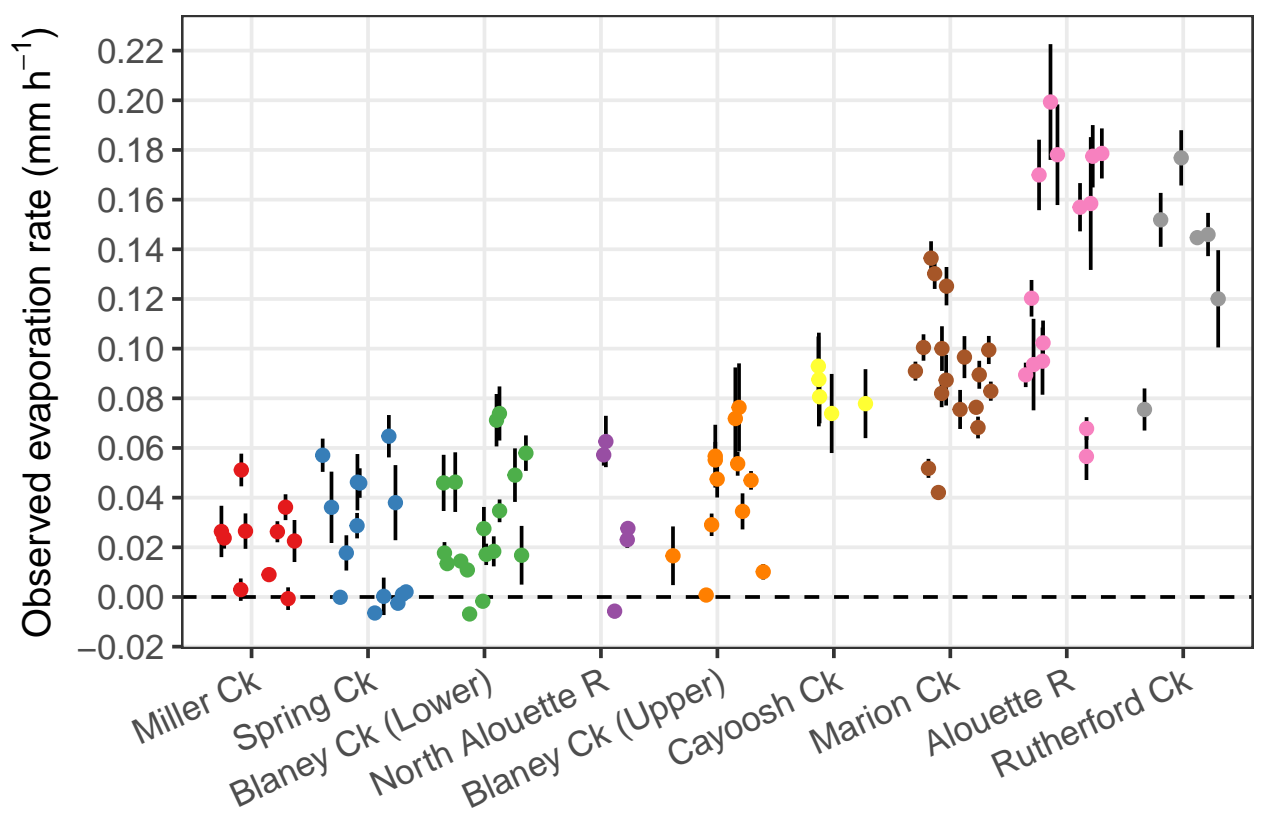

Figure 4.6: The observed evaporation rates at each stream, arranged by increasing mean evaporation rate. The $95 \%$ confidence intervals associated with each observation due to sampling variability are indicated by the bars extending above and below each point.

Table 4.3: All unique model random effect distributions, depending on the number of model parameters. ID is a code to identify the significant random effects for each model form as presented in Table 4.4 .

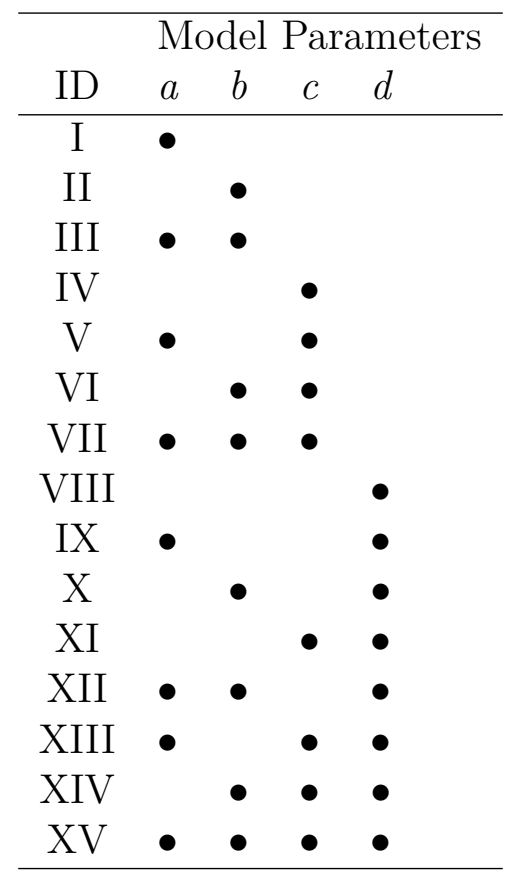


Table 4.4: Model significance after the initial round of model testing. The significant model forms refers to the random effect distributions identified in Table 4.3. The models were fit to measurements made 0.5 and $1.5 \mathrm{~m}$ above the stream surface.

\begin{tabular}{|c|c|c|c|}
\hline \multirow[b]{2}{*}{$\#$} & \multirow[b]{2}{*}{ Model } & \multicolumn{2}{|c|}{ Significant model forms } \\
\hline & & $0.5 \mathrm{~m}$ & $1.5 \mathrm{~m}$ \\
\hline 0 & $E=(a+b \cdot u) \cdot \Delta e$ & I - III & I - III \\
\hline 1 & $E=(a+b \cdot u+c \cdot \phi) \cdot \Delta e$ & & \\
\hline 2 & $E=\left(a+b \cdot u+c \cdot \gamma_{\Delta \theta}\right) \cdot \Delta e$ & & \\
\hline 3 & $E=\left(a+b \cdot u+c \cdot \gamma_{F}\right) \cdot \Delta e$ & & \\
\hline 4 & $E=(a+b \cdot u+c \cdot \phi \cdot u) \cdot \Delta e$ & & III, IV, VII \\
\hline 5 & $E=\left(a+b \cdot u+c \cdot \gamma_{\Delta \theta} \cdot u\right) \cdot \Delta e$ & & \\
\hline 6 & $E=\left(a+b \cdot u+c \cdot \gamma_{F} \cdot u\right) \cdot \Delta e$ & & \\
\hline 7 & $E=\left(a+b \cdot u+c \cdot \phi+d \cdot \gamma_{\Delta \theta}\right) \cdot \Delta e$ & & II - V, IX, XII \\
\hline 8 & $E=\left(a+b \cdot u+c \cdot \phi+d \cdot \gamma_{F}\right) \cdot \Delta e$ & & I - V, VII \\
\hline 9 & $E=\left(a+b \cdot u+c \cdot \phi \cdot u+d \cdot \gamma_{\Delta \theta}\right) \cdot \Delta e$ & & II - IV, VIII, IX \\
\hline 10 & $E=\left(a+b \cdot u+c \cdot \phi \cdot u+d \cdot \gamma_{F}\right) \cdot \Delta e$ & & II - IV, VI, VIII - IX \\
\hline 11 & $E=\left(a+b \cdot u+c \cdot \phi+d \cdot \gamma_{\Delta \theta} \cdot u\right) \cdot \Delta e$ & XI & $\mathrm{X}$ \\
\hline 12 & $E=\left(a+b \cdot u+c \cdot \phi+d \cdot \gamma_{F} \cdot u\right) \cdot \Delta e$ & $\mathrm{XI}$ & III, X \\
\hline 13 & $E=\left(a+b \cdot u+c \cdot \phi \cdot u+d \cdot \gamma_{\Delta \theta} \cdot u\right) \cdot \Delta e$ & $\mathrm{~V}$ & I - XII, XIV - XV \\
\hline 14 & $E=\left(a+b \cdot u+c \cdot \phi \cdot u+d \cdot \gamma_{F} \cdot u\right) \cdot \Delta e$ & $\mathrm{~V}$ & I - X, XII - XIII \\
\hline 15 & $E=(a+b \cdot \phi \cdot u) \cdot \Delta e$ & I - III & I - III \\
\hline 16 & $E=\left(a+b \cdot \phi \cdot u+c \cdot \gamma_{\Delta \theta}\right) \cdot \Delta e$ & & I - III, V - VI \\
\hline 17 & $E=\left(a+b \cdot \phi \cdot u+c \cdot \gamma_{F}\right) \cdot \Delta e$ & & $\mathrm{I}-\mathrm{VI}$ \\
\hline 18 & $E=\left(a+b \cdot \phi \cdot u+c \cdot \gamma_{\Delta \theta} \cdot u\right) \cdot \Delta e$ & & I - III, V - VII \\
\hline 19 & $E=\left(a+b \cdot \phi \cdot u+c \cdot \gamma_{F} \cdot u\right) \cdot \Delta e$ & & $\mathrm{I}-\mathrm{VI}$ \\
\hline
\end{tabular}

Table 4.5: Goodness-of-fit statistics computed from leave-one-out cross-validated model predictions for a selection of models. The random effect distribution (R.E. dist.) used for each model is provided, and the corresponding model parameters are indicated in bold. The root-mean-square error (RMSE, $\mathrm{mm} \mathrm{h}^{-1}$ ), mean bias error $\left(\mathrm{MBE} \mathrm{mm} \mathrm{h}^{-1}\right.$ ), mean absolute error (MAE, $\mathrm{mm} \mathrm{h}^{-1}$ ), and the Nash-Sutcliffe efficiency (NSE) are the model goodness-of-fit statistics provided.

\begin{tabular}{cclccccc}
\hline & $\#$ & Model & R.E. dist. & RMSE & MBE & MAE & NSE \\
\hline \multirow{2}{*}{$1.5 \mathrm{~m}$} & 0 & $E=(\boldsymbol{a}+b \cdot u) \cdot \Delta e$ & I & 0.0187 & $3.5 \mathrm{e}-4$ & $1.5 \mathrm{e}-2$ & 0.862 \\
& 19 & $E=\left(\boldsymbol{a}+b \cdot \phi \cdot u+c \cdot \gamma_{F} \cdot u\right) \cdot \Delta e$ & I & 0.0166 & $2.8 \mathrm{e}-4$ & $1.4 \mathrm{e}-2$ & 0.891 \\
\hline \multirow{2}{*}{$0.5 \mathrm{~m}$} & 0 & $E=(a+\boldsymbol{b} \cdot u) \cdot \Delta e$ & II & 0.0162 & $2.6 \mathrm{e}-4$ & $1.3 \mathrm{e}-2$ & 0.897 \\
& 15 & $E=(\boldsymbol{a}+b \cdot \phi \cdot u) \cdot \Delta e$ & I & 0.0159 & $2.5 \mathrm{e}-4$ & $1.3 \mathrm{e}-2$ & 0.900 \\
\hline
\end{tabular}


Table 4.6: The population-level estimated coefficients and coefficient standard errors for the selected models.

\begin{tabular}{cclll}
\hline & \multicolumn{3}{c}{ Estimated coefficient value [standard error] } \\
& $\#$ & $a\left(\mathrm{~mm} \mathrm{~h}^{-1} \mathrm{kPa}^{-1}\right)$ & $b\left(\mathrm{~mm} \mathrm{~h}^{-1} \mathrm{~s} \mathrm{~m}^{-1} \mathrm{kPa}^{-1}\right)$ & $c\left(\mathrm{~mm} \mathrm{~h}^{-1} \mathrm{~s}^{3} \mathrm{~m}^{-2} \mathrm{kPa}^{-1}\right)$ \\
\hline \multirow{2}{*}{$1.5 \mathrm{~m}$} & 0 & $0.0663[0.0079]$ & $0.0449[0.0069]$ & $0.0766[0.0234]$ \\
\hline \multirow{2}{*}{$0.5 \mathrm{~m}$} & 0 & $0.0837[0.0033]$ & $0.1201[0.0169]$ & \\
& 15 & $0.0944[0.0034]$ & $0.0684[0.0069]$ & $0.0437[0.0072]$ \\
\hline
\end{tabular}

expanded model fit to the 1.5-m measurements, Model 19, provided an $11 \%$ reduction in the RMSE. The cross-validated model predictions for the selected models in Table 4.5 are shown in Figure 4.7. While the expanded 0.5-m model had better goodness-of-fit indicators than the expanded 1.5-m model, it was more prone to site-specific over- or under-estimation of evaporation as shown by the distribution of residual errors in Figure 4.8.

The best performing base and expanded models, under cross-validation, each had a mixedeffects structure with random effects on only one model parameter, as indicated in bold in Table 4.5. For the base model for the 1.5-m measurement height, the best-performing mixed-effects structure estimated site-specific adjustments for the a coefficient, while the best mixed-effects structure for the $0.5-\mathrm{m}$ base model estimated site-specific adjustments for the $b$ coefficient. For the best expanded models for both measurement heights, the best perfoming mixed-effects structures estimated site-specific adjustments for the $a$ coefficient. While the fixed-effects coefficients are used during model cross-validation, the magnitude of the site-specific adjustments for a given model provides information on how much site-specific variability is not accounted for by the model predictors.

There was a notable difference in the variability of the site-specific adjustments between the base and expanded models (Figure 4.9). The base model's site-specific adjustments were between 0.4 to $37 \%$ of the fixed-effect coefficient value for the $1.5-\mathrm{m}$ model, and between 1 and $25 \%$ for the $0.5-\mathrm{m}$ model. This indicates that there was site-specific variability unaccounted for by the base model predictors. However, the expanded model's site-specific adjustments were less than $0.001 \%$ of the fixed-effect coefficient value for both the $1.5-\mathrm{m}$ and $0.5-\mathrm{m}$ models. This indicates that the same magnitude of error reduction achieved in the base models through site-specific adjustments could not be achieved through site-specific adjustments upon expansion of the base models with additional predictors. 


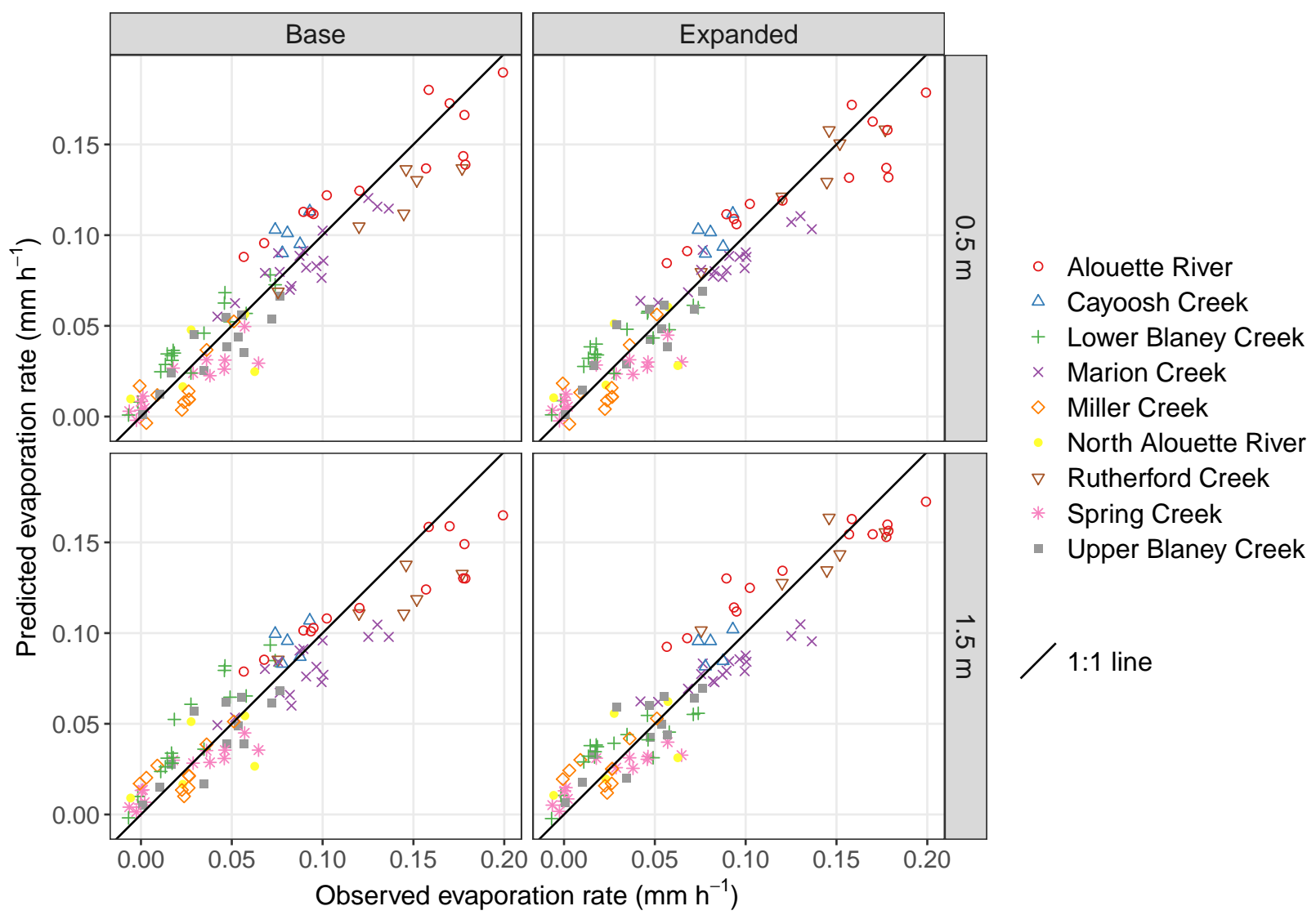

Figure 4.7: Cross-validated model predictions for the base mass transfer model and the two best expanded models, Models 15 and 19, for meteorological measurements made $0.5 \mathrm{~m}$ and $1.5 \mathrm{~m}$ above the stream surface, respectively. 


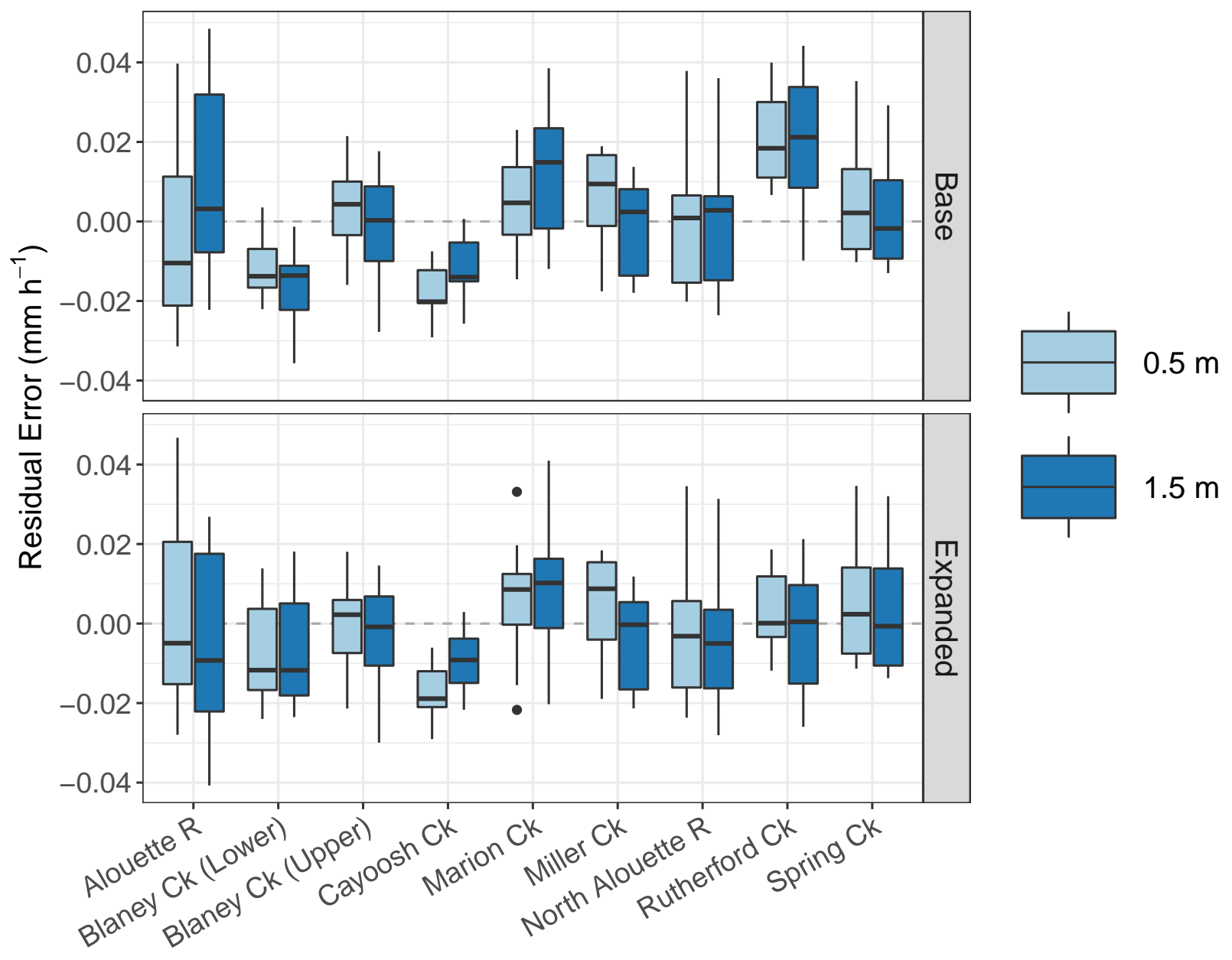

Figure 4.8: The site-specific residual error distribution for the base and expanded 0.5-m and 1.5-m models. The residuals were computed from cross-validated model predictions. 


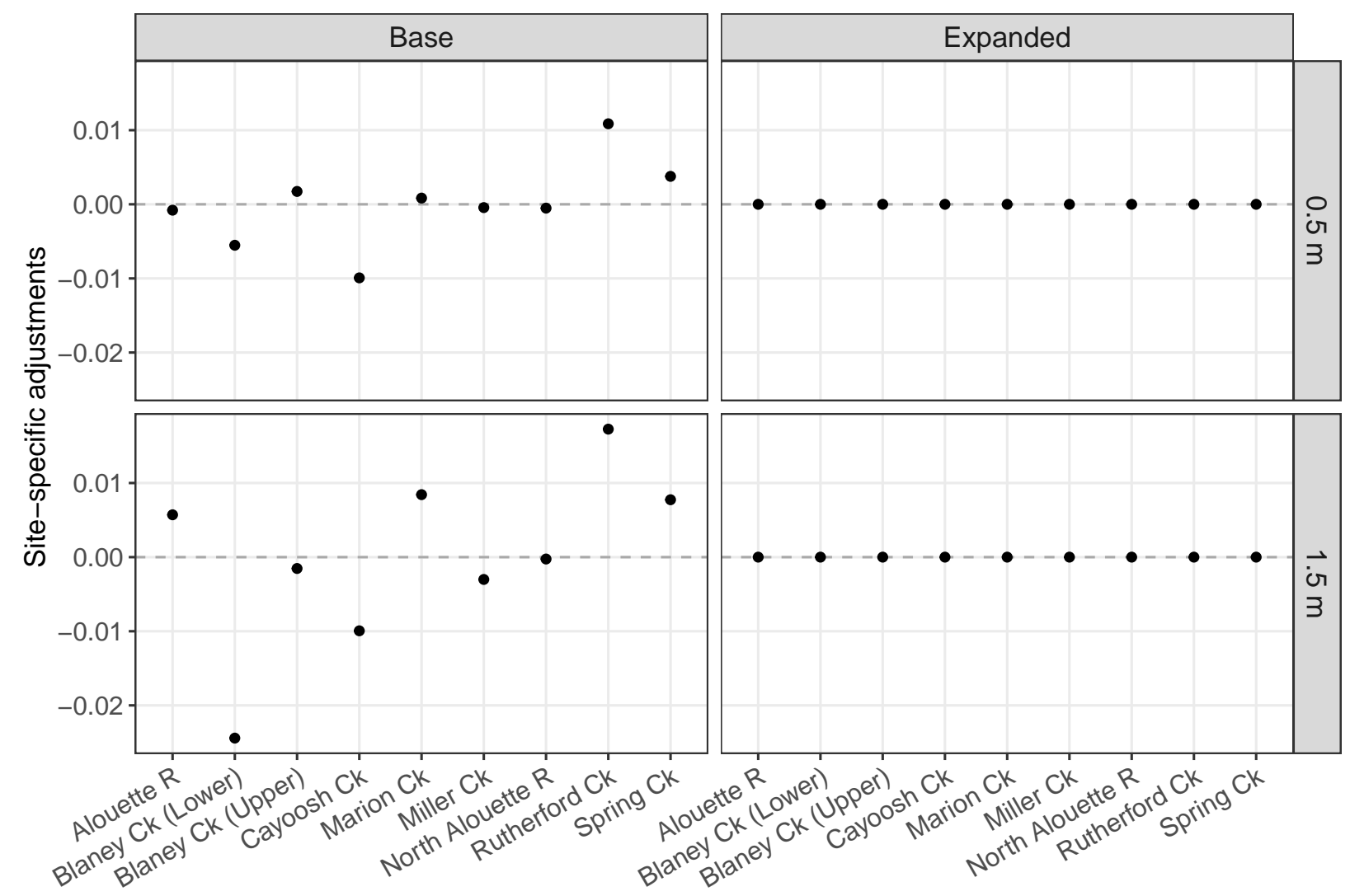

Figure 4.9: The site-specific adjustments for each model. The 0.5-m base model had adjustments to the $b$ coefficient, while the other models had adjustments to the $a$ coefficient. 


\subsubsection{Wind Function Comparison}

The wind functions from five similar evaporation studies are presented in Table 4.7 and compared against this study's base model coefficients. These are studies that either directly measured stream evaporation (Benner, 2000; Guenther et al., 2012; Maheu et al., 2014; Caissie, 2016) or are widely adopted in stream temperature modelling studies (Webb and Zhang, 1997). These literature wind functions were applied to the meteorological data from this study. Input data was matched to a given literature wind function measurement height where available (e.g., 0.5-m measurements were used for Benner's wind function). For wind functions fit to measurements made $2 \mathrm{~m}$ above a stream, the $1.5-\mathrm{m}$ height wind speeds were adjusted using a power law relation (Sutton, 1953). No adjustments were made to the vapour pressures. The literature wind function predictions are shown in Figure 4.10 along with the cross-validated predictions from the 1.5-m base model. 


\section{$\circ$ Literature wind function * This study $\quad$, 1:1 line}

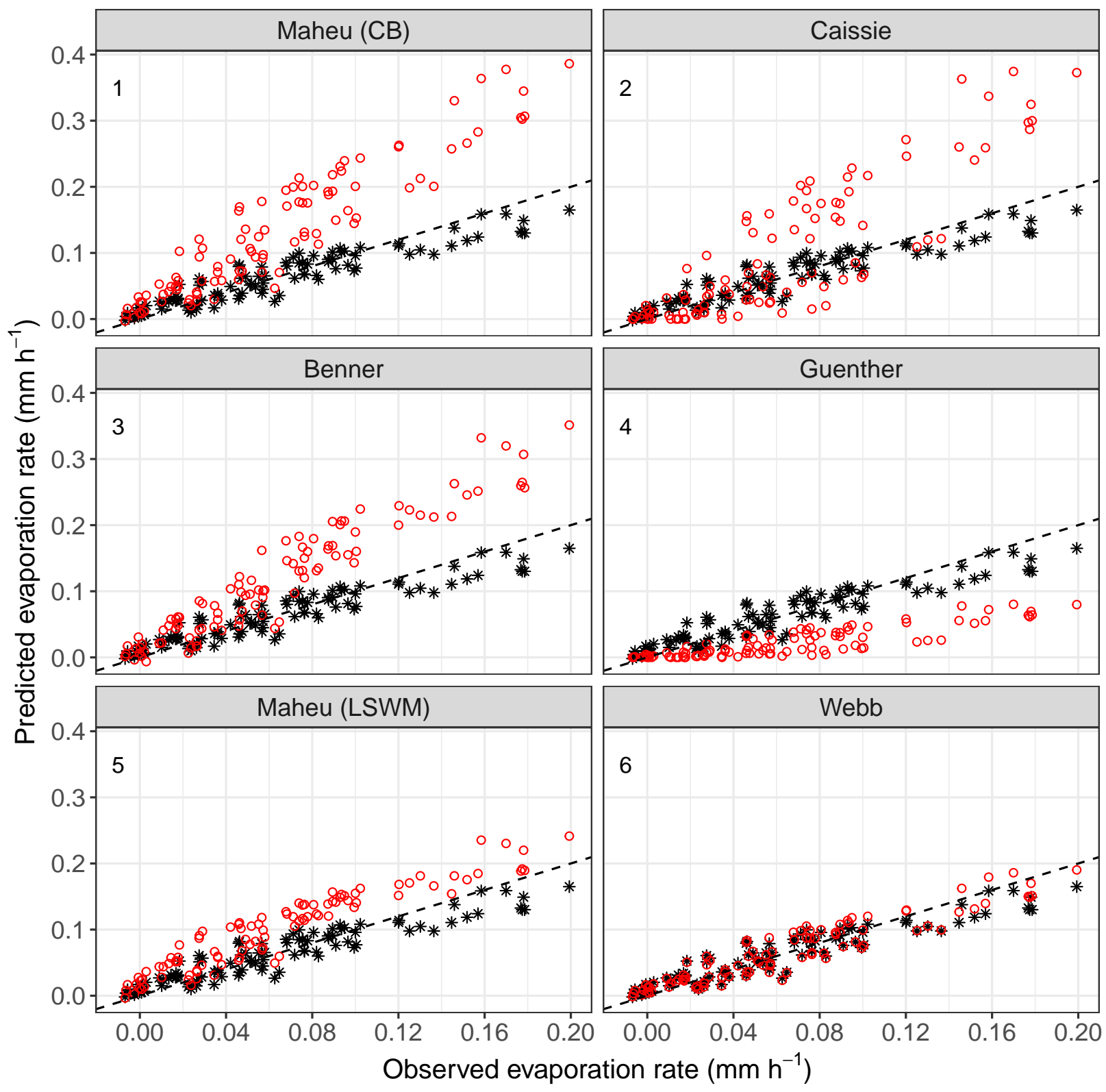

Figure 4.10: The evaporation rates estimated by applying six literature wind functions to this study's dataset. The wind function coefficients and the study references are provided in Table 4.7. The two panels for Maheu correspond to the wind functions for Catamaran Brook (CB) and the Little Southwest Miramichi River (LSWM). The panels are ordered from 1 to 6 by decreasing model root-mean-square error. The predicted evaporation rates for this study are cross-validated predictions from the 1.5 -m model. 
Table 4.7: A comparison of wind function coefficients, $a$ and $b$, derived from stream evaporation measurements, and one commonly cited in stream temperature modelling studies. In the seventh column, $T_{p}$ indicates the evaporation pan water temperature.

\begin{tabular}{|c|c|c|c|c|c|c|}
\hline Source & $\begin{array}{l}\text { Site } \\
\text { Description }\end{array}$ & $\begin{array}{l}a \\
(\mathrm{~mm} \\
\mathrm{h}^{-1} \\
\left.\mathrm{kPa}^{-1}\right)\end{array}$ & $\begin{array}{l}b \\
\left(\mathrm{~mm} \mathrm{~h}^{-1}\right. \\
\mathrm{s} \quad \mathrm{m}^{-1} \\
\left.\mathrm{kPa}^{-1}\right)\end{array}$ & $\begin{array}{l}\text { Measurement } \\
\text { height }(\mathrm{m})\end{array}$ & $\begin{array}{l}\text { Stream } \\
\text { width }(\mathrm{m})\end{array}$ & $\begin{array}{l}T_{p} \\
\text { measured? }\end{array}$ \\
\hline This study & $\begin{array}{l}\text { Forested } \\
\text { streams }\end{array}$ & $\begin{array}{l}0.0663 \\
0.0815\end{array}$ & $\begin{array}{l}0.0449 \\
0.0437\end{array}$ & $\begin{array}{l}1.5 \\
0.5\end{array}$ & 3.1 to 27.6 & yes \\
\hline $\begin{array}{l}\text { Benner } \\
(2000)\end{array}$ & $\begin{array}{l}\text { Streams in mead- } \\
\text { ows and forest }\end{array}$ & 0.144 & 0.085 & 0.5 & 2.7 to 19.5 & yes \\
\hline $\begin{array}{l}\text { Guenther et } \\
\text { al. (2012) }\end{array}$ & Forested stream & - & 0.0424 & 1.5 & 1.5 & yes \\
\hline Maheu et al. & Forested stream & 0.11 & 0.122 & 2 & 8 & no \\
\hline (2014) & Forested stream & 0.123 & 0.035 & 2 & 80 & no \\
\hline $\begin{array}{l}\text { Caissie et al. } \\
\text { (2016) }\end{array}$ & Forested stream & - & 0.19 & 2 & 1.7 & no \\
\hline $\begin{array}{l}\text { Webb and } \\
\text { Zhang } \\
(1997)\end{array}$ & $\begin{array}{l}\text { Streams in pas- } \\
\text { ture and wood- } \\
\text { land }\end{array}$ & 0.055 & 0.059 & 2 & 0.8 to 11.3 & no \\
\hline
\end{tabular}




\section{Chapter 5}

\section{Laboratory Results}

\subsection{Relation Between Solution Molarity and Electrical Conductivity}

The results of the electrical conductivity to molarity calibration are shown in Appendix E, Figure E.1. The regression fit to the model defined by Equation 3.1 had a root-mean-square error of $8.69 \times 10^{-5} \mathrm{~mol} \mathrm{~L}^{-1}$ and an adjusted $\mathrm{R}^{2}$ of 0.99 . The estimated coefficients, $m$ and $b$, were $1.10 \times 10^{-2}$ and $-1.836 \times 10^{-2}$, respectively. The electrical conductivity calibration spanned conductivities from 16.00 to $19.54 \mathrm{mS} \mathrm{cm}^{-1}$, which exceeded the range of measured conductivities during the flume trials and ensured no trial data would need to be extrapolated.

\subsection{Meteorological Conditions and Evaporation Rates}

The meteorological conditions, flume water electrical conductivity, and evaporation rates are presented in Figures 5.1a to 5.1d. The figure titles provide the flume parameter conditions for the given trial, where the slope is $2^{\circ}$ or $6^{\circ}$, and the presence/absence of LEGO is denoted ' $\mathrm{L}$ ' or ' $\mathrm{nL}$ '. The air temperatures throughout all trials were consistently between 20.9 and $21.5^{\circ} \mathrm{C}$. The wind speed ranged from 0.65 to $1.30 \mathrm{~m} \mathrm{~s}^{-1}$ with a mean of $0.93 \mathrm{~m} \mathrm{~s}^{-1}$. The variability in the measured wind speed can likely be attributed to the low precision of wind speed control available on the fan used. As the air temperatures did not experience significant fluctuation, the relative humidity tracked the trends in the vapour pressure of the air, with a mean value of $1.27 \mathrm{kPa}$.

The flume water experienced sustained heating through all trials due to the heat dissipated by the pump. Water temperatures were approximately $17{ }^{\circ} \mathrm{C}$ when drawn from the tap, but after the initial 10 minutes of circulation through the flume, water temperatures warmed 
to $21.3{ }^{\circ} \mathrm{C}$, on average. The maximum water temperatures at the end of the trials ranged from 26.5 to $27.1{ }^{\circ} \mathrm{C}$, with a mean of $26.8^{\circ} \mathrm{C}$. The vapour pressure at the surface of the water increased accordingly, and ranged from a minimum of $2.82 \mathrm{kPa}$ to a maximum of 3.56 $\mathrm{kPa}$, with a mean of $3.27 \mathrm{kPa}$. As a result of the high vapour pressures at the water surface relative to the air above it, the vapour pressure difference between the water and the air had a minimum value of $1.53 \mathrm{kPa}$, maximum of $2.35 \mathrm{kPa}$, with a mean of $2.00 \mathrm{kPa}$. The air above the flume was always unstable $(\Delta \theta>0)$. The measured electrical conductivity (EC) increased as time elapsed, although the increases were not at consistent rates. For the trials where the flume slope was $6^{\circ}$ (Figures 5.1c and 5.1d), the EC measurements showed more scatter than for the trials where the slope was $2^{\circ}$ (Figures 5.1a and 5.1b). The evaporation rates were generally positive and increasing, and ranged from 0.59 to $2.96 \mathrm{~mm} \mathrm{~h}^{-1}$, with a mean of $1.68 \mathrm{~mm} \mathrm{~h}^{-1}$.

\subsection{Statistical Analysis}

The predicted evaporation rates from Equation 3.5 are presented in Figure 5.2 along with the $95 \%$ confidence intervals. The model fit had a root-mean-square error of $0.572 \mathrm{~mm} \mathrm{~h}^{-1}$, and an adjusted $R^{2}=0.050$. The results of the analysis of variance test are presented in Table 5.1. The test gives $\mathrm{p}=0.8195>0.05$ for the test between Equation 3.6 and Equation 3.5, so the addition of the flume parameter variables does not significantly improve the model predictions. This can be interpreted as an indication that there is likely no statistically significant influence of the flume parameters on the evaporation rate.

Table 5.1: Analysis of variance for the difference between the reduced and full evaporation models (Equations 3.6 and 3.5). RSS is the residual sum of squares and DF is the degrees of freedom for the model.

\begin{tabular}{ccccc}
\hline Model & RSS & DF & F value & p value \\
\hline Reduced & 7.5080 & 18 & & \\
Full & 5.8894 & 27 & 0.5497 & 0.8195 \\
\hline
\end{tabular}



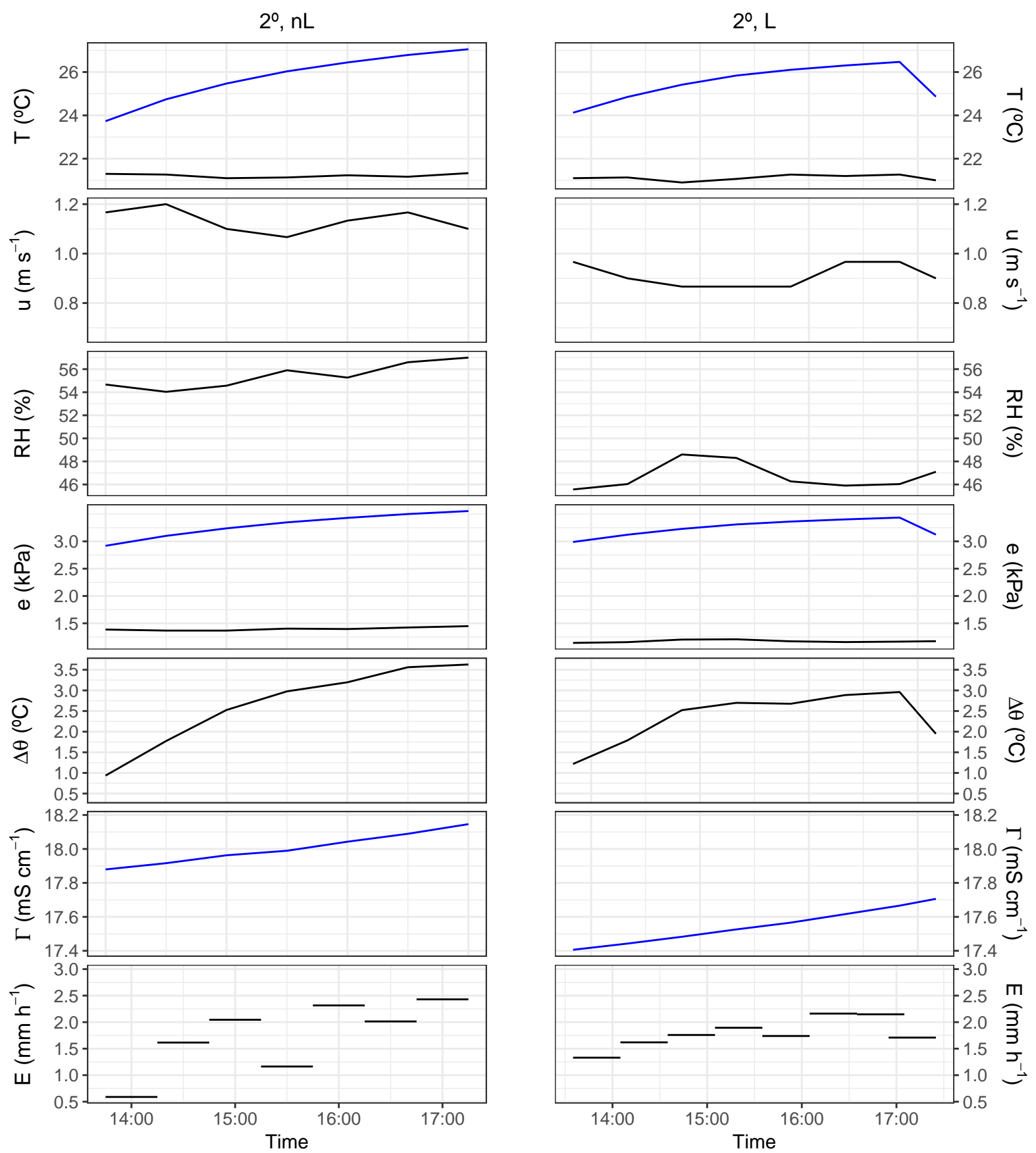

- Air - Water

- Air - Water

(a)

(b)

Figure 5.1: The meteorological conditions, flume water electrical conductivity, and calculated evaporation rates for each of the flume trials. Each subfigure title provides the state of the flume parameters of slope and LEGO. 

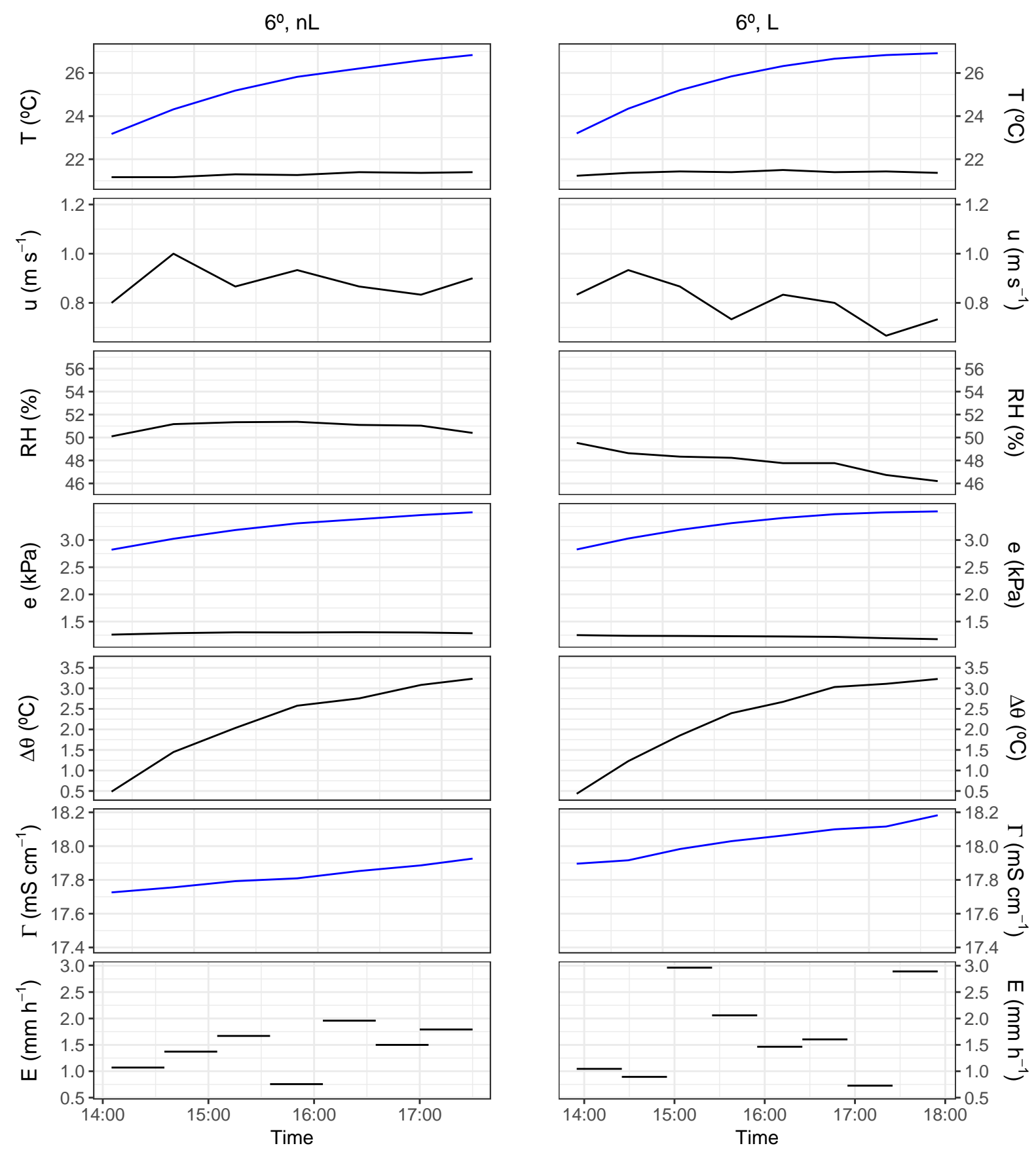

- Air - Water
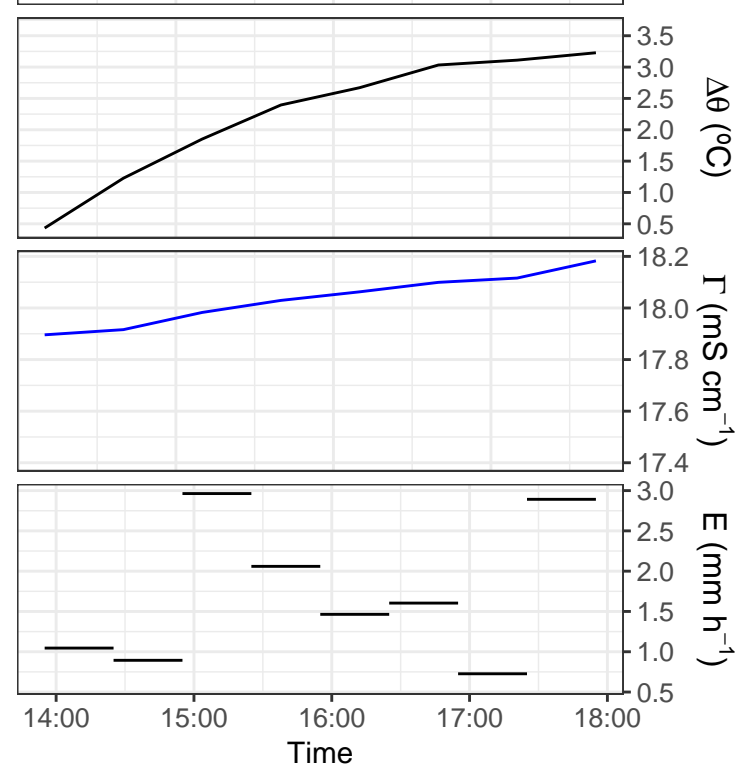

(c)

(d)

Figure 5.1: The meteorological conditions, flume water electrical conductivity, and calculated evaporation rates for each of the flume trials. Each subfigure title provides the state of the flume parameters of slope and LEGO (cont.). 


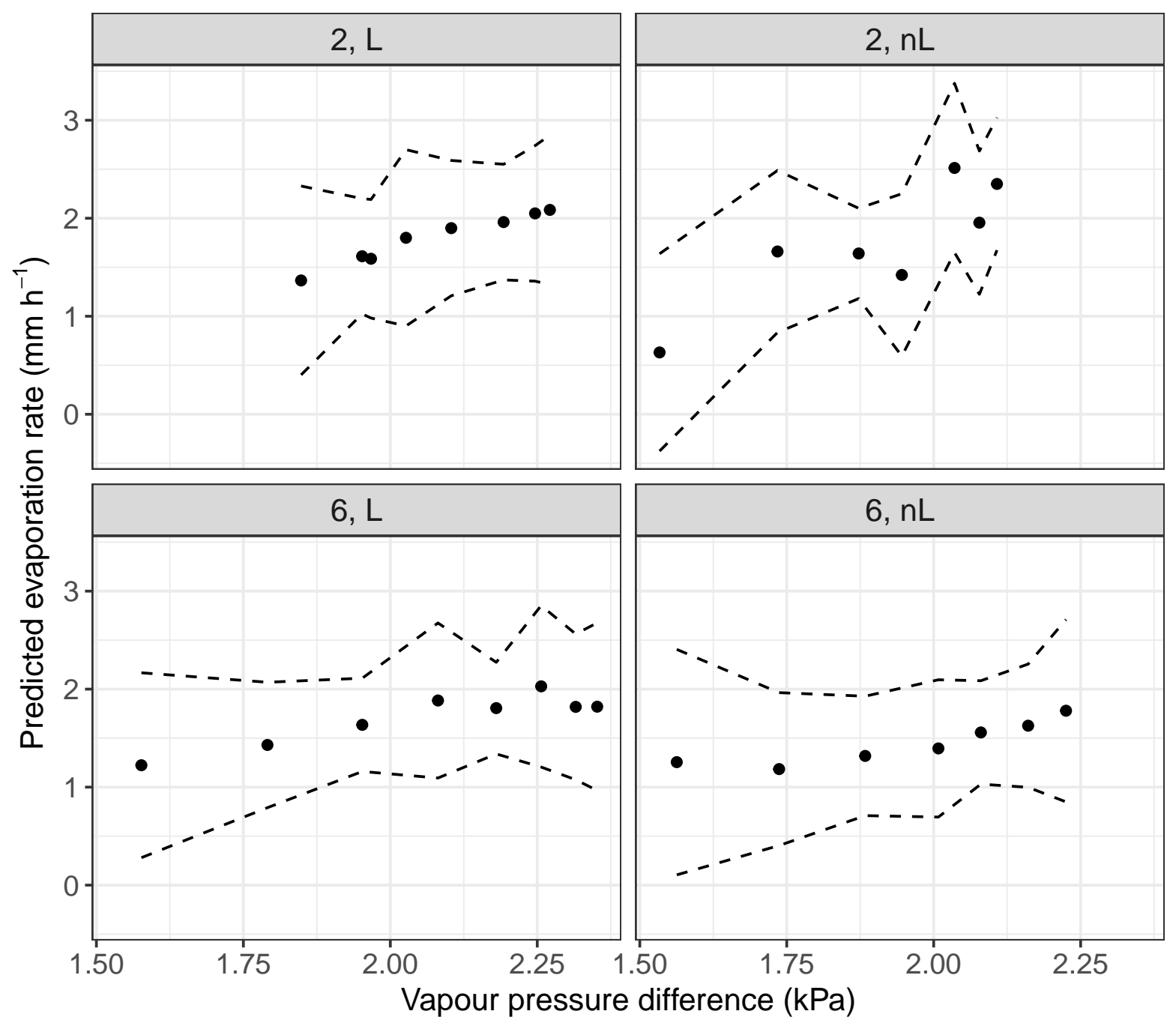

Figure 5.2: The model-predicted evaporation rates with $95 \%$ confidence intervals, for each trial. 


\section{Chapter 6}

\section{Discussion}

\subsection{Field Results}

\subsubsection{Evaporation as a Component of a Stream Heat Budget}

For these sheltered, forested streams, the mean and maximum evaporation rates were 0.06 and $0.20 \mathrm{~mm} \mathrm{~h}^{-1}$, which correspond to heat fluxes of $41 \mathrm{~W} \mathrm{~m}^{-2}$ and $136 \mathrm{~W} \mathrm{~m}^{-2}$. For comparison, the latent heat fluxes measured or estimated by four evaporation or stream temperature studies are presented in Table 6.1. Benner (2000) measured mean and maximum daily evaporation rates of approximately 0.44 and $1.32 \mathrm{~mm} \mathrm{~h}^{-1}$ from their aridland channel reaches, which correspond to heat fluxes of $299 \mathrm{~W} \mathrm{~m}^{-2}$ and $898 \mathrm{~W} \mathrm{~m}^{-2}$, respectively. Benner also modelled the energy budget for their study site using meteorological measurements made on August $9^{\text {th }}$, 1996; they predicted a mean daily evaporative heat loss of $239 \mathrm{~W} \mathrm{~m}^{-2}$, which corresponded to $37 \%$ of the mean total heat loss. Additionally, Maheu et al. (2014) and Caissie (2016) reported evaporative heat fluxes ranging from 10 to $42 \%$ of their forested streams. Net radiation to a small, subcanopy stream comparable to those in this study was observed to be $128 \mathrm{~W} \mathrm{~m}^{-2}$ during midday in the summer (Brown, 1969). Assuming this value, the mean evaporation rates measured in this study would comprise $33 \%$ of the net radiation. These results indicate that evaporation can be a moderate to significant component of the heat budget for temperate, forested streams.

\subsubsection{Assessment of Evaporation Pan Methodology}

Given the design of the pans and their mode of deployment in this study, each individual pan was able to provide an estimate of evaporation with a mean uncertainty of $0.004 \mathrm{~mm} \mathrm{~h}^{-1}$, relative to mean and maximum measured rates of $0.06 \mathrm{~mm} \mathrm{~h}^{-1}$ and $0.20 \mathrm{~mm} \mathrm{~h}^{-1}$, respectively. 
Table 6.1: Reported latent heat fluxes from a range of streams. In the table, $T_{w}$ is the stream temperature, $\phi$ is the canopy closure, $\bar{u}$ is the mean wind speed, and $\bar{Q}_{e}$ is the mean latent heat flux.

\begin{tabular}{lllllll}
\hline & Stream & & & & & \% of total \\
Study & width $(\mathrm{m})$ & $T_{w}\left({ }^{\circ} \mathrm{C}\right)$ & $\phi(\%)$ & $\bar{u}\left(\mathrm{~m} \mathrm{~s}^{-1}\right)$ & $\bar{Q}_{e}\left(\mathrm{~W} \mathrm{~m}^{-2}\right)$ & heat loss \\
\hline Brown (1969) & $<1^{\mathrm{a}}$ & 11.5 & 80 & - & $7^{\mathrm{a}, \mathrm{b}}$ & 6 \\
Caissie et al., (2016) & 1.7 & 15.1 & 85 to 90 & 0.11 & 1.4 & 10 \\
Benner (2000) & $15^{\mathrm{a}}$ & 19.2 & - & 1.4 & 239 & 37 \\
Maheu et al., (2014) & 80 & 19.5 & 20 & $0.8^{\mathrm{a}}$ & 86 & 42 \\
\hline
\end{tabular}

${ }^{a}$ Estimated

b Midday peak

Therefore, the pans provide a viable approach to quantifying evaporation, and could be used in future studies to measure evaporation in a broader range of conditions (e.g., higher water temperatures and wind speeds) to expand the range of applicability of fitted wind functions. However, there are four specific points that require further consideration: (1) the need to account for the non-constant surface area, (2) differences in water temperature between the pans and the stream, (3) sampling variability among pans, and (4) the inability to deploy the pans at sites with high water velocities or rough flow.

The tapered sides of the pans resulted in a non-uniform water surface area over the range of water masses that were measured, which resulted in up to $4 \%$ difference in the surface area. If the pan opening's dimensions were assumed to be the surface area of the pan water, it would have been a $13 \%$ overestimate of the average measured surface area. Using this assumption, the mean and maximum evaporation rates would have been computed as 0.05 and $0.17 \mathrm{~mm} \mathrm{~h}^{-1}$, rather than the 0.06 and $0.20 \mathrm{~mm} \mathrm{~h}^{-1}$ reported. The method for determining water surface area developed through this research is particularly useful because it requires no additional measurements to be made when conducting field work.

The water temperature in the evaporation pans differed substantially from that of the stream water, ranging from $-1.43{ }^{\circ} \mathrm{C}$ lower to $4.47{ }^{\circ} \mathrm{C}$ higher than stream temperature. It was suggested by Maheu (personal communication, July 2019) that the pans be filled with fresh stream water after each mass measurement to avoid this issue. However, the time series of pan and stream water temperatures show that frequent pan water temperature fluctuations occurred within measurement intervals, and warming occurred within 10 to 20 minutes of pan deployment on numerous occasions (Figure B.1). If this temperature difference were not accounted for, the vapour pressure difference used in the wind function would be incorrect. For most cases, the vapour pressure difference would be underestimated, leading to an overestimate of the fitted wind function coefficients. Given the observed rates 
of pan warming, it is recommended that future users of this methodology measure the surface temperature of the water in the evaporation pans with high temporal resolution (e.g., every 10 minutes).

The magnitude of the sampling variability was influenced by the non-uniformity of conditions experienced by the nine pans in a given measurement interval. These different conditions could be caused, for example, by differences in pan heating due to sunlight infiltrating canopy gaps, or different pan exposures to wind due to in-stream boulders, and resulted in variable evaporation rates among the pans. Streams with low evaporation rates but diverse pan conditions, like Spring Creek, had high relative magnitudes of sampling variability (177\% of the mean evaporation at Spring Creek). In contrast, streams with high evaporation rates and uniform pan conditions, like Marion Creek, had lower relative magnitudes of sampling variability ( $7 \%$ of the mean evaporation at Marion Creek). Overall, the mean sampling variability generally increased with mean evaporation rate at a stream. For example, Miller Creek had the lowest mean evaporation rate of $0.02 \mathrm{~mm} \mathrm{~h}^{-1}$ and an associated mean sampling variability of $0.006 \mathrm{~mm} \mathrm{~h}^{-1}$. The same values for Rutherford Creek, with the greatest mean evaporation rate, were $0.14 \mathrm{~mm} \mathrm{~h}^{-1}$ and $0.010 \mathrm{~mm} \mathrm{~h}^{-1}$, respectively. This indicates that the sampling variability, at the $95 \%$ confidence interval, can be high relative to low evaporation rate measurements. Considering all streams, the results indicate that a sampling variability of less than $15 \%$ of the measurements can be achieved by deploying nine evaporation pans, but sampling variability will unduly increase if the pans are exposed to variable conditions not representative of the variability in stream evaporation.

The evaporation pans were also sensitive to high flow velocities and non-placid flow conditions. Of the 900 measurements of evaporation, nine were omitted due to the pans becoming submerged by fast flow. An additional 27 observations were omitted because water was seen to splash in or out of the pans as they were jostled by fast flow. Benner (2000) noted that evaporation was enhanced by flowing water under low wind speeds and/or low vapour pressure differences, which may be common conditions for small streams under a dense canopy (e.g., Guenther et al., 2012). As the requirement for placid flow limits the deployment of the evaporation pans to pools or slow flow reaches, the measured evaporation rates may not be representative of an entire reach if it contains other stream morphologies like riffles or steps, and is subject to low wind speeds and/or vapour pressure differences.

Steep, cascading mountain streams are also of interest for stream temperature modelling studies, but their morphologies prohibit the use of evaporation pans to derive suitable wind function coefficients. In these instances, an energy-balance approach to model stream evaporation would be more suitable, as demonstrated by recent proglacial stream temperature modelling work by Dufficy (2019). Dufficy reported free and forced convection coefficients 
from a modified wind function that are greater than those derived in this study, or in other studies previously discussed. The reported hourly estimates for $a$ ranged from 0.642 to 0.879 $\mathrm{mm} \mathrm{h}^{-1} \mathrm{kPa}^{-1}$, and $b$ ranged from 0.164 to $0.284 \mathrm{~mm} \mathrm{~h}^{-1} \mathrm{~s} \mathrm{~m}^{-1} \mathrm{kPa}^{-1}$. Dufficy's results indicate that the physical processes driving evaporation in a proglacial stream operate at a different magnitude than those present in temperate, forested mountain streams, and that wind functions derived from evaporation pans are not applicable in these systems.

\subsubsection{Effect of Measurement Height on Performance of the Base Model}

Meteorological measurements made at $0.5 \mathrm{~m}$ above the stream surface produced better predictions than measurements made at $1.5 \mathrm{~m}$. Previous studies typically made meteorological observations at 1.5 or $2 \mathrm{~m}$ height above the surface, with the exception of Benner (2000), who made them at $0.5 \mathrm{~m}$. Krajewski et al. (1982) suggested measuring wind speed directly above the stream surface when fitting a wind function, and Dingman (2015) suggested that the wind function coefficients will vary with measurement height. In this study, it was the $a$ coefficient that was the main difference between the wind functions fit to data from different measurement heights ( 0.0815 vs. $0.0663 \mathrm{~mm} \mathrm{~h}^{-1} \mathrm{kPa}^{-1}$ for the ' $0.5 \mathrm{~m}$ ' and ' $1.5 \mathrm{~m}$ ' model, respectively). The difference in the $a$ parameter value indicates a greater influence of the vapour pressure difference on stream evaporation with decreasing measurement height, particularly when considering sheltered streams with poorly developed wind profiles.

One consideration about the choice of measurement height relates to the fact that stream stage varies with discharge, which can be particularly important for proglacial streams, which experience significant diel fluctuations in discharge. For example, a wind function derived from measurements at a height of $0.5 \mathrm{~m}$ would not be accurate if the water surface rose and the instruments were only $0.3 \mathrm{~m}$ above the water surface. Because the gradients of wind speed and vapour pressure should be greatest close to the water surface and decrease with increasing height, this source of error would be greatest for wind functions derived from measurements at a low height and least for wind functions derived from measurements at a greater height above the water surface. Additionally, wind speed measurements made closer to the stream surface are subject to measurement uncertainty. Therefore, it is recommended that future studies measure meteorological conditions at approximately $1.5 \mathrm{~m}$ above the stream, where the application of coefficients from the ' 1.5 m' model would likely be less sensitive to stage-related or other changes in the measurement height. 


\subsubsection{Effects of Additional Predictor Variables}

The addition of a canopy variable alone resulted in six significant model forms when fit to measurements made $1.5 \mathrm{~m}$ above the stream (Table 4.4). When tested under cross-validation, none of these models provided improvements over the base model. The addition of a stability variable alone never produced a significant model. However, the addition of the variables together provided modest model improvement, with an $11 \%$ reduction in root-mean-square error, and an increase in the Nash-Sutcliffe efficiency from 0.862 to 0.891.

The expansion of the base model with a stability variable alone was never significant when fitting the model to measurements made $0.5 \mathrm{~m}$ above the stream. The addition of a canopy openness variable alone produced three significant model forms, while the addition of both stability and canopy openness variables produced four significant model forms (Table 4.4). However, it was the addition of a canopy openness variable alone that provided some, albeit marginal, improvement over the base model (2\% reduction in root-mean-square error, increased Nash-Sutcliffe efficiency from 0.897 to 0.900).

The results of the model fitting with stability predictors suggest that stability plays a minor role compared to the forced convection influence of wind on vapour transfer for small, sheltered streams. This is supported in particular by the daytime and night-time wind functions reported by Maheu et al. (2014). Daytime conditions were predominantly stable while unstable conditions dominated at night. Despite the unstable conditions, the night-time wind function's free convection coefficient, $a$, did not increase, but rather the forced convection coefficient increased from 0.035 to $0.0742 \mathrm{~mm} \mathrm{~h}^{-1} \mathrm{~s} \mathrm{~m}^{-1} \mathrm{kPa}^{-1}$, compared to the daytime wind function. These results are also supported by Guenther et al. (2012), who reported a wind function intercept equal to zero, indicating the dominance of forced convection for their small, forested stream. However, the limited range of stability conditions observed in this study may have been insufficient to comprehensively evaluate its influence, particularly when considering warmer, sheltered and unsheltered streams.

The additional benefit of adding stability and canopy openness predictors for both measurement heights was that they accounted for the site-to-site variability that could not be accounted for by the base model (Figure 4.9). While the stability indices can be computed from the same meteorological data required to compute the vapour pressures, canopy openness is not typically available. Canopy openness can be estimated using satellite imagery (Carreiras et al., 2006), and using light detection and ranging (LiDAR) (Korhonen et al., 2011). LiDAR estimates of canopy openness are more accurate than estimates from satellite imagery (Smith et al., 2009), but LiDAR data are currently expensive to obtain and lack the temporal resolution of satellite imagery. Given these concerns and those discussed in section 6.1 .3 , it is recommended to use the expanded ' $1.5 \mathrm{~m}$ ' model if canopy openness measurements 
are available, or reliable estimates can be obtained, given its superior performance over the base model. Furthermore, when additional research is done to cover a broader range of stream temperatures, wind speeds, and stability conditions, it would be beneficial to further explore the influence of stability as a predictor, to improve model performance under diverse conditions.

\subsubsection{Comparison of Wind Function Coefficients}

Most studies measuring stream evaporation have been focused on one or at most two streams (Guenther et al., 2012; Maheu et al., 2014; Caissie, 2016), or worked in hydroclimates different to that of southwest British Columbia (Benner, 2000). These studies produced site-specific estimates of the wind function coefficients (Table 4.7), which represented evaporation under the influence of the local physiography, climate, and stream characteristics. The aridland stream reaches studied by Benner (2000) produced a wind function, fit to meteorological measurements $0.5 \mathrm{~m}$ above the stream, with both coefficients nearly double those found by this study. However, Guenther et al. (2012) and Caissie (2016) derived wind functions with the free convection term, $a$, equal to zero for the small, sheltered streams they studied. It is worth noting that evaporation pan warming was not accounted for by Maheu et al. (2014) and Caissie (2016). By computing the saturation vapour pressure using the stream temperature and assuming the same value for the pans, the wind function coefficients would be artificially elevated. There is some evidence of this when comparing the wind functions of Guenther et al. and Caissie; their respective study streams are similar, but the forced convection coefficient reported by Caissie was substantially greater than that reported by Guenther et al. (0.19 vs $0.0424 \mathrm{~mm} \mathrm{~h}^{-1} \mathrm{~s} \mathrm{~m}^{-1} \mathrm{kPa}^{-1}$, respectively).

Webb and Zhang (1997) also developed a generalized wind function. Although it is not specified how they derived their wind function coefficients, it is clear they did not fit their wind function to stream evaporation measurements. Their wind function coefficients are similar to those presented in this study (Table 4.7), more so for the ' 1.5 m' model. Considering the ' $1.5 \mathrm{~m}$ ' model, the slope coefficient, $b$, in this study is slightly less, and the intercept slightly greater than that presented by Webb and Zhang. There is an increased difference between their intercept and the ' $0.5 \mathrm{~m}$ ' model's intercept ( 0.055 vs. $0.0815 \mathrm{~mm} \mathrm{~h}^{-1} \mathrm{kPa}^{-1}$ ), which reflects the wind function coefficient variability due to measurement height (Dingman, 2015). By reaching a similar wind function empirically, this study provides validation of the wind function developed by Webb and Zhang, which is frequently used to model stream evaporation.

The results of the wind function comparison presented in Figure 4.10 indicate variable 
model performance. Generally, wind functions with lower $b$ coefficients (between 0.035 and 0.06) had lower prediction errors. Models where the intercept of the wind function is zero, as in the models from Guenther et al. and Caissie, tend to over- or underestimate evaporation. An intercept equal to zero implies that there is no evaporation in the absence of wind. Given the starting-speed limitations of the cup-type anemometers typically employed for meteorological measurements, low wind speeds are likely to be under-reported. As a result, an intercept of zero may not be an accurate representation of the evaporation processes occurring in small, sheltered streams, and is in contrast to the non-zero intercepts reported by this study and by Webb and Zhang. The two generalized wind functions by Benner and by Webb and Zhang performed quite differently; Benner's model consistently overestimated evaporation whereas Webb and Zhang's model matched the predictions from this study's base model. One key difference between these two studies is the climate of their respective study regions. This indicates that generalized wind functions may not be good estimators when applied to different environments than where they were developed.

An additional consideration is the presence of an internal boundary layer (IBL) over a stream and the influence this and the measurement height will have on the wind function coefficients. Within an IBL, the temperature, humidity, and wind profiles will be different than in an overlying adjusted boundary layer (ABL) (Elliott, 1958). The ABL will represent conditions more representative of the upwind land surfaces while the IBL will be adjusting to the energy and water exchanges at the stream surface. For small (i.e. $<2 \mathrm{~m}$ stream width) and/or densely sheltered streams (e.g., Griffith Creek as observed by Guenther et al., 2012), relatively high measurement heights will be more likely to observe conditions in the ABL, rather than the conditions dominating evaporation at the stream surface. If the measurement height is within an IBL, the estimated wind functions coefficients would be lower than if they were made in an ABL above the stream; for example, if the vapour pressure difference is higher in the IBL than the ABL, wind function coefficients fitted to measurements made in the ABL would be elevated. Evidence of this is present when comparing the wind function coefficients reported by Guenther et al. (2012) and Caissie (2016) for their similar streams: they reported a wind function slope of 0.0424 vs. $0.19 \mathrm{~mm} \mathrm{~h}^{-1} \mathrm{~s} \mathrm{~m}^{-1} \mathrm{kPa}^{-1}$, and used measurement heights of 1.5 and $2 \mathrm{~m}$, respectively. It is expected that wider streams will have a boundary layer representative of the stream surface conditions extend to a greater height above the surface, resulting in estimated wind function coefficients that are less biased.

Each of these studies investigated the evaporation processes occurring in systems of different scales and subject to different forcing conditions (e.g., the magnitude of vapour pressure difference, stability, and the strength of wind profile development). Each study brings insight to the influence of certain physical processes in a given context, but the differences in 
methodologies adopted by each study limits our ability to synthesize the results in a single, transferable model. Therefore, there is a need to extend evaporation measurements to cover a range of sites using a consistent methodology.

\subsubsection{Application in Stream Temperature Modelling}

The results from the wind function comparison in Figure 4.10 show that only Webb and Zhang's generalized wind function performed well in comparison to the predictions from this study. The site-specific wind functions did not perform well when applied to a range of streams because their wind functions were fit to represent the unique conditions and processes at individual sites. Considering the range of streams where evaporation has been measured, only one stream was wider than $30 \mathrm{~m}$ (the Little Southwest Miramichi River studied by Maheu et al., 2014), and only one stream had a mean temperature $>20^{\circ} \mathrm{C}$ during the study

period (the Upper Middle Fork of the John Day River studied by Benner, 2000). Warm, wide streams in a temperate climate have not been well represented in the existing evaporation studies. Due to this lack of representation, additional measurements of evaporation from warm streams, of all widths and degrees of sheltering, in a temperate climate, are required to derive wind function coefficients capable of successfully modelling stream evaporation. In addition to the stream width, temperature, and density of riparian vegetation, the weather conditions under which the data were collected has been suggested to play a role in wind function variability as well (Jobson, 1980; Benner, 2000). To make future wind functions more robust, measurements should be made to encompass the range of typical weather conditions in a study region. It is recommended that the wind function coefficients developed through future research be applied to streams of similar thermal regimes, physiography, and hydroclimate; failure to do so may result in biased predictions of evaporation, and subsequently of latent heat fluxes.

\subsection{Laboratory Results}

\subsubsection{Flume Experiment Design}

The analysis of the flume data was unable to detect a statistically significant effect of slope or roughness on evaporation. This result is counter to the hypothesis that aeration associated with steep, rough channels should enhance turbulent exchange between the water and the overlying air. The laboratory experiments conducted by Benner (2000), while limited, did indicate a relationship between the evaporation rate and flow velocity at low vapour pressure differences and no wind. However, Benner also noted that in the presence of wind or as the 
vapour pressure difference increased, the influence of flowing water on the evaporation rate diminished. Recent alpine stream temperature modelling research by Dufficy (2019) indicates that evaporation from aerated, cascading proglacial streams with stable overlying air is not well represented by mass transfer equations derived for lower gradient, less aerated forested streams. These studies indicate that aeration and flow velocity do have an influence on stream evaporation, but that the influences of vapour pressure difference, wind, and stability need to be carefully considered. The statistical insignificance of this experiment may be the result of three issues.

One notable issue was the magnitude of noise relative to the signal in the electrical conductivity (EC) measurements. Aerated water produced fluctuations of 0.10 to $0.15 \mathrm{mS}$ $\mathrm{cm}^{-1}$ with every scan of the EC probe (1 scan per second), while the 10-minute averages were typically 0.01 to $0.02 \mathrm{mS} \mathrm{cm}^{-1}$. Without enhanced aeration, there was occasionally no change in EC between measurements, which computes to an unrealistic evaporation rate of zero. The heat produced by the pump may have also caused several issues. The EC sensor computes a temperature-corrected electrical conductivity and may have suffered from compensation errors due to the rapid flume warming. Additionally, the instability in the flume resulting from water temperatures greater than air temperatures may have enhanced evaporation to the point where the influence of flow velocity and roughness were not distinguishable. With these issues identified and held in consideration with the findings of Benner (2000) and Dufficy (2019), the underlying principles of this method are likely sound and this study failed to capture the effect of slope or roughness due to methodological issues.

The issue of the signal to noise ratio could be addressed by increasing the total volume of water lost to evaporation by increasing the flume surface area. A greater loss of volume with each measurement interval would produce a greater change in solution concentration, resulting in a greater change in electrical conductivity. Measuring the EC in some form of well-mixed stilling chamber may reduce the EC measurement variability in aerated flows. Perhaps most importantly, the flume water temperature could be controlled by installing a heat exchange system that is submerged in the catch-basin. Glycol-based heat exchange systems are scalable, efficient, and relatively inexpensive. Water-based systems are more affordable and are also efficient, may be unacceptably wasteful if the water is not cooled and recycled.

The main difficulty in empirically describing the influence of aeration and flow velocity on evaporation is the difficulty associated with measuring evaporation from moving water. The primary benefit of the EC method developed for this experiment is that readily available instruments can be employed to measure the evaporation rate with 5- to 10-minute temporal resolution without interrupting the flow. Additionally, a recirculating flow system allows 
for conservation of mass principles to be applied. There are other approaches that could be employed in a controlled laboratory setting, that could not be used in natural systems. For example, a gravimetric approach could take advantage of fluid transfer between a measurement chamber and the flume catch-basin via a siphoning tube as changes in hydrostatic head due to evaporation are equalized. Also, the Beer-Lambert law could be used to relate a change in solution absorbance to a change in solute concentration, again relying on the relationship between water volume loss and concentration change. More sophisticated methods may also be employed using changes in tracer concentration (e.g. spectrofluorometry). 


\section{Chapter 7}

\section{Conclusion}

\subsection{Key Findings}

Evaporation rates were measured at streams with a range of widths (3.1 to $27.6 \mathrm{~m}$ ), temperature regimes, and degrees of sheltering. A total of 864 approximately hourly evaporation measurements were made, and the evaporation rates ranged from -0.01 to $0.20 \mathrm{~mm} \mathrm{~h}^{-1}$, with a mean rate of $0.06 \mathrm{~mm} \mathrm{~h}^{-1}$. A generalized, Dalton-type mass transfer equation was derived using these measurements.

Measured evaporation using the floating pans had an uncertainty of $0.004 \mathrm{~mm} \mathrm{~h}^{-1}$, which is adequate for resolving the variability in evaporation rates through time and among sites. One complication is that water temperature in the pans differed from stream temperature by up to $4.54{ }^{\circ} \mathrm{C}$, with stream-specific average differences ranging from -0.66 to $1.64{ }^{\circ} \mathrm{C}$, so that adjustments had to be made to the stream temperature time series prior to computing vapour pressure at the water surface. In future applications of this methodology, it is recommended that water temperature in the pans be measured approximately every 10 minutes.

The wind function was fit using measurements made 1.5 and $0.5 \mathrm{~m}$ above the stream and had respective root-mean-square errors of 0.0187 and $0.0162 \mathrm{~mm} \mathrm{~h}^{-1}$ under crossvalidation, and respective Nash-Sutcliffe efficiencies of 0.862 and 0.897 . The model fit to 1.5-m measurements had an $a$ coefficient of $0.0663 \mathrm{~mm} \mathrm{~h}^{-1} \mathrm{kPa}^{-1}$, and a $b$ coefficient of $0.0449 \mathrm{~mm} \mathrm{~h}^{-1} \mathrm{~s} \mathrm{~m}^{-1} \mathrm{kPa}^{-1}$, while the model fit to $0.5-\mathrm{m}$ measurements had respective coefficient values of 0.0815 and 0.0437 . These values are greater than the values reported by previous studies that derived unique wind functions for small ( $<2 \mathrm{~m}$ width), forested streams (Guenther et al., 2012; Caissie, 2016), but are less than the values reported from wider streams (> $30 \mathrm{~m}$ width) or arid regions (Benner, 2000; Maheu et al., 2014). This work validates the commonly used wind function reported by Webb and Zhang (1997), and expands upon the only previous empirically derived generalized wind function, derived by 
Benner (2000), but which is better suited to arid regions.

Canopy openness was a significant addition to the wind function for both meteorological measurement heights, while a stability index, the buoyant force, was a significant addition only when the model was fit to measurements from $1.5 \mathrm{~m}$. The reductions in prediction error achieved with these additional variables were greater for measurements at $1.5 \mathrm{~m}$ rather than $0.5 \mathrm{~m}$, which is in line with comments by Brutsaert and Yu (1968) regarding greater representation of turbulent mixing processes at higher measurement heights above an open water surface. However, absolute prediction errors were smaller using measurements from 0.5 $\mathrm{m}$. The lack of significance of stability as a predictor for the ' $0.5 \mathrm{~m}$ ' model could be due to the lack of variability in stability conditions, as conditions were typically stable.

Both the basic Dalton-type models and the expanded models had consistent performance under cross-validation. The addition of stability and canopy openness variables reduced site-specific variability in evaporation predictions, as determined through the mixed-effects modelling approach. These results indicate that both the base and expanded models are applicable to a range of temperate mountain streams to produce representative estimates of evaporation.

Laboratory experiments conducted to determine the influence of aeration and flow velocity on evaporation were intended to build upon the work of Benner (2000). Aeration and flow velocity were not determined to have a significant influence on the evaporation rate from a flume. The lack of statistical significance may be attributed to methodological issues, rather than being an accurate representation of the physical processes.

\subsection{Recommendations for Future Work}

This study produced a wind function that is applicable to a range of temperate, sheltered streams. Future research should expand stream evaporation measurements to cover a broader range of streams than surveyed through this work. In particular, streams with temperatures greater than the maximum observed during this study $\left(21.5^{\circ} \mathrm{C}\right)$ would be worth further investigation. With higher stream temperatures, evaporation rates could increase to the point where it actively forces an upper limit on stream temperature, if thermal equilibrium is reached. Additionally, measuring evaporation from an expanded range of stream widths (e.g., $<3 \mathrm{~m}$ and $>30 \mathrm{~m}$ ), degrees of sheltering, and under both stable and unstable conditions

would aid the further development of a robust, generalized wind function applicable to a broader range of streams.

The lack of fetch associated with the high degree of sheltering in small, forested streams limits the application of standard boundary layer theory and necessitates the use of empirical 
wind functions, as derived in this study. In particular, narrow streams may have internal boundary layers that do not extend to the height of the meteorological instruments, especially when winds blow across the channel. It would be useful for future studies to examine the nature of wind and humidity profiles above streams as a function of distance from the bank, the direction of airflow over the stream, and atmospheric stability. Such studies would provide a stronger basis for understanding the variability of wind function coefficients and for generating a broadly applicable model for predicting stream evaporation and associated heat loss.

Conducting further laboratory studies is the best current approach to verify the influence of aeration and flow velocity on evaporation. Further work to elucidate these relationships would be particularly helpful in interpreting and modelling evaporation rates from small, sheltered streams under low wind speed conditions, and cascading, aerated alpine streams. Future flume-based experiments would benefit from incorporating a temperature-control mechanism to counteract undesired heating from a pump-based system, and the potentially confounding influence of instability over the flume. Future studies could explore potential alternative methodologies to measure evaporation from moving water in a laboratory setting. The following are some examples of alternative methodologies:

- a gravimetric approach that measures the mass loss associated with fluid transfer between a measurement chamber and a flume via a siphoning tube, as changes in hydrostatic head due to evaporation are equalized;

- a spectrophotometric approach that relates changes in solution absorbance to a change in solute concentration due to evaporation;

- a spectrofluorometric approach that can measure changes in a specialized tracer concentration due to evaporation. 


\section{Bibliography}

Arya SP. 1988. Introduction to micrometeorology. Academic Press, San Diego.

Bartholow JM. 2000. Estimating cumulative effects of clearcutting on stream temperatures. Rivers 7: 284-297

Benner DA. 2000. Evaporative heat loss of the Upper Middle Fork of the John Day River, Northeastern Oregon. MSc thesis, Oregon State University.

Benyahya L, Caissie D, El-Jabi N, Satish MG. 2010. Comparison of microclimate vs. remote meteorological data and results applied to a water temperature model (Miramichi River, Canada). Journal of Hydrology 380: 247-259 DOI: 10.1016/j.jhydrol.2009.10.039

Brady DK, Graves WL, Geyer JC. 1969. Surface heat exchange at power plant cooling lakes. In Cooling Water Discharge Project Report No. 5 Edison Electric Institute, New York.

Brown GW. 1969. Predicting temperatures of small streams. Water Resources Research 5: 68-75 DOI: 10.1029/WR005i001p00068

Brown GW, Krygier JT. 1970. Effects of clear-cutting on stream temperature. Water Resources Research 6: 1133-1139 DOI: 10.1029/WR006i004p01133

Brutsaert W. 1982. Evaporation into the atmosphere. Springer Netherlands. DOI: 10.1007/978-94-017-1497-6

Brutsaert W, Yu SL. 1968. Mass transfer aspects of pan evaporation. Journal of Applied Meteorology 7: 563-566 DOI: 10.1175/1520-0450(1968)007<0563:MTAOPE $>2.0 . C O ; 2$

Caissie D. 2006. The thermal regime of rivers: A review. Freshwater Biology 51: 1389-1406 
DOI: $10.1111 /$ j.1365-2427.2006.01597.x

Caissie D. 2016. River evaporation, condensation and heat fluxes within a first-order tributary of Catamaran Brook (New Brunswick, Canada). Hydrological Processes 30: 1872-1883 DOI: 10.1002/hyp.10744

Carreiras JMB, Pereira JMC, Pereira JS. 2006. Estimation of tree canopy cover in evergreen oak woodlands using remote sensing. Forest Ecology and Management 223: 45-53 DOI: 10.1016/j.foreco.2005.10.056

Dalton J. 1802. Experimental essays on the constitution of mixed gases; on the force of steam or vapor from water and other liquids in different temperatures, both in a Torricellian vacuum and in air; on evaporation and on the expansion of gases by heat. Memoirs of the Literary and Philosophical Society of Manchester 5: 535-602

Dingman SL. 2015. Physical hydrology: Third edition. Waveland Press.

Dufficy AL. 2019. Energy balance analysis of the temperature dynamics of a steep proglacial stream. MSc thesis, the University of British Columbia. DOI: 10.14288/1.0378544

Eaton JG, McCormick JH, Stefan HG, Hondzo M. 1995. Extreme value analysis of a fish/temperature field database. Ecological Engineering 4: 289-305 DOI: 10.1016/09258574(95)92708-R

Ebersole JL, Liss WJ, Frissell CA. 2001. Relationship between stream temperature, thermal refugia and rainbow trout Oncorhynchus mykiss abundance in arid-land streams in the northwestern United States. Ecology of Freshwater Fish 10: 1-10 DOI: 10.1034/j.16000633.2001.100101.x

Elliott JM, Hurley MA. 1997. A functional model for maximum growth of Atlantic Salmon parr, Salmo salar, from two populations in northwest England. Functional Ecology 11: 592-603 DOI: 10.1046/j.1365-2435.1997.00130.x

Elliott WP. 1958. The growth of the atmospheric internal boundary layer. Eos, Transactions American Geophysical Union 39: 1048-1054 DOI: 10.1029/TR039i006p01048

Ficklin D, Barnhart B, Knouft J, Stewart I, Maurer E, Letsinger S, Whittaker G. 2014. Climate change and stream temperature projections in the Columbia River basin: Habitat implications of spatial variation in hydrologic drivers. Hydrology and Earth System Sciences 
18: 4897-4912 DOI: 10.5194/hess-18-4897-2014

Forsythe GE, Malcolm MA, Moler CB. 1977. Computer methods for mathematical calculations. Wiley.

Frazer GW, Canham CD, Lertzman KP. 1999. Gap Light Analyzer (GLA) Version 2.0: Imaging software to extract canopy structure and gap light transmissions indices from true-colour fisheye photographs, users manual and program documentation. Simon Fraser University, Burnaby, British Columbia; the Institute of Ecosystem Studies, Milbrook, New York.

Fried JS, Torn MS, Mills E. 2004. The impact of climate change on wildfire severity: A regional forecast for Northern California. Climatic Change 64: 169-191

Garner G, Malcolm IA, Sadler JP, Hannah DM. 2014. What causes cooling water temperature gradients in a forested stream reach? Hydrology and Earth System Sciences 18: 5361-5376 DOI: $10.5194 /$ hess-18-5361-2014

Guenther SM, Gomi T, Moore RD. 2014. Stream and bed temperature variability in a coastal headwater catchment: Influences of surface-subsurface interactions and partial-retention forest harvesting. Hydrological Processes 28: 1238-1249 DOI: 10.1002/hyp.9673

Guenther SM, Moore RD, Gomi T. 2012. Riparian microclimate and evaporation from a coastal headwater stream, and their response to partial-retention forest harvesting. Agricultural and Forest Meteorology 164: 1-9 DOI: 10.1016/j.agrformet.2012.05.003

Gulliver JS, Stefan HG. 1986. Wind function for a sheltered stream. Journal of Environmental Engineering 112: 387-399

Intergovernmental Panel on Climate Change. 2014. Climate change 2013 - the physical science basis: Working group I contribution to the fifth assessment report of the Intergovernmental Panel on Climate Change. Cambridge University Press. DOI: 10.1017/CBO9781107415324

Isaak DJ, Luce CH, Rieman BE, Nagel DE, Peterson EE, Horan DL, Parkes S, Chandler GL. 2010. Effects of climate change and wildfire on stream temperatures and salmonid thermal habitat in a mountain river network. Ecological Applications 20: 1350-1371 DOI: $10.1890 / 09-0822.1$

Isaak DJ, Young MK, Luce CH, Hostetler SW, Wenger SJ, Peterson EE, Ver Hoef JM, Groce MC, Horan DL, Nagel DE. 2016. Slow climate velocities of mountain streams portend 
their role as refugia for cold-water biodiversity. Proceedings of the National Academy of Sciences of the United States of America 113: 4374-4379 DOI: 10.1073/pnas.1522429113

Jensen AJ. 1990. Growth of young migratory brown trout Salmo trutta correlated with water temperature in Norwegian rivers. Journal of Animal Ecology 59: 603-614 DOI: $10.2307 / 4883$

Jobson HE. 1980. Thermal modeling of flow in the San Diego Aqueduct, California, and its relation to evaporation. United States Geological Survey Professional Paper 1122. US Department of Interior, Washington, DC.

Kim KS, Chapra SC. 1997. Temperature model for highly transient shallow streams. Journal of Hydraulic Engineering 123: 30-40 DOI: 10.1061/(ASCE)0733-9429(1997)123:1(30)

King TV, Neilson BT. 2019. Quantifying reach-average effects of hyporheic exchange on Arctic river temperatures in an area of continuous permafrost. Water Resources Research 55: 1951-1971 DOI: 10.1029/2018WR023463

Korhonen L, Korpela I, Heiskanen J, Maltamo M. 2011. Airborne discrete-return LIDAR data in the estimation of vertical canopy cover, angular canopy closure and leaf area index. Remote Sensing of Environment 115: 1065-1080 DOI: 10.1016/j.rse.2010.12.011

Krajewski WF, Kraszewski AK, Grenney WJ. 1982. A graphical technique for river water temperature predictions. Ecological Modelling 17: 209-224 DOI: 10.1016/0304-3800(82)900321

Leach JA, Moore RD. 2010. Above-stream microclimate and stream surface energy exchanges in a wildfire-disturbed riparian zone. Hydrological Processes 24: 2369-2381 DOI: 10.1002/hyp.7639

Leach JA, Moore RD. 2011. Stream temperature dynamics in two hydrogeomorphically distinct reaches. Hydrological Processes 25: 679-690 DOI: 10.1002/hyp.7854

Leach JA, Moore RD. 2019. Empirical stream thermal sensitivities may underestimate stream temperature response to climate warming. Water Resources Research 55 DOI: 10.1029/2018WR024236

LeBosquet M Jr., Tsivoglou EC. 1950. Simplified dissolved oxygen computations. Sewage and Industrial Wastes 22: 1054-1061

Luce C, Staab B, Kramer M, Wenger S, Isaak D, McConnell C. 2014. Sensitivity of summer 
stream temperatures to climate variability in the Pacific Northwest. Water Resources Research 50: 3428-3443 DOI: 10.1002/2013WR014329

Magnusson J, Jonas T, Kirchner JW. 2012. Temperature dynamics of a proglacial stream: Identifying dominant energy balance components and inferring spatially integrated hydraulic geometry. Water Resources Research 48 DOI: 10.1029/2011WR011378

Maheu A, Caissie D, St-Hilaire A, El-Jabi N. 2014. River evaporation and corresponding heat fluxes in forested catchments. Hydrological Processes 28: 5725-5738 DOI: 10.1002/hyp.10071

Morin G, Nzakimuena T-J, Sochanski W. 1994. Prévision des températures de l'eau en rivières à l'aide d'un modèle conceptuel: Le cas de la rivière Moisie. Canadian Journal of Civil Engineering 21: 63-75

Morse WL. 1972. Stream temperature prediction under reduced flow. Journal of the Hydraulics Division 98: 1031-1047

Parkinson EA, Lea EV, Nelitz MA, Knudson JM, Moore RD. 2016. Identifying temperature thresholds associated with fish community changes in British Columbia, Canada, to support identification of temperature sensitive streams. River Research and Applications 32: 330-347 DOI: 10.1002/rra.2867

Ryan PJ, Harleman DRF. 1973. An analytical and experimental study of transient cooling pond behavior. Dept. of Civil Engineering, Massachusetts Institute of Technology.

Schneider CA, Rasband WS, Eliceiri KW. 2012. NIH Image to ImageJ: 25 years of image analysis. Nature Methods 9: 671-675 DOI: 10.1038/nmeth.2089

Sinokrot BA, Gulliver JS. 2000. In-stream flow impact on river water temperatures. Journal of Hydraulic Research 38: 339-349 DOI: 10.1080/00221680009498315

Sinokrot BA, Stefan HG. 1993. Stream temperature dynamics: Measurements and modeling. Water Resources Research 29: 2299-2312 DOI: 10.1029/93WR00540

Smith AMS, Falkowski MJ, Hudak AT, Evans JS, Robinson AP, Steele CM. 2009. A crosscomparison of field, spectral, and lidar estimates of forest canopy cover. Canadian Journal of Remote Sensing 35: 447-459 DOI: 10.5589/m09-038

Stelling E. 1882. Ueber die abhängigkeit der verdunstung des wassers von seiner temperatur und von der feuchtigkeit und bewegung der luft. Österreichische Gesellschaft für 
Meteorologie 17: 372-373

Sutton OG. 1953. Micrometeorology: A study of physical processes in the lowest layers of the earth's atmosphere. McGraw-Hill, New York.

U.S. Standard Atmosphere, 1976. 1976. National Oceanic and Atmospheric Administration; the National Aeronautics and Space Administration; the United States Air Force: Washington, D.C.

Vugts HF. 1974. Calculation of temperature variations of small mountain streams. Journal of Hydrology 23: 267-278 DOI: 10.1016/0022-1694(74)90007-9

Webb BW, Zhang Y. 1997. Spatial and seasonal variability in the components of the river heat budget. Hydrological Processes 11: 79-101 DOI: 10.1002/(SICI)10991085(199701)11:1<79::AID-HYP404>3.0.CO;2-N

Webb BW, Zhang Y. 1999. Water temperatures and heat budgets in Dorset chalk water courses. Hydrological Processes 13: 309-321 DOI: 10.1002/(SICI)10991085(19990228)13:3<309::AID-HYP740>3.0.CO;2-7

Webb BW, Hannah DM, Moore RD, Brown LE, Nobilis F. 2008. Recent advances in stream and river temperature research. Hydrological Processes 22: 902-918 DOI: 10.1002/hyp.6994

Wichert GA, Lin P. 1996. A species tolerance index for maximum water temperature. Water Quality Research Journal 31: 875-893 DOI: 10.2166/wqrj.1996.048

Wu H, Kimball JS, Elsner MM, Mantua N, Adler RF, Stanford J. 2012. Projected climate change impacts on the hydrology and temperature of Pacific Northwest rivers. Water Resources Research 48 DOI: 10.1029/2012WR012082 


\section{Appendix A}

\section{Anemometer Calibration}

The calibration of the field-deployed anemometers revealed that the anemometers measuring wind speed at $1.5 \mathrm{~m}$ and at $0.5 \mathrm{~m}$ in the field had greater under-reporting of wind speed at low wind speeds compared to higher wind speeds; the mean percent differences ranged from -68 to $-76 \%$ for the $10^{\text {th }}$ percentile of $1.5-\mathrm{m}$ and $0.5-\mathrm{m}$ anemometers' measurements relative to the calibration anemometers, compared to the mean percent differences of -7 to -9 $\%$ for the $90^{t h}$ percentile, respectively. The segmented linear regressions were successful in correcting the field anemometer's measurements to be in closer agreement with the calibration anemometers' measurements. The calibration reduced the mean percent differences in the $10^{\text {th }}$ and $90^{\text {th }}$ percentiles to 12 to $-16 \%$ and -0.5 to $-2.8 \%$, for the $1.5-\mathrm{m}$ and $0.5-\mathrm{m}$ anemometers, respectively (Table A.1). The regressions for the 1.5-m and 0.5-m anemometer calibrations had root-mean-square errors of 0.07 and $0.12 \mathrm{~m} \mathrm{~s}^{-1}$ relative to mean wind speeds of 0.92 and $0.90 \mathrm{~m} \mathrm{~s}^{-1}$, respectively.

Table A.1: The statistics of anemometer measurement difference prior to and post calibration. The differences were computed as Field Anemometer - Calibration Anemometer.

\begin{tabular}{|c|c|c|c|c|c|}
\hline \multirow{3}{*}{$\begin{array}{l}\text { Data } \\
\text { Percentile }\end{array}$} & \multirow{3}{*}{ Anemometer } & \multicolumn{2}{|c|}{ Pre-calibration } & \multicolumn{2}{|c|}{ Post-calibration } \\
\hline & & Mean & Mean & Mean & Mean \\
\hline & & $\begin{array}{l}\text { Difference } \\
\left(\mathrm{m} \mathrm{s}^{-1}\right)\end{array}$ & Difference (\%) & $\begin{array}{l}\text { Difference } \\
\left(\mathrm{m} \mathrm{s}^{-1}\right)\end{array}$ & Difference (\%) \\
\hline \multirow{2}{*}{10} & $0.5 \mathrm{~m}$ & -0.54 & -76 & -0.17 & -16 \\
\hline & $1.5 \mathrm{~m}$ & -0.31 & -68 & 0.05 & 12 \\
\hline \multirow{2}{*}{90} & $0.5 \mathrm{~m}$ & -0.14 & -9 & -0.05 & -2.8 \\
\hline & $1.5 \mathrm{~m}$ & -0.11 & -7 & -0.01 & -0.5 \\
\hline
\end{tabular}

Both field-deployed anemometers are shown to under-report wind speed, but the 0.5-m anemometer had consistently greater errors compared to the 1.5-m anemometer. This can likely be attributed to a greater frictional resistance in the anemometer head rather than 


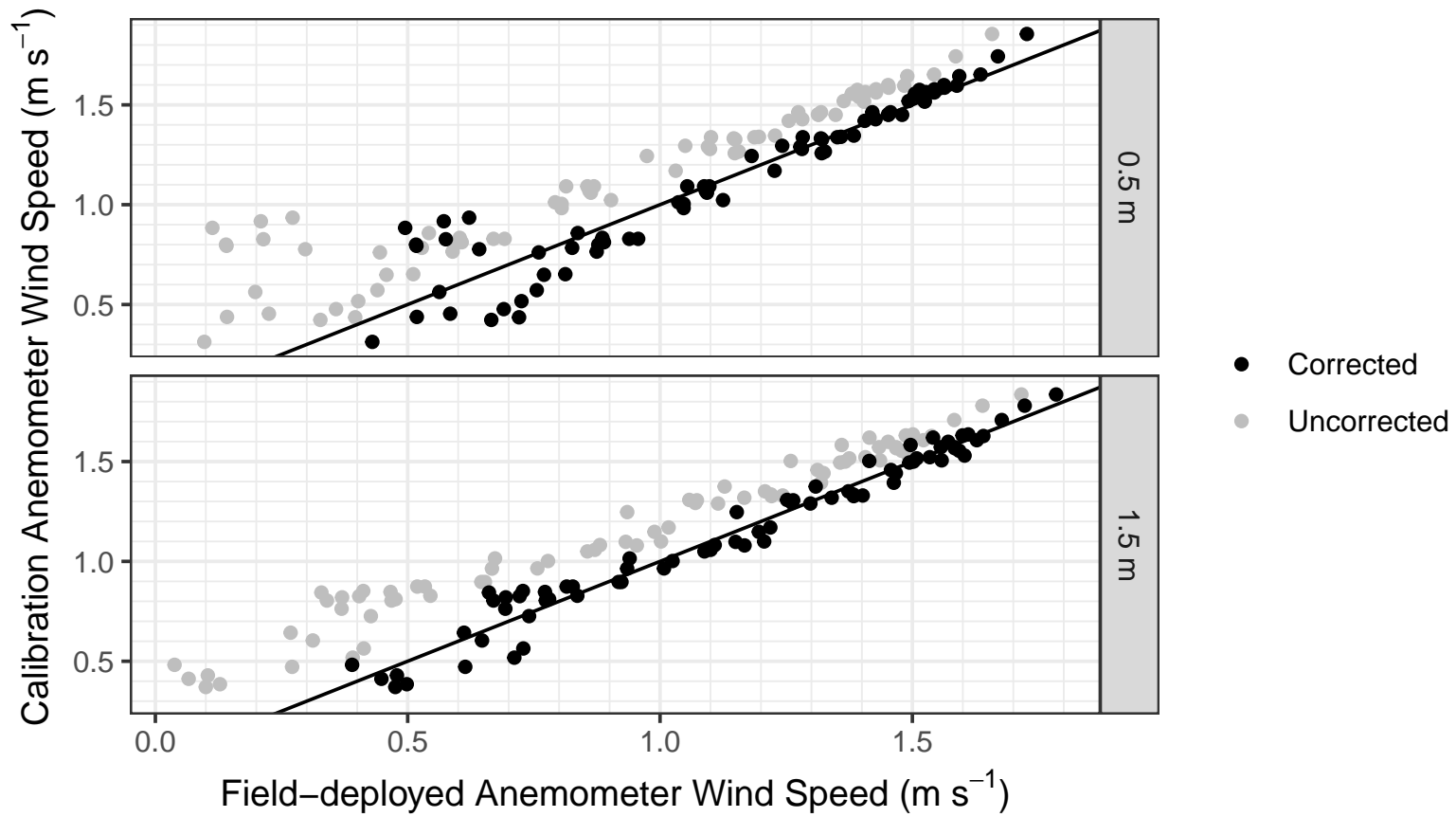

Figure A.1: The uncorrected and corrected field-deployed anemometer wind speed measurements over the calibration period compared to the calibration anemometers. The black lines represent the 1:1 line.

occurring as a result of actual differences in wind blowing on the anemometers; as shown in Figure A.2, the calibration anemometers' measurements during the calibration period are in agreement with each other, in contrast to the field anemometers, which show increased scatter between their measurements despite being nearly adjacent during the calibration. This increased frictional resistance has the greatest influence at lower wind speeds, with increased scatter visible below wind speeds of $0.7 \mathrm{~m} \mathrm{~s}^{-1}$. As a result, it is likely that the field measurements of wind speed by the $0.5-\mathrm{m}$ anemometer are under-reported even after correction. 


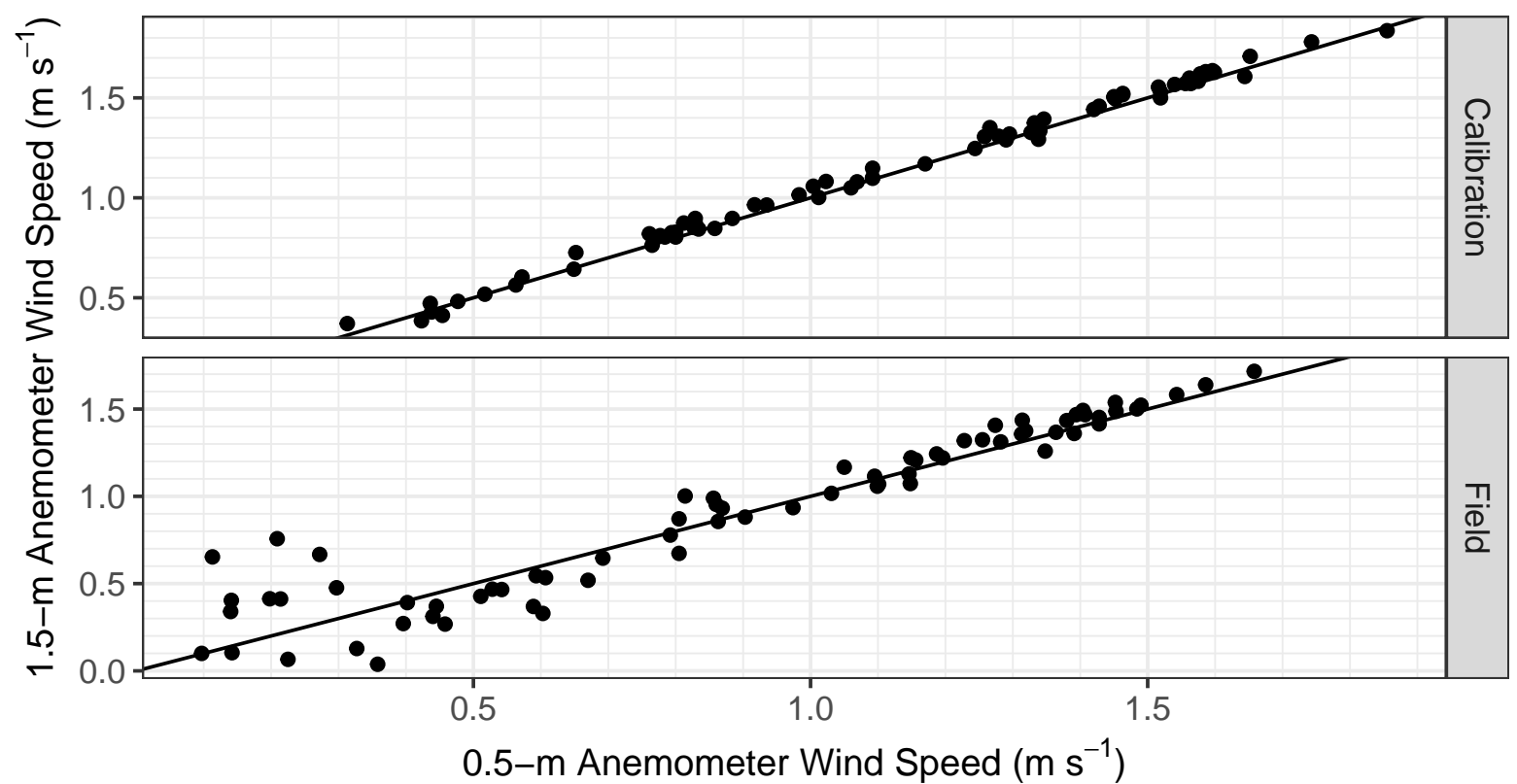

Figure A.2: Comparing the agreement in wind speed measurements between field anemometer and calibration anemometer pairs during the calibration period. The black lines are the 1:1 lines. 


\section{Appendix B}

\section{Evaporation Pan Water Temperature and Surface Area}

The full time series of stream temperature and individual evaporation pan water temperatures are presented in Figure B.1.

The evaporation pan mass and water surface area measurements, and the fit regression, are shown in Figure B.2. The coefficients for Equation 2.2, $a_{1}, a_{2}$, and $a_{0}$, fit by the regression were $-1.736 \times 10^{-4}, 2.424 \times 10^{-1}$, and -4.736 . The regression had a root-mean-square error of $1.84 \times 10^{-4} \mathrm{~m}^{2}$, with an adjusted $\mathrm{R}^{2}$ of 0.88 . When applied to the field data, the regression provides $95 \%$ prediction intervals that correspond approximately $\pm 2 \%$ of the estimated surface area. It is worth noting that there were four measurements of pan mass that were beyond the range of the calibration data, so their extrapolated surface area measurements are subject to increased uncertainty. The maximum and minimum estimated pan water surface areas are 0.0398 and $0.0382 \mathrm{~m}^{2}$, which correspond to -3.9 and $-7.2 \%$ differences from the surface area obtained using the evaporation pan dimensions $\left(0.0412 \mathrm{~m}^{2}\right)$. 


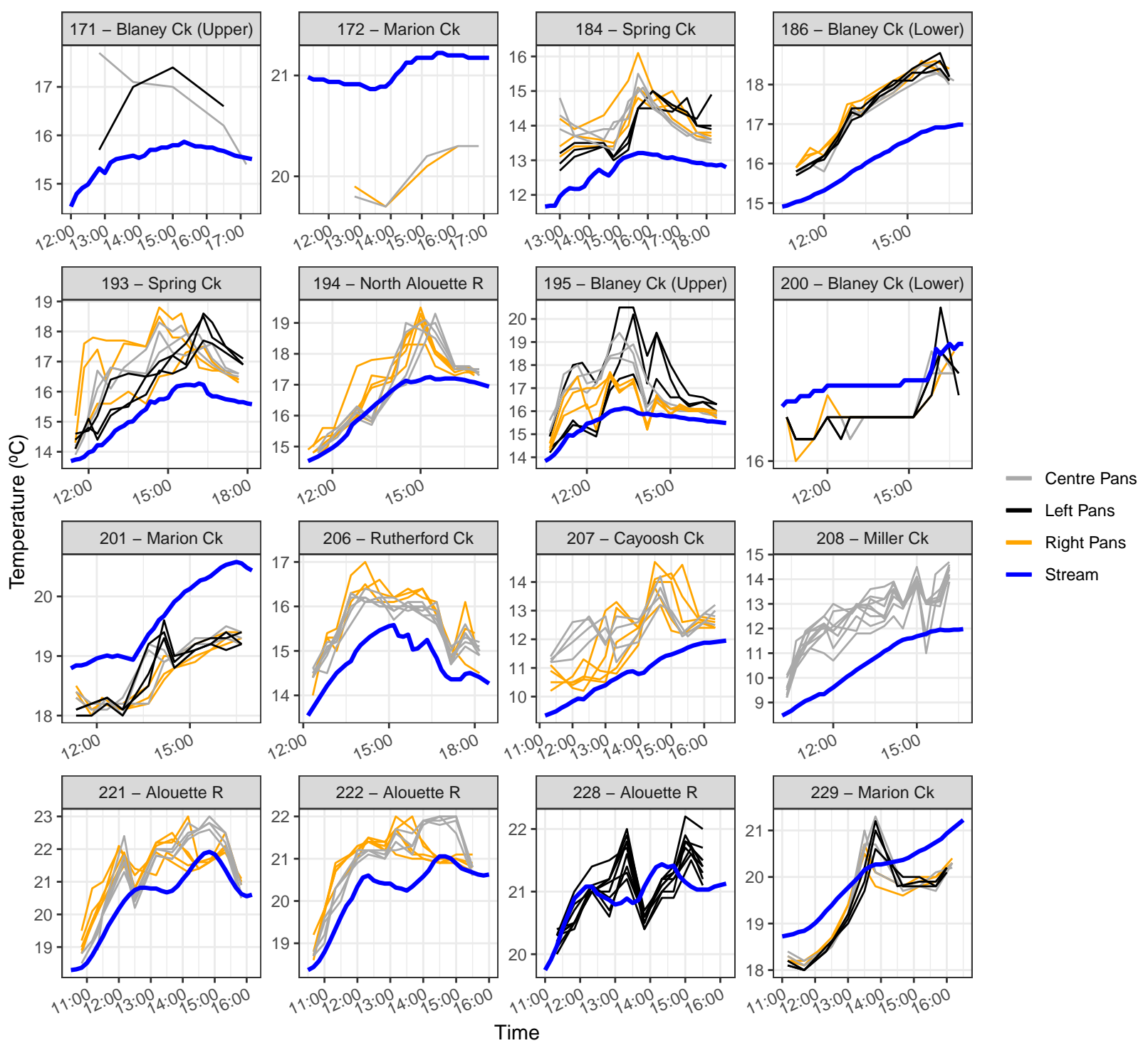

Figure B.1: Stream and evaporation pan water temperatures over the course of evaporation measurements. The stream water temperatures are at 10 minute temporal resolution, while the pan water temperature measurements are at approximately 20 minute intervals. The grid panels are titled with the day of year and location. Days with insufficient pan water temperature measurements were omitted from this figure. 


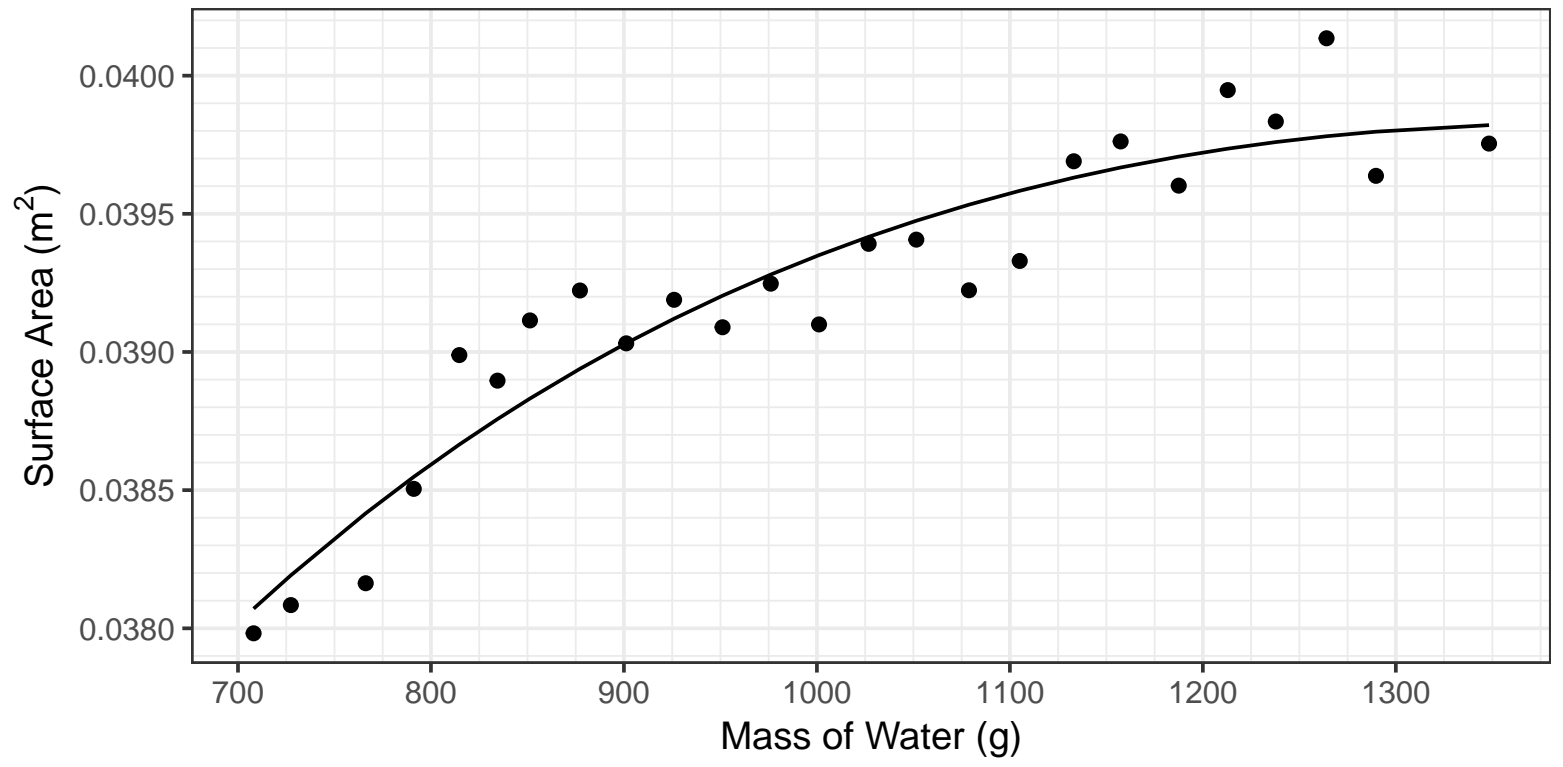

Figure B.2: The calibration of evaporation pan water surface area. The line is the fit regression. 


\section{Appendix C}

\section{Meteorological Conditions and Evaporation Rates}

The meteorological and stream temperature data in Figures C.1a to C.1t are at 10 minute intervals, and the evaporation rate measurements are at approximately 1 to 1.5 hour intervals. The lack of wind on June 7th and July 19th at Spring Creek and Blaney Creek (Lower) was noted during field work, so the data are believed to be accurate (Figures C.1b and C.1l). 


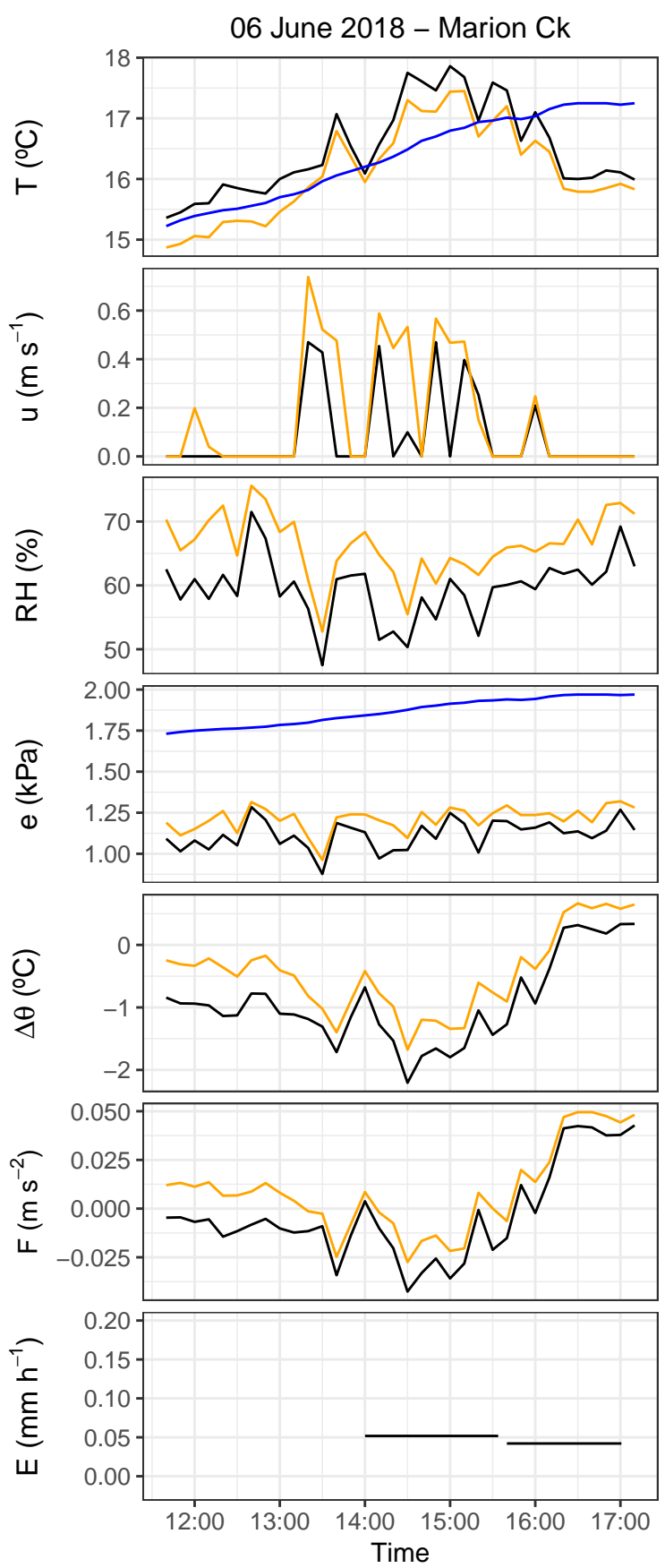

$-1.5 \mathrm{~m}-0.5 \mathrm{~m}-$ Stream

(a)
07 June 2018 - Spring Ck
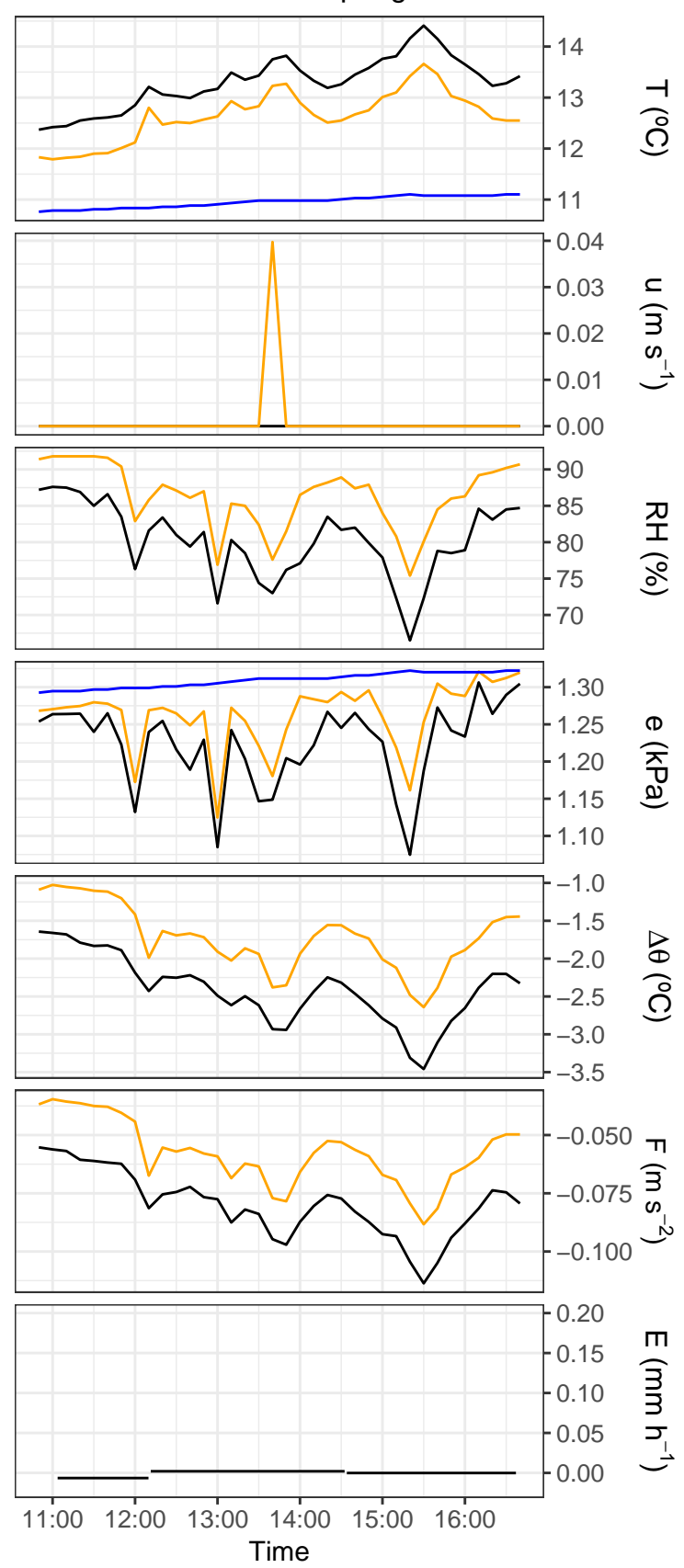

$-1.5 \mathrm{~m}-0.5 \mathrm{~m}-$ Stream

(b)

Figure C.1: Meteorological and stream conditions, and measured evaporation rates for each day of data collection. 


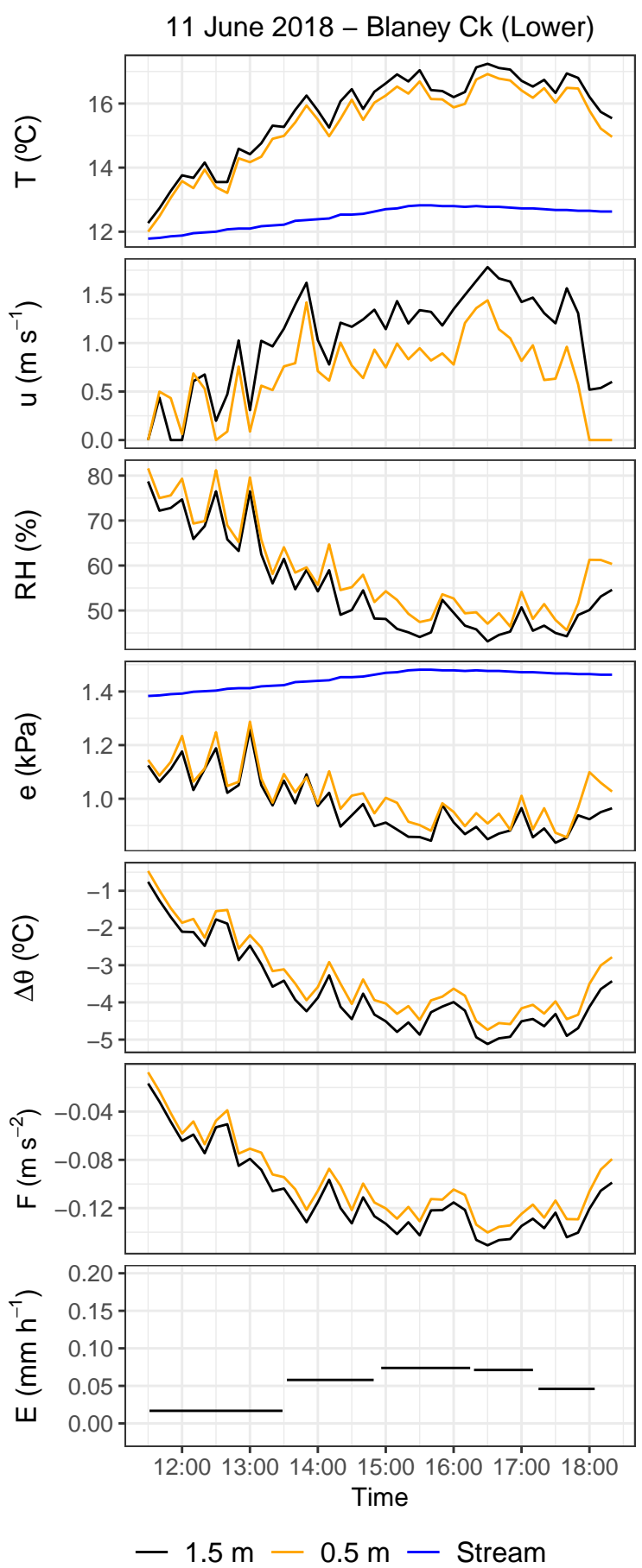

(c)
16 June 2018 - Miller Ck
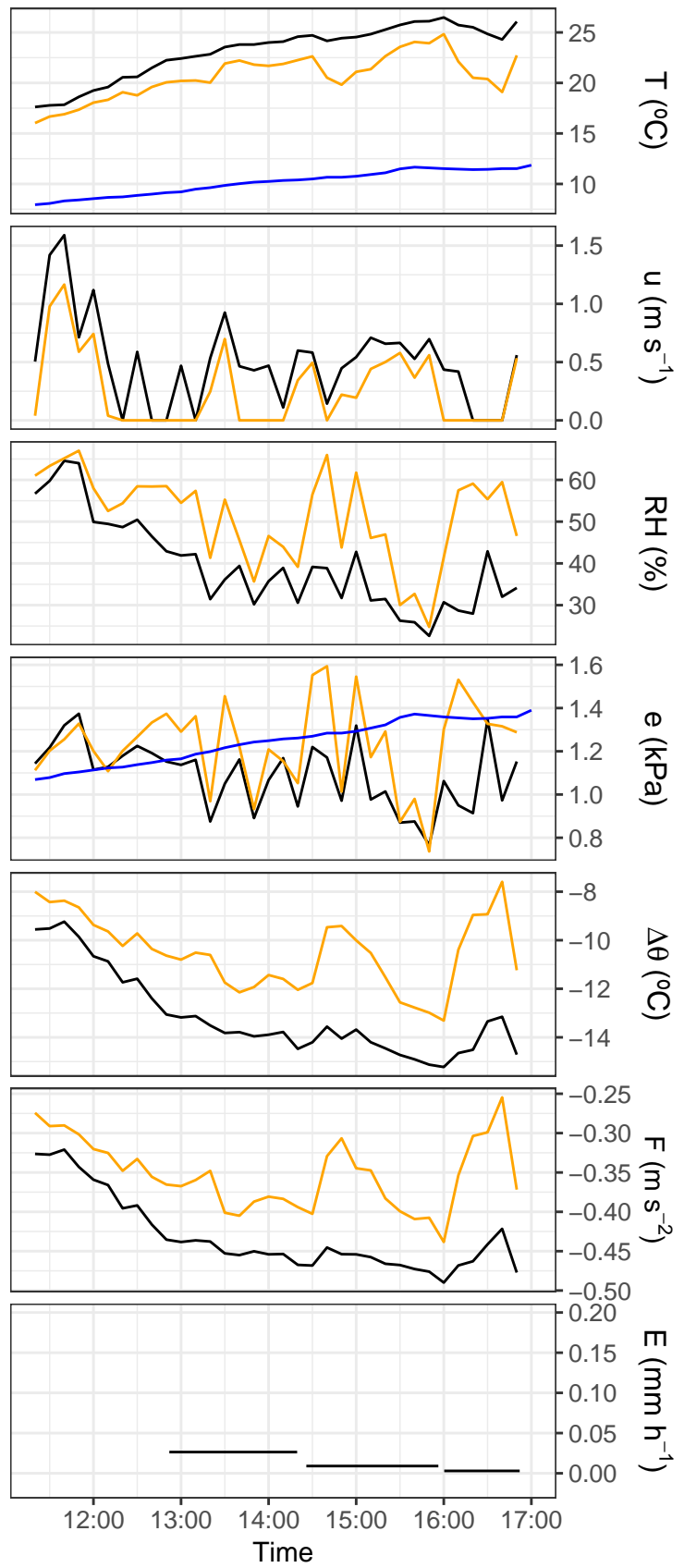

$-1.5 \mathrm{~m}-0.5 \mathrm{~m}-$ Stream

Figure C.1: Meteorological and stream conditions, and measured evaporation rates for each day of data collection (cont.). 

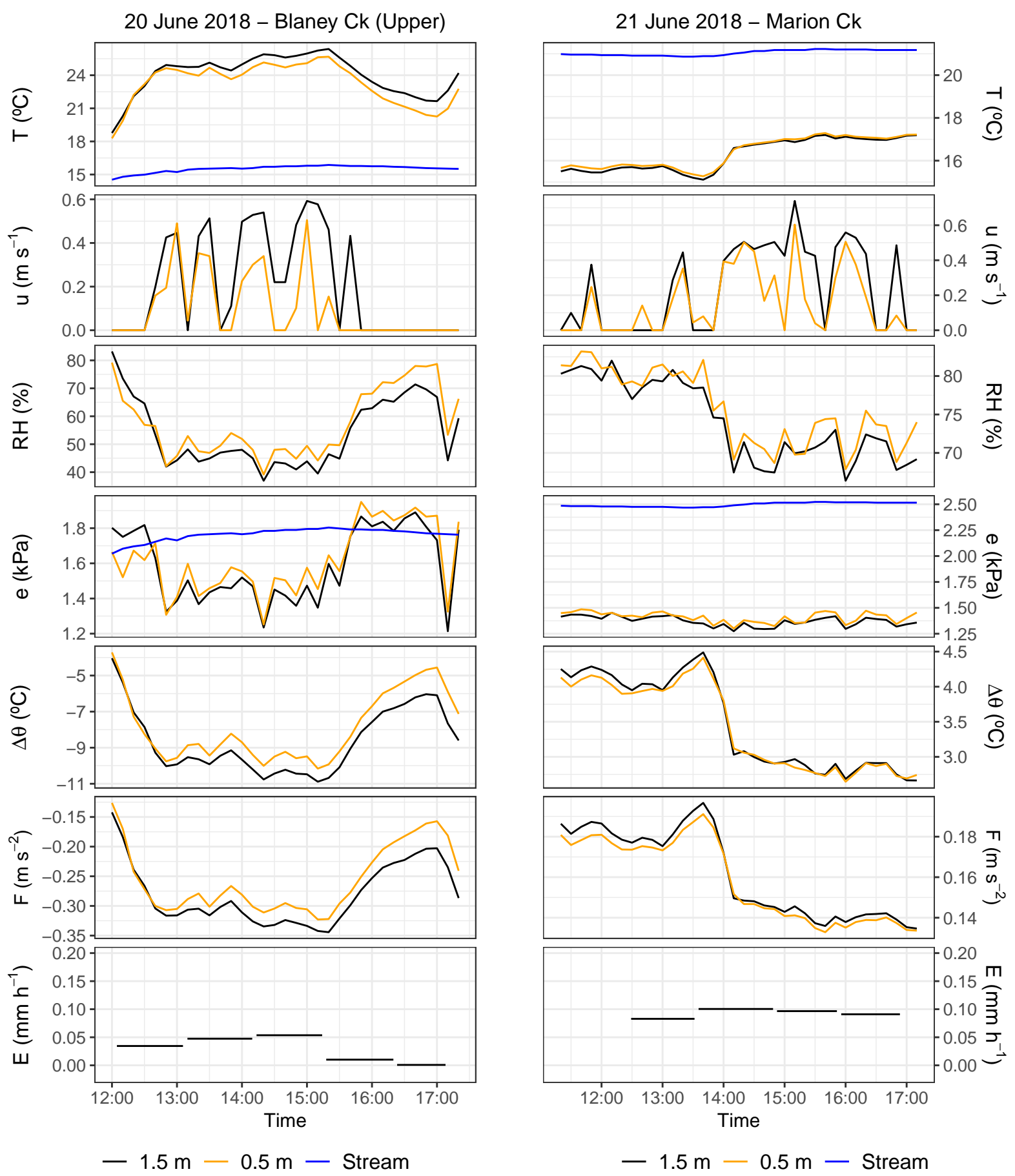

(e)

(f)

Figure C.1: Meteorological and stream conditions, and measured evaporation rates for each day of data collection (cont.). 

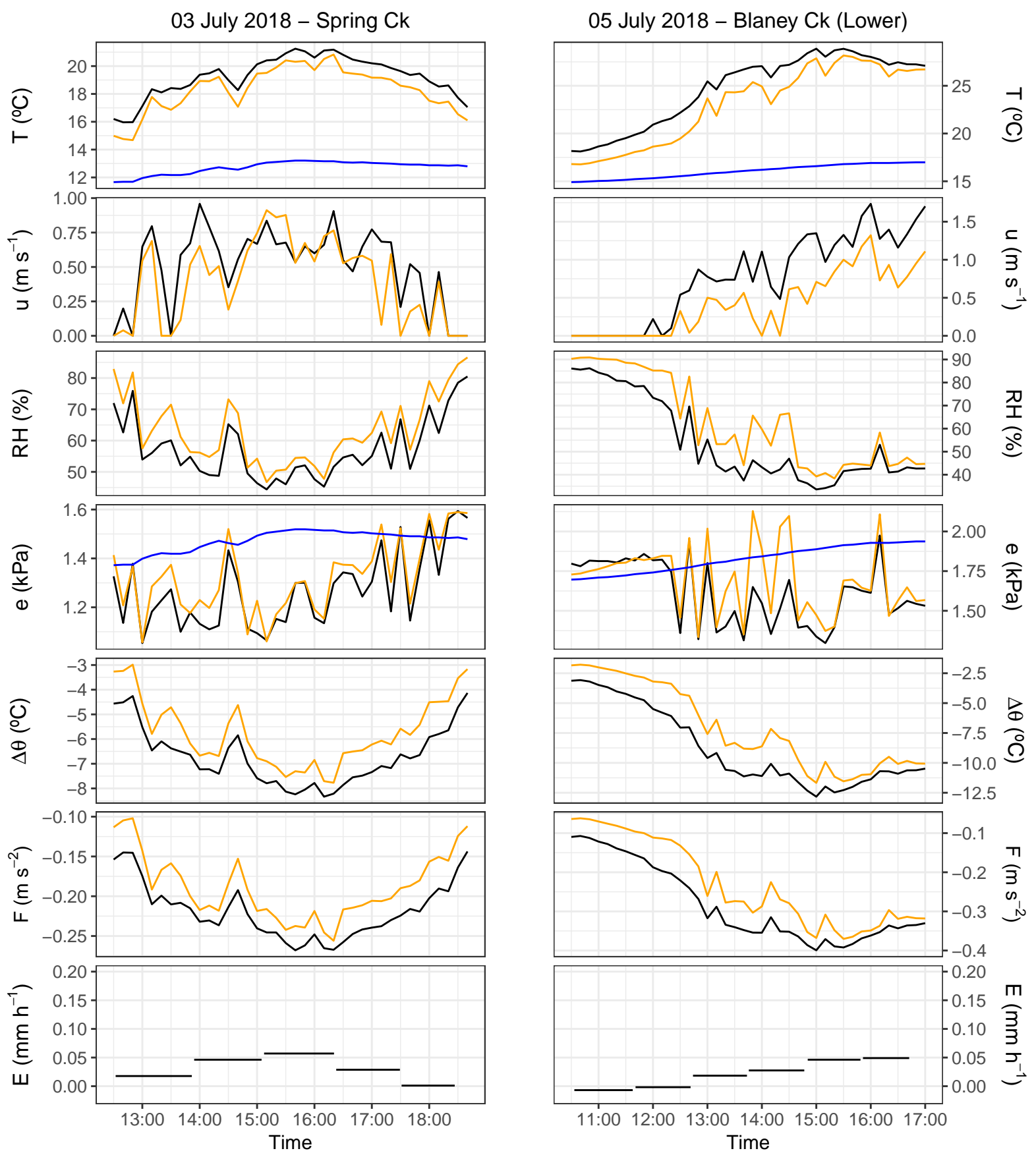

$-1.5 \mathrm{~m}-0.5 \mathrm{~m}-$ Stream

$-1.5 \mathrm{~m}-0.5 \mathrm{~m}-$ Stream

(g)

(h)

Figure C.1: Meteorological and stream conditions, and measured evaporation rates for each day of data collection (cont.). 

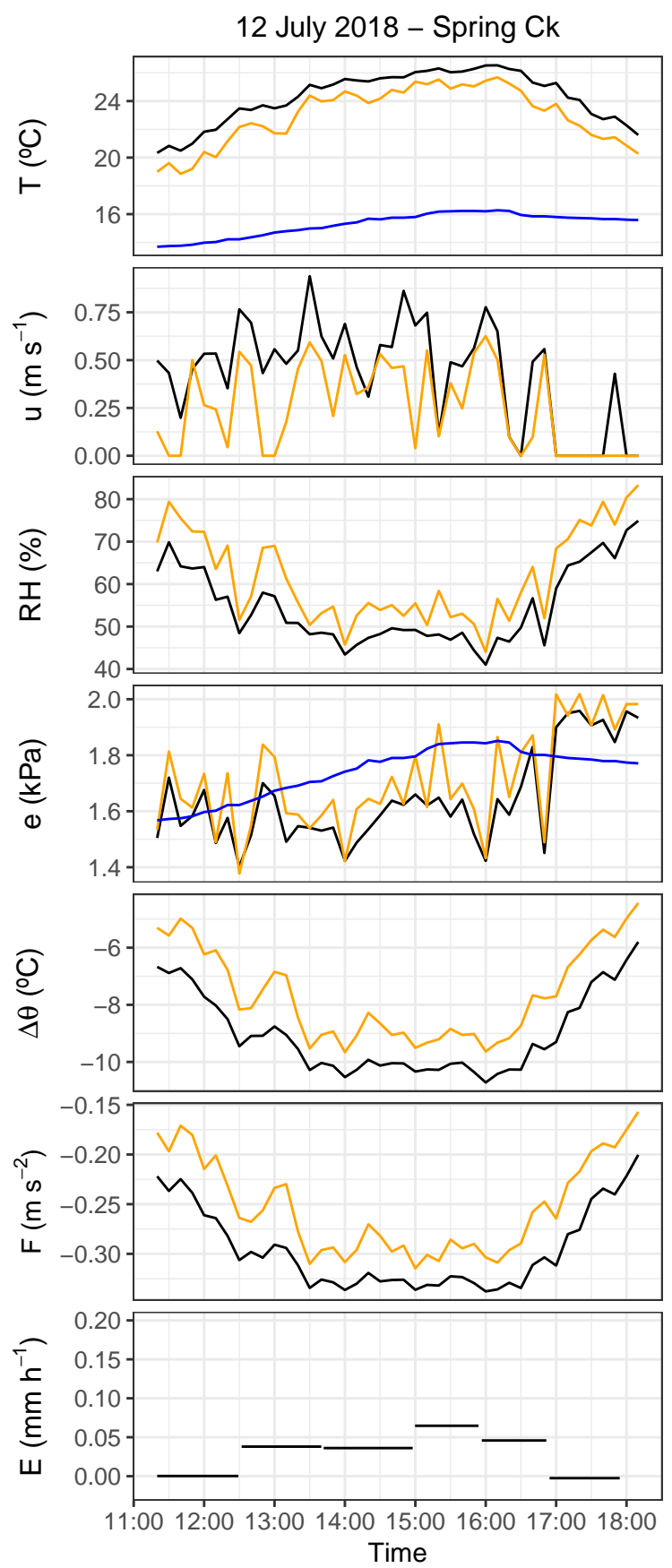

$-1.5 \mathrm{~m}-0.5 \mathrm{~m}-$ Stream

(i)
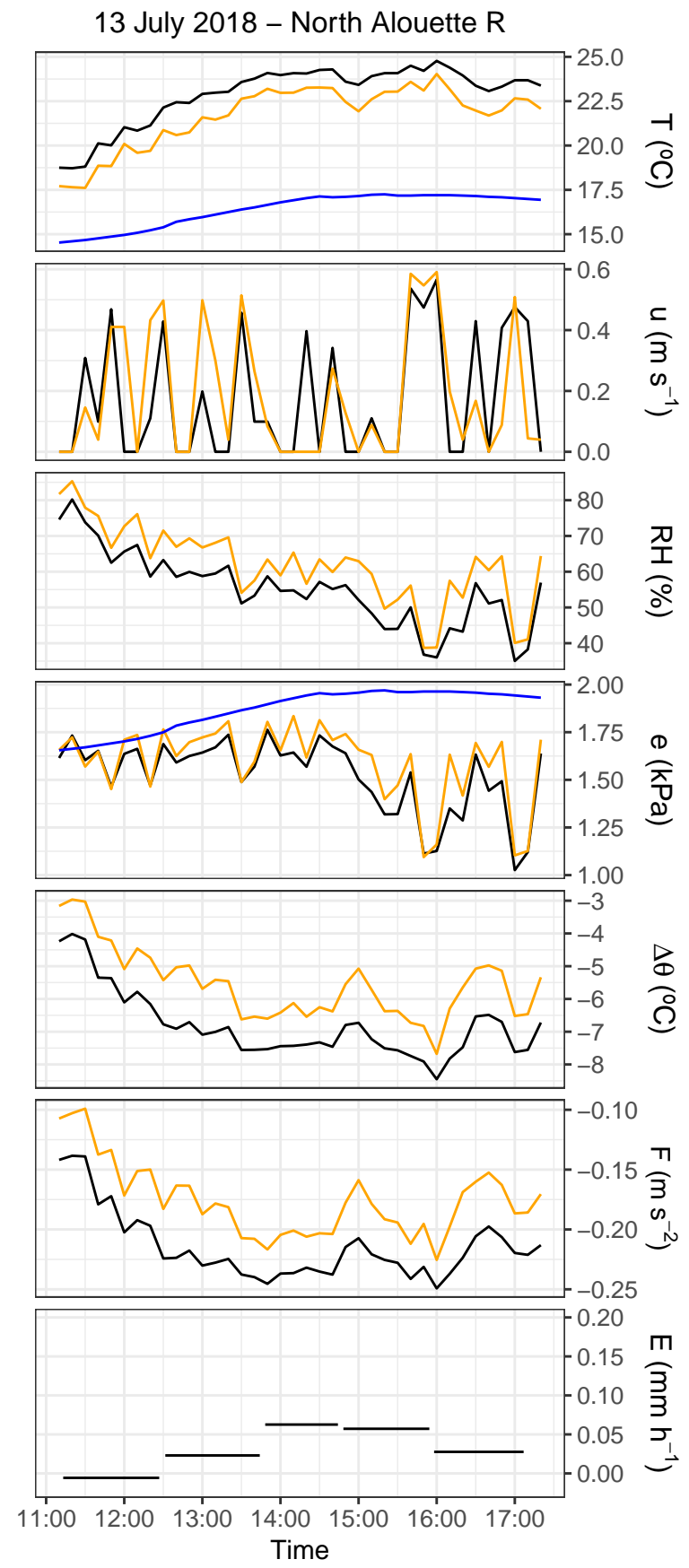

$-1.5 \mathrm{~m}-0.5 \mathrm{~m}-$ Stream

(j)

Figure C.1: Meteorological and stream conditions, and measured evaporation rates for each day of data collection (cont.). 


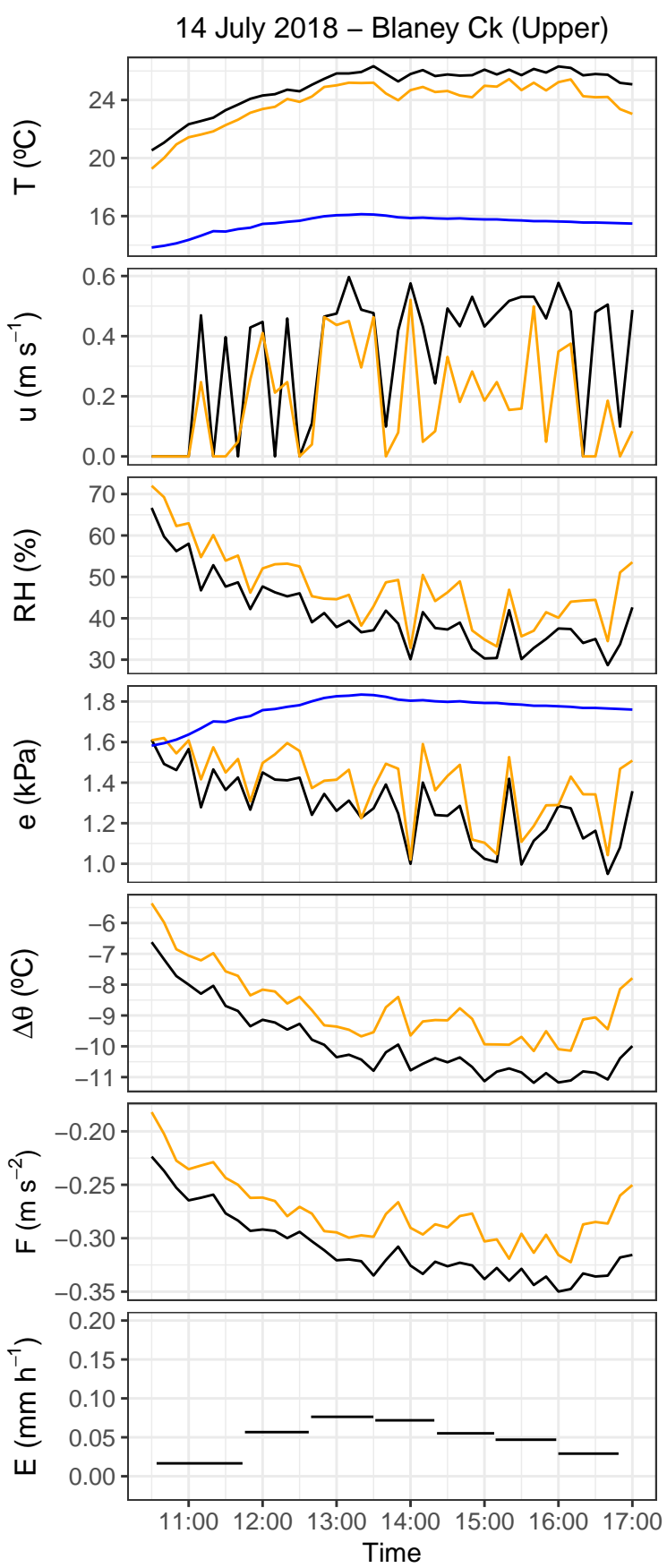

$-1.5 \mathrm{~m}-0.5 \mathrm{~m}-$ Stream
19 July 2018 - Blaney Ck (Lower)
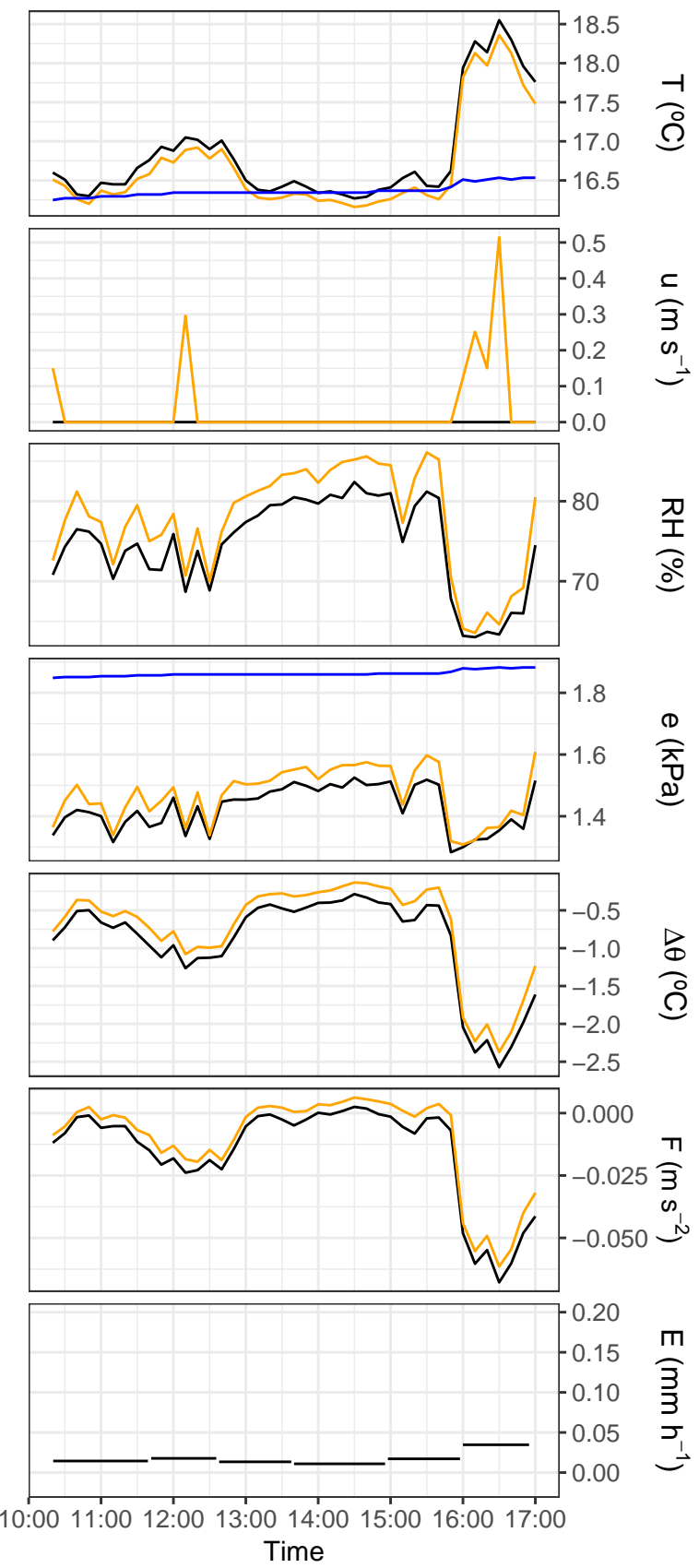

$-1.5 \mathrm{~m}-0.5 \mathrm{~m}-$ Stream

$(\mathrm{k})$

Figure C.1: Meteorological and stream conditions, and measured evaporation rates for each day of data collection (cont.). 

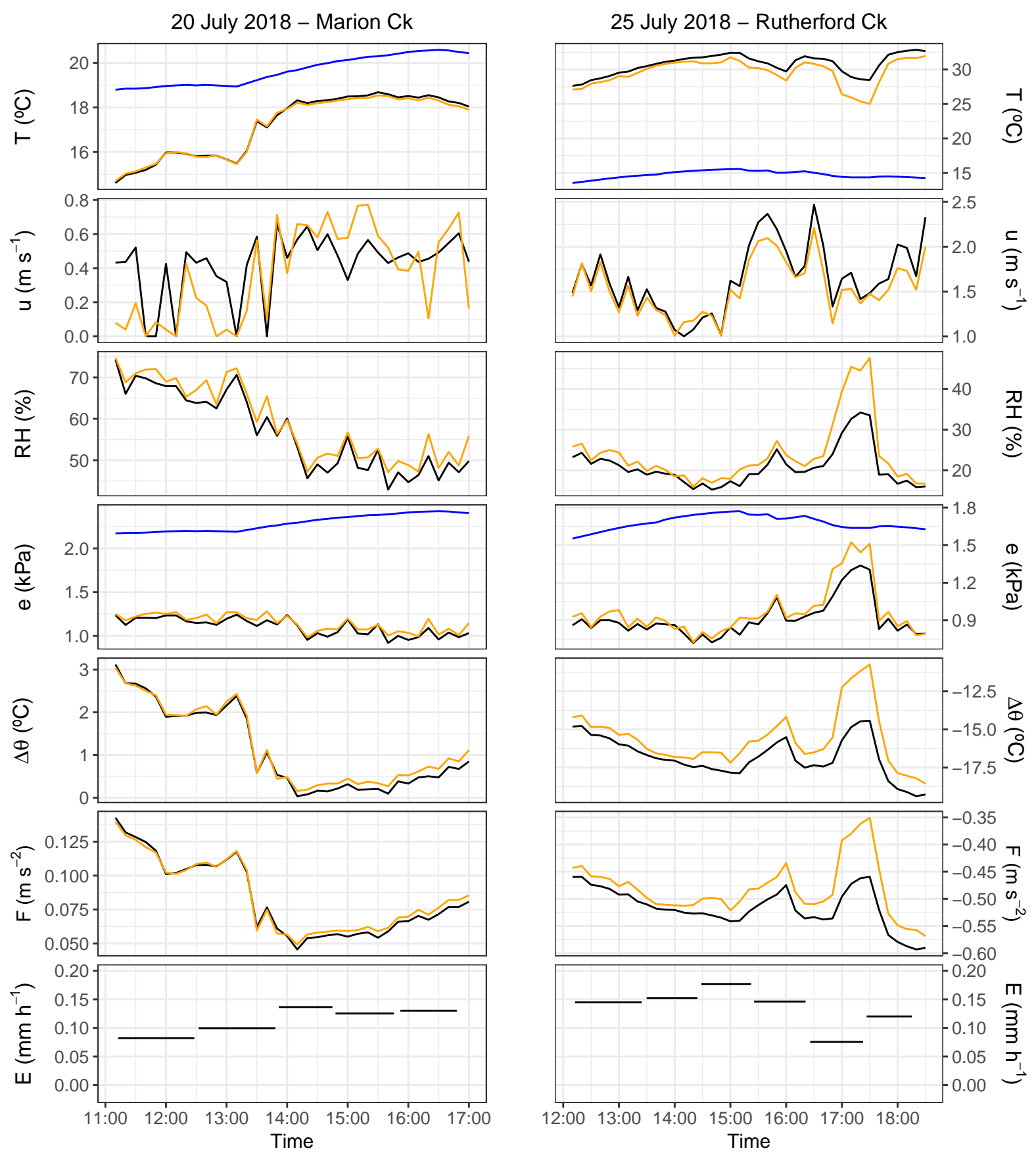

$$
-1.5 \mathrm{~m}-0.5 \mathrm{~m}-\text { Stream }
$$$$
-1.5 \mathrm{~m}-0.5 \mathrm{~m}-\text { Stream }
$$

(m)

(n)

Figure C.1: Meteorological and stream conditions, and measured evaporation rates for each day of data collection (cont.). 

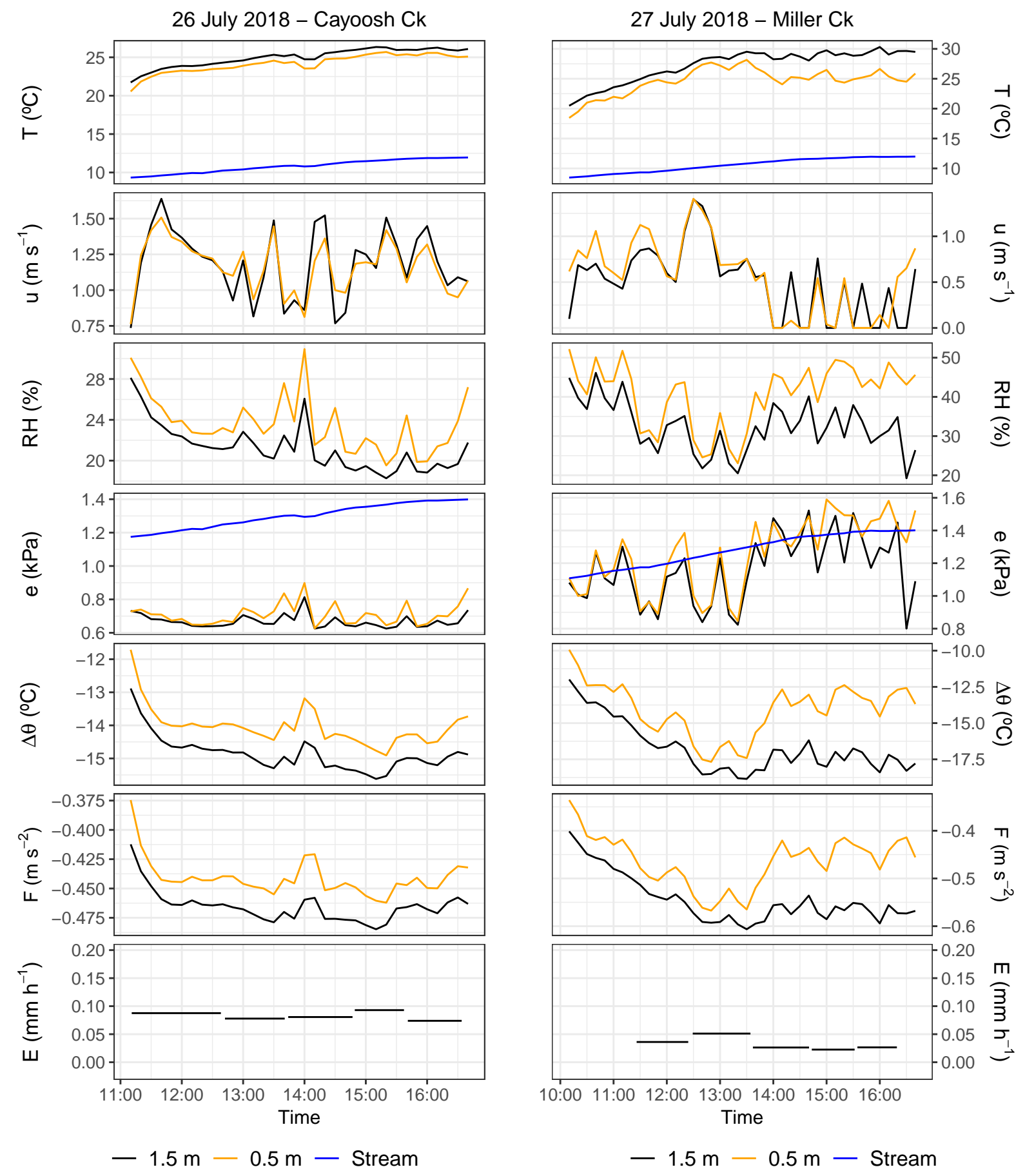

(o)

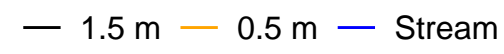

(p)

Figure C.1: Meteorological and stream conditions, and measured evaporation rates for each day of data collection (cont.). 

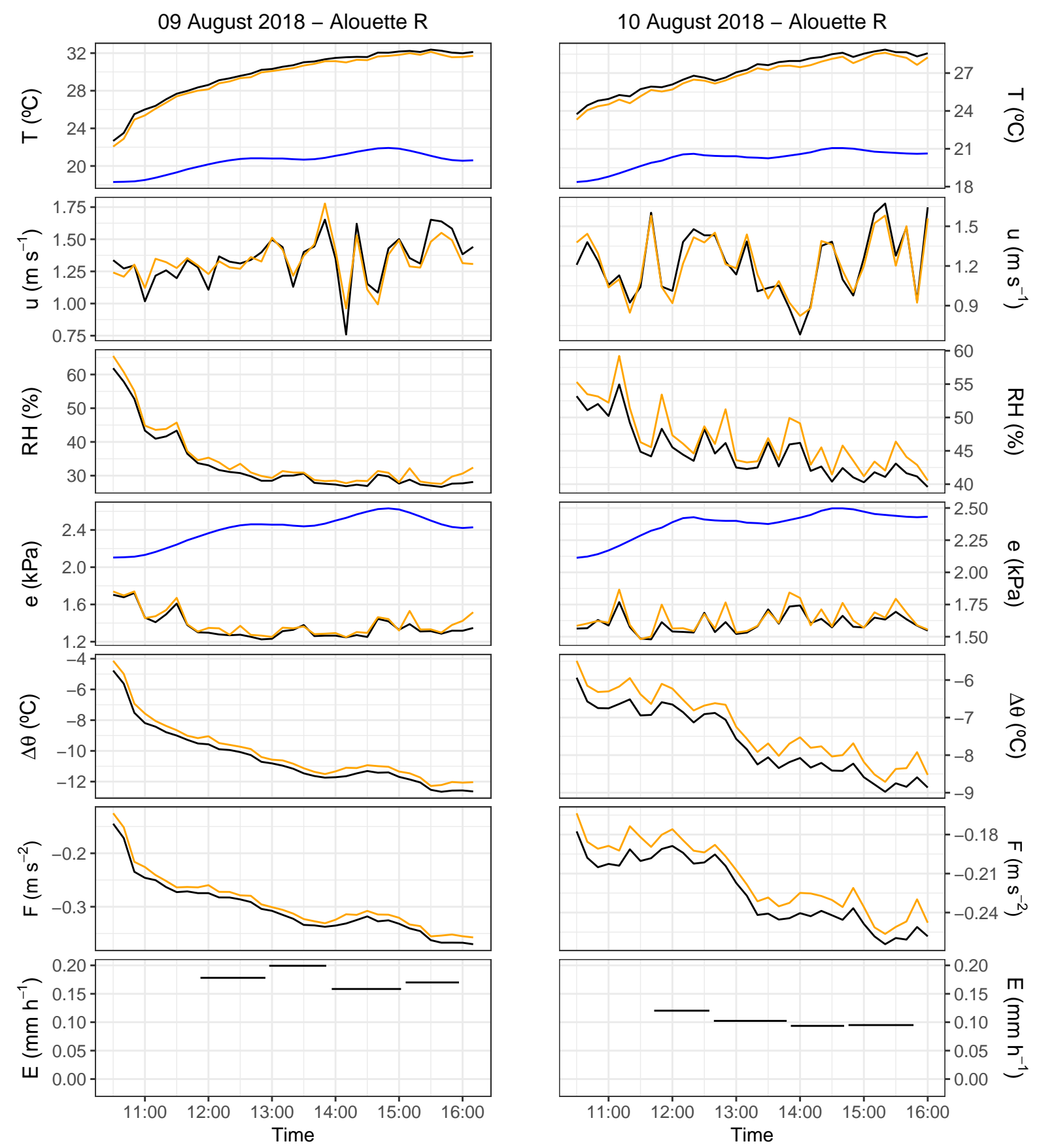

$-1.5 \mathrm{~m}-0.5 \mathrm{~m}-$ Stream

$-1.5 \mathrm{~m}-0.5 \mathrm{~m}-$ Stream

(q)

(r)

Figure C.1: Meteorological and stream conditions, and measured evaporation rates for each day of data collection (cont.). 


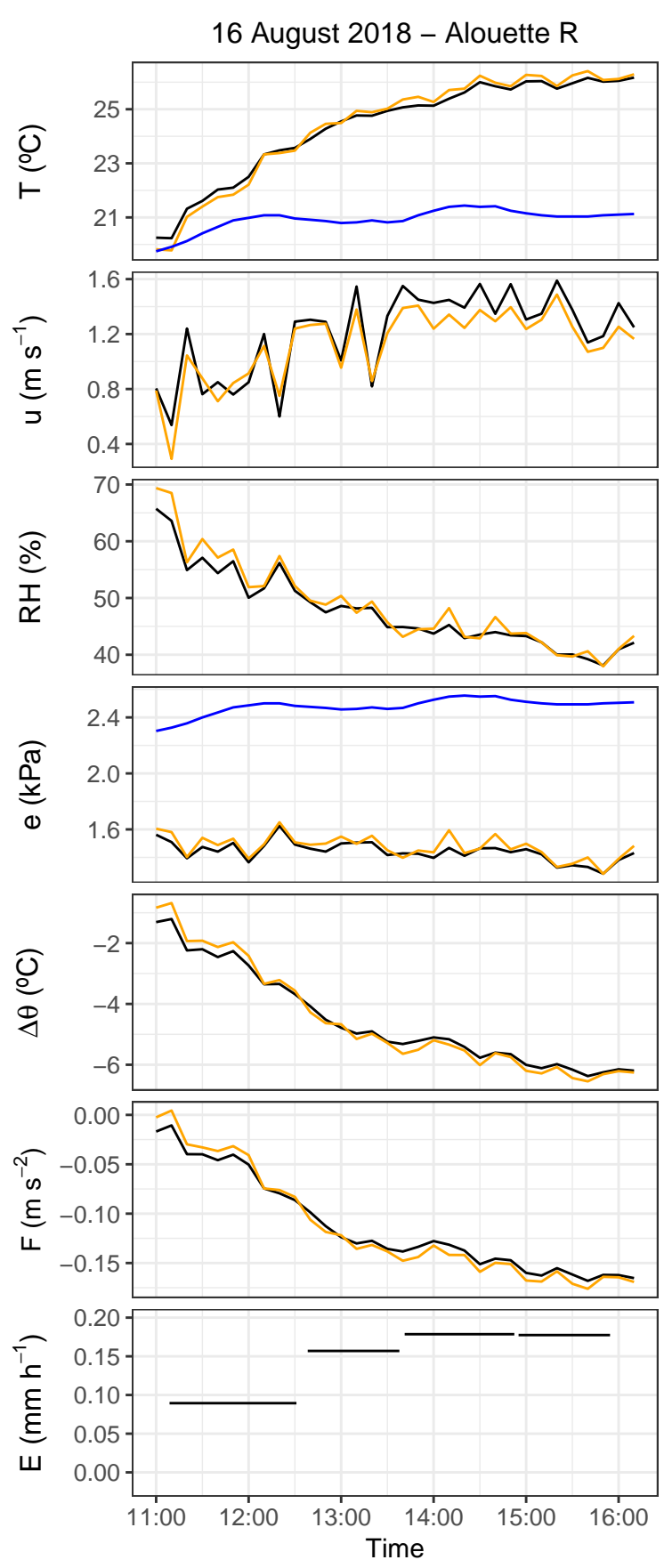

$-1.5 \mathrm{~m}-0.5 \mathrm{~m}-$ Stream

(s)
17 August 2018 - Marion Ck
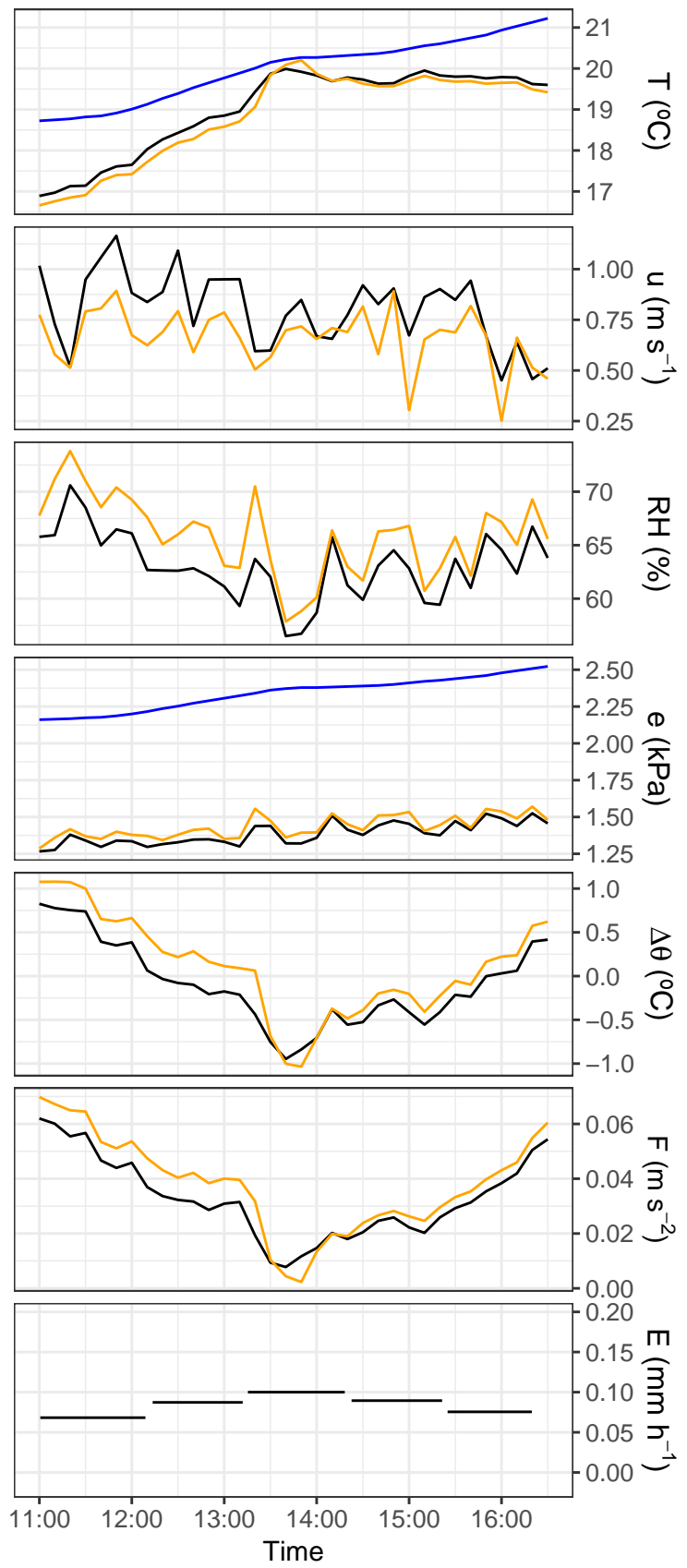

$-1.5 \mathrm{~m}-0.5 \mathrm{~m}-$ Stream

Figure C.1: Meteorological and stream conditions, and measured evaporation rates for each day of data collection (cont.). 


\section{Appendix D}

\section{Evaporation Rate Error Analysis}

Two measurements and one regression estimate was used to calculate each evaporation rate: the mass of the evaporation pan when it was placed into and removed from the stream; the time when the evaporation pan was placed into and removed from the stream; and the regression prediction of the evaporation pan's average water surface area. The measurement uncertainties were calculated as follows:

$$
\begin{gathered}
\delta m_{w}=\sqrt{\delta m_{w, \text { in }}^{2}+\delta m_{w, \text { out }}^{2}} \\
\delta t=\sqrt{\delta t_{\text {in }}^{2}+\delta t_{\text {out }}^{2}} \\
\delta E=E \cdot \sqrt{\left(\frac{\delta m_{w}}{\Delta m_{w}}\right)^{2}+\left(\frac{\delta t}{\Delta t}\right)^{2}+\left(\frac{\delta A_{p}}{A_{p}}\right)^{2}} \times c_{e}
\end{gathered}
$$

where $\delta m_{w, i}$ is the portable balance's accuracy of $\pm 0.1 \mathrm{~g}, \delta t_{i}$ is the error in time observation of $\pm 60 \mathrm{~s}, \delta m_{w}$ and $\delta t$ are the combined measurement uncertainties of computing the change in evaporation pan mass $\left(\Delta m_{w}, \mathrm{~g}\right)$ and the elapsed time between mass measurements $(\Delta t, \mathrm{~s})$, $\delta A_{p}$ is the standard error of each pan water surface area prediction $\left(\delta A_{p} \approx 1 \times 10^{-4} \mathrm{~m}^{2}\right), A_{p}$ is the predicted pan water surface area in $\mathrm{m}^{2}, E$ is the computed evaporation rate in $\mathrm{m} \mathrm{s}^{-1}$, $\delta E$ is the evaporation rate uncertainty in $\mathrm{mm} \mathrm{h}^{-1}$, and $c_{e}$ is a conversion factor equal to 3.6 to convert units from $\mathrm{m} \mathrm{s}^{-1}$ to $\mathrm{mm} \mathrm{h}^{-1}$. 


\section{Appendix E}

\section{Relation Between Solution Molarity and Electrical Conductivity}

The data used to fit the electrical conductivity calibration regression are presented in Figure E.1.

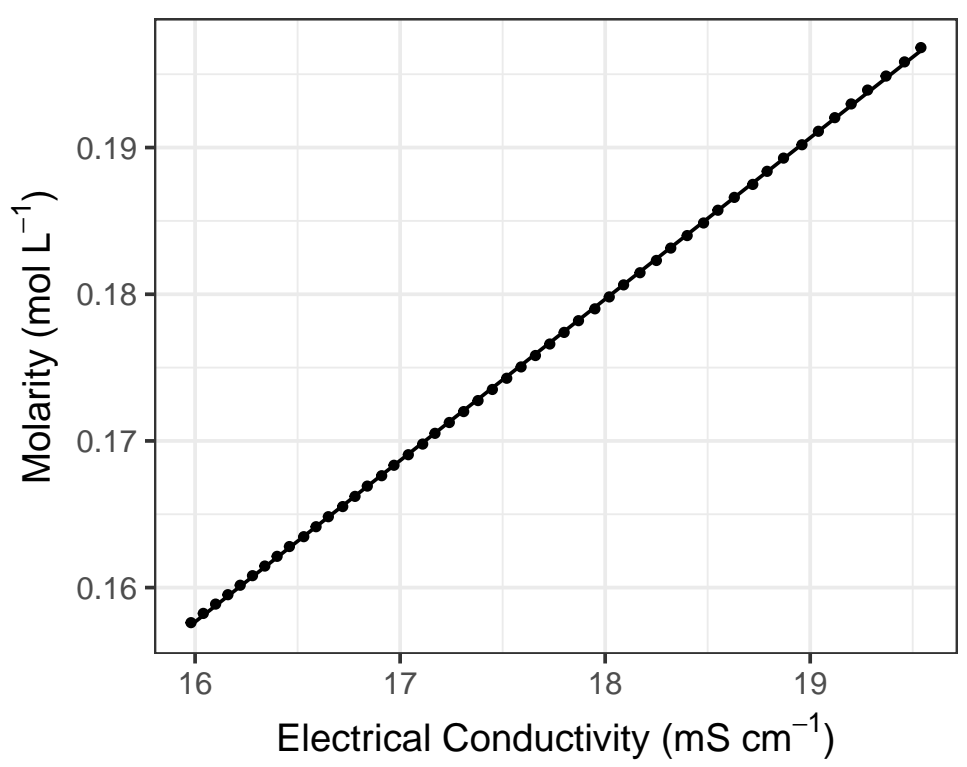

Figure E.1: The calibration results relating electrical conductivity to a salt solution molarity. The line is the fit regression. 